Claremont Colleges

Scholarship@ Claremont

CGU Theses \& Dissertations

CGU Student Scholarship

2011

\title{
Impact of IT on the Role of a Community of Practice Moderator in the Coalescing Stage of Development
}

Farnaz Barvarz Piepkorn

Claremont Graduate University

\section{Recommended Citation}

Piepkorn, Farnaz Barvarz, "Impact of IT on the Role of a Community of Practice Moderator in the Coalescing Stage of Development" (2011). CGU Theses \& Dissertations. Paper 47.

http://scholarship.claremont.edu/cgu_etd/47

DOI: $10.5642 / \operatorname{cguetd} / 47$

This Open Access Dissertation is brought to you for free and open access by the CGU Student Scholarship at Scholarship @ Claremont. It has been accepted for inclusion in CGU Theses \& Dissertations by an authorized administrator of Scholarship @ Claremont. For more information, please contact scholarship@cuc.claremont.edu. 
The Impact of IT on the Role of a Community of Practice Moderator in the Coalescing Stage

\author{
Dissertation
}

Prepared by,

Farnaz (Farah) Piepkorn 


\section{ABSTRACT}

This dissertation uses case study research to evaluate the impact of Information Technology (IT) on the moderator's role in directing a community of practice (CoP) in its Coalescing stage of development. Ten CoPs were studied.

While each of these CoPs is in a different stage of development, the analysis focuses on the Coalescing stage because it is considered the most critical. A detailed case study of each CoP, including a survey of moderators and members, and interviews with moderators is

presented. Analysis of these cases indicated that use of IT -- defined as communication, software, and hardware tools -- has a reciprocal effect on the role of the moderator. In other words, a moderator can achieve CoP goals and conduct its activities more efficiently and effectively by use of various IT tools. A moderator's competence and inclination to using IT tools also affects his or her role and the way he or she conducts the activities and plans to achieve the CoP goals.

Those moderators who used IT tools to conduct their CoP's activities perceived their CoPs to be more successful than those who did not. Other factors such as company support, moderator's position and influence in the company, and the resources available to the CoP were the deciding factors on the moderator's role in facilitating a successful CoP. This dissertation concludes with a list of future research possibilities, obstacles to moderators, and improvement opportunities for large companies with several CoPs. All of the research studies on communities of practice so far have assumed that each company has only one CoP. This dissertation not only provides insight to a company with various CoPs, but it also offers a comparison study among different CoPs within the same company. 


\section{Dedication}

I dedicate this dissertation to my parents, Ali and Pouran Barvarz, who taught me everything I know about hard work, perseverance, and strength. Their love, sacrifice, and devotion has enabled me to overcome all challenges I faced.

I would like to thank my husband Craig and my daughter Jacqueline for their immense support, allowing me to focus on my studies and conduct my research.

I would like to thank my dear brother Farzad Barvarz who has always encouraged me with so much pride. 


\section{Acknowledgements}

I am particularly grateful to my advisor, Dr. Lorne Olfman who patiently provided me with great feedback on my work, encouragement when I was down, and guidance when I needed it the most. It was a great honor to work with him on this dissertation.

I would like to thank Dr. Terry Ryan and Dr. Tamir Bechor for providing me with great input on my dissertation and guiding me to conduct productive research and write this dissertation.

I would like to thank all my professors at Claremont Graduate University for providing me with a great education and allowing me to be a better teacher than I ever imagined.

Many thanks to Mr. Ken Kubo, Mr. Wes Baba, Mr. Dan Cabbell, Dr. Steve Toner, Dr. Dave Hugus, Dr. Sonya Zhang, Dr. Bill Bryant, and other friends, who supported me with encouraging words when I prepared for my dissertation defense. 


\section{Table of Contents}

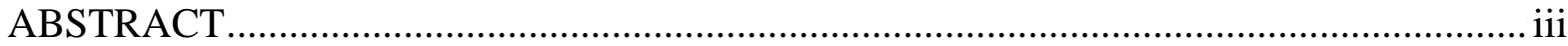

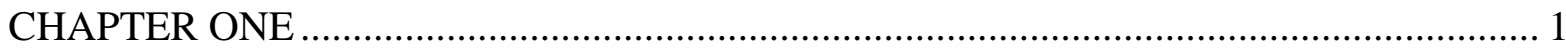

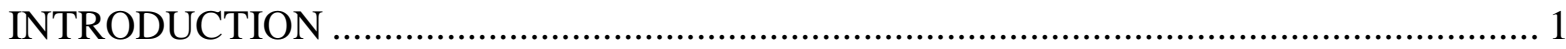

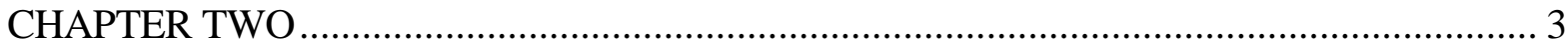

A LITERATURE REVIEW OF COMMUNITIES OF PRACTICE....................................... 3

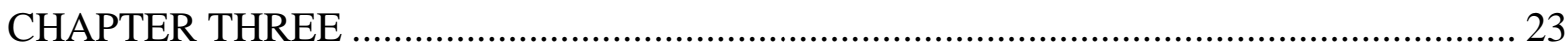

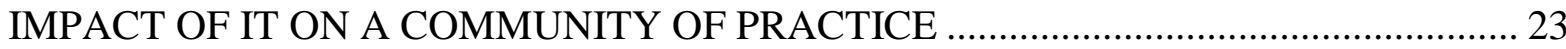

3.1 Typical Activities in Each Stage of Development................................................. 35

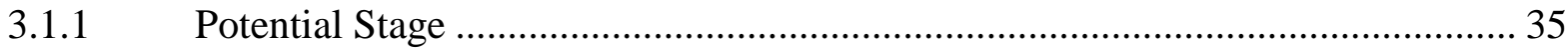

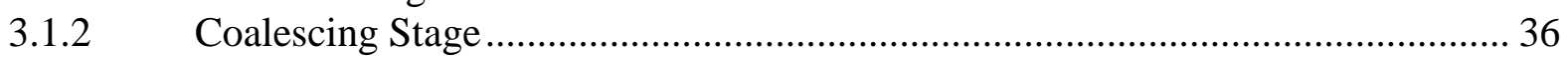

3.1.3 Active Stage .................................................................................................... 37

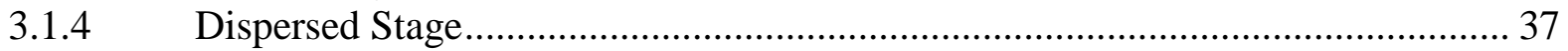

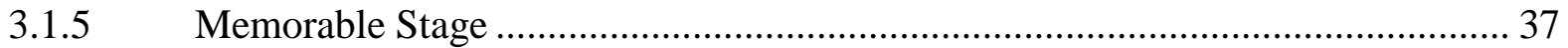

3.2 Role of a Moderator in a Community of Practice............................................... 37

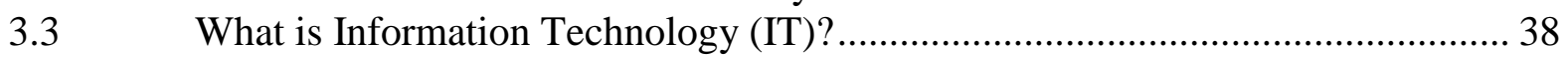

3.4 What does CoP Effectiveness Mean? .................................................................... 39

3.5 What Are The Success Factors in a CoP?............................................................ 39

3.5.1 IT Culture In Each CoP at the Company …….................................................... 40

3.5.2 Roles of Different Members of a CoP .............................................................. 40

3.5.3 Why Does the Company Support CoPs? ............................................................... 41

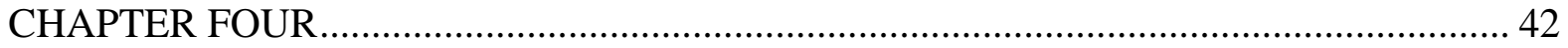

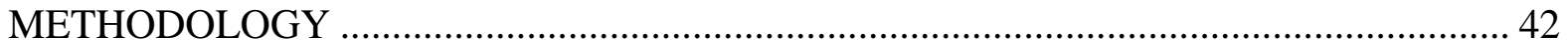

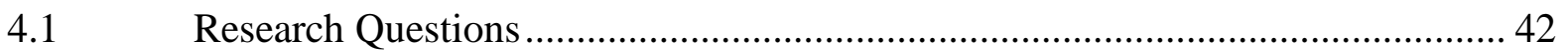

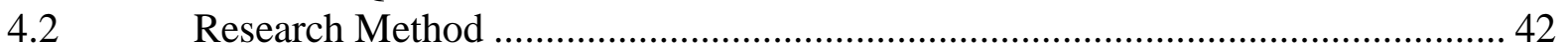

$4.3 \quad$ Case-Study Research .......................................................................................... 43

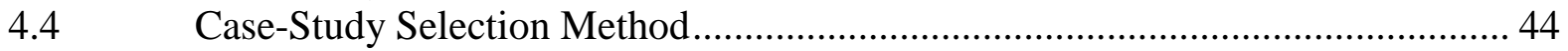

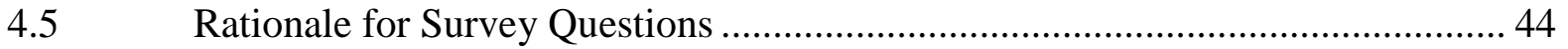

4.6 Communities of Practice at the Company .............................................................. 45

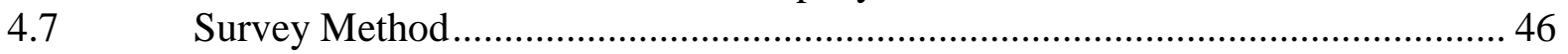

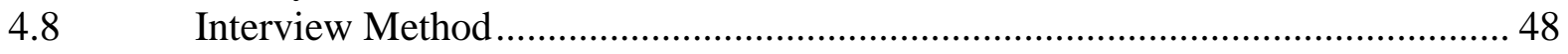

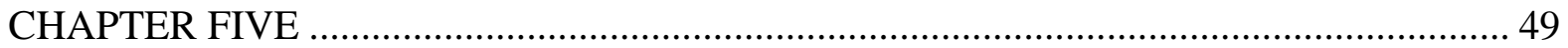

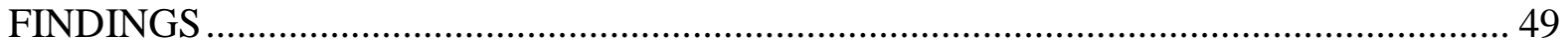

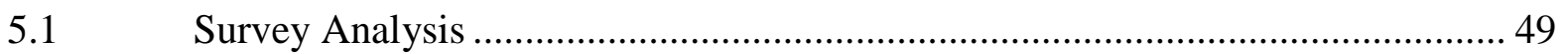

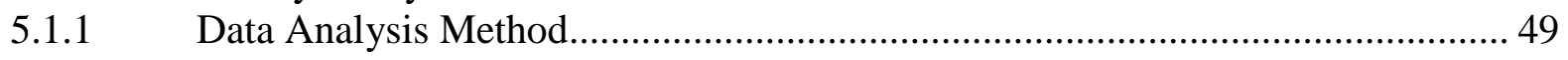

5.1.1.1. Open Coding ............................................................................................... 49

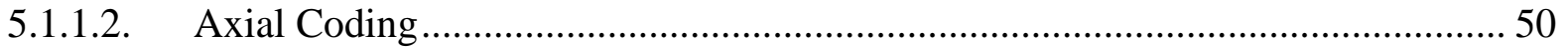

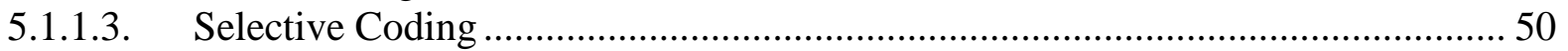

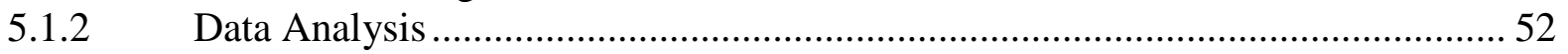

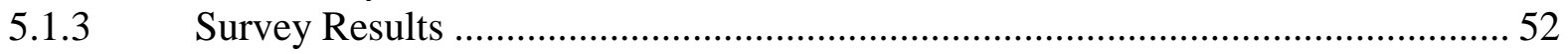

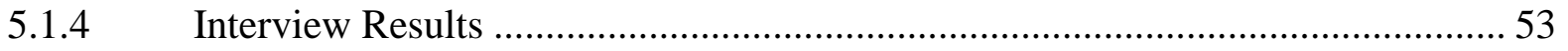

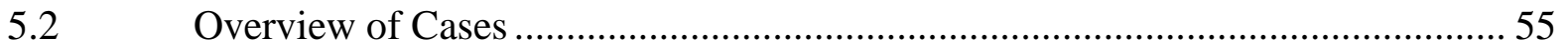

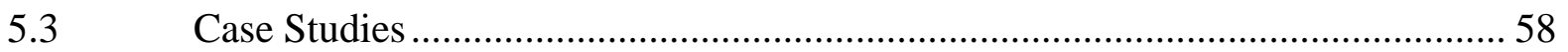

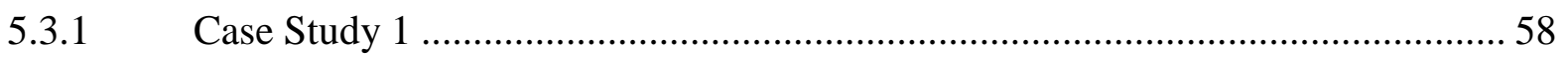

5.3.1.1. CoP Description .............................................................................................. 58

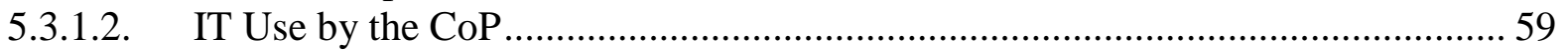

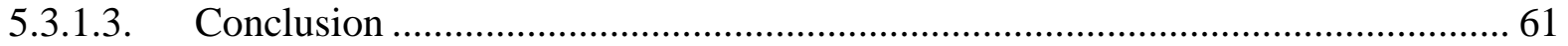




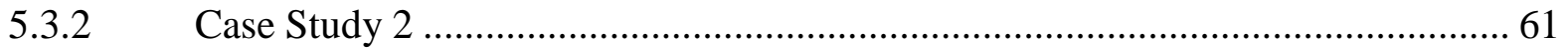

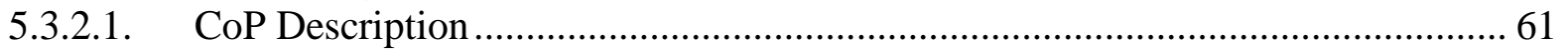

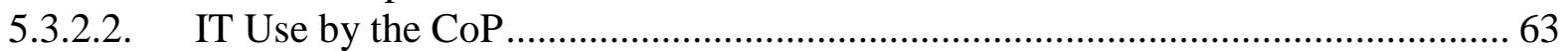

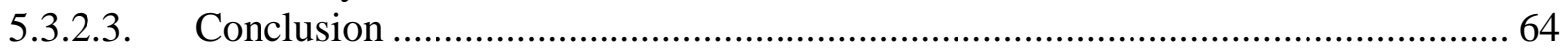

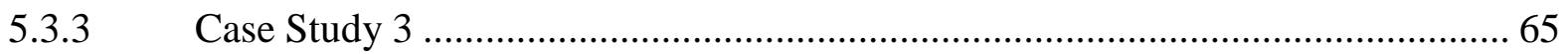

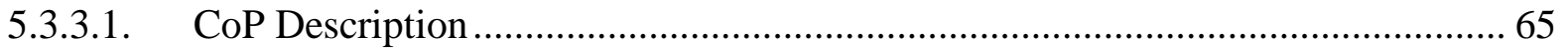

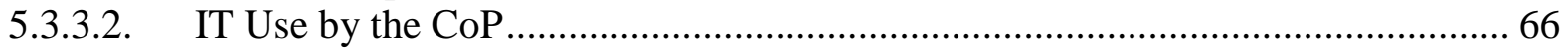

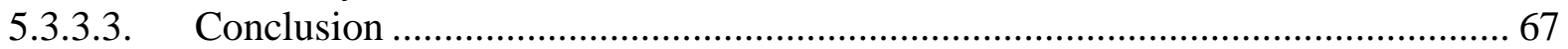

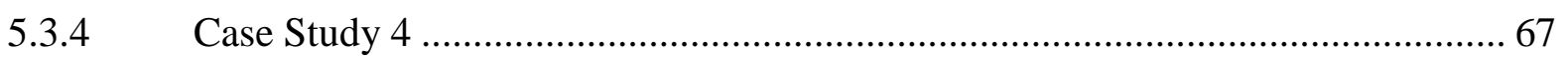

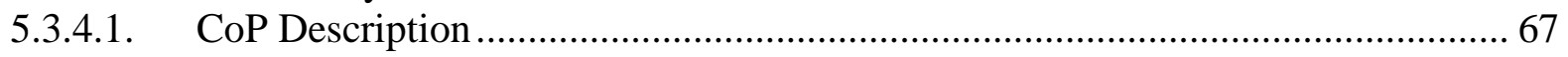

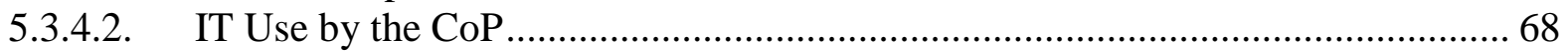

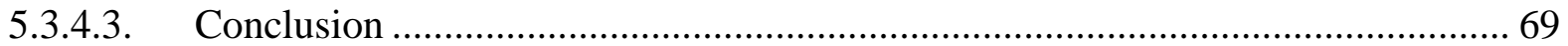

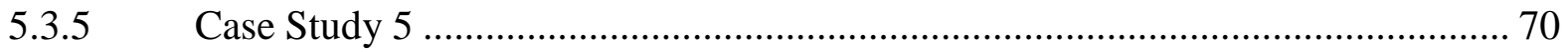

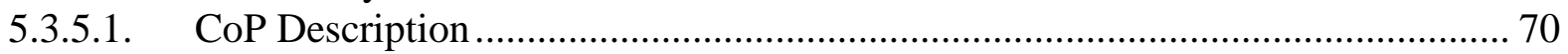

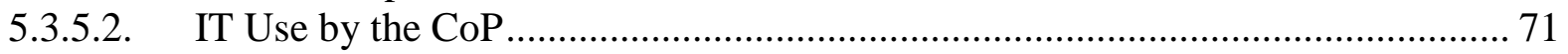

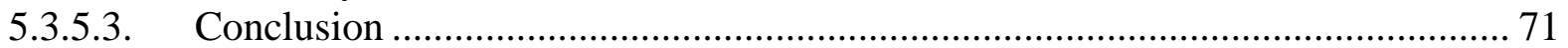

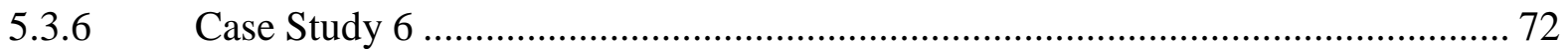

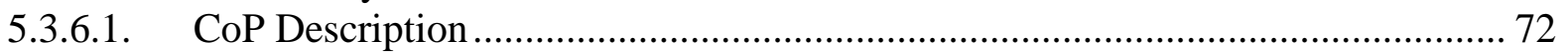

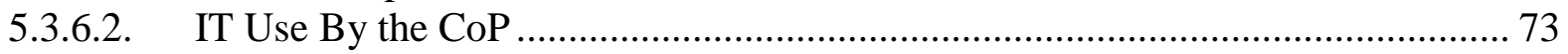

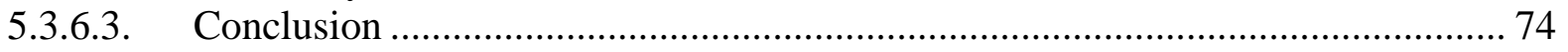

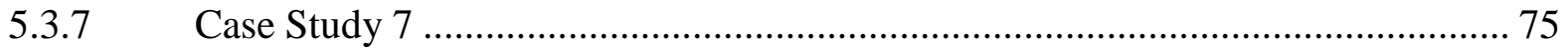

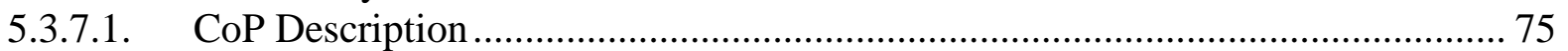

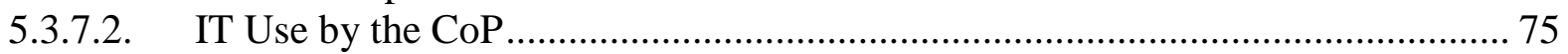

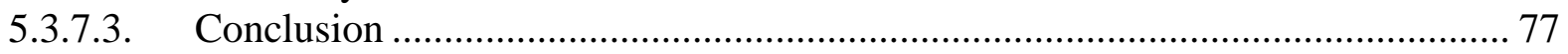

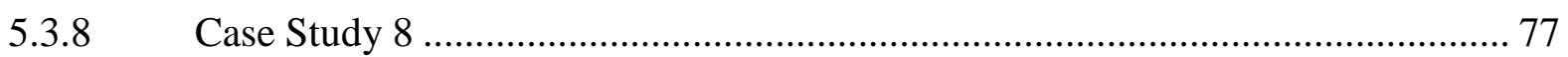

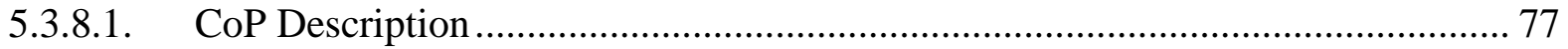

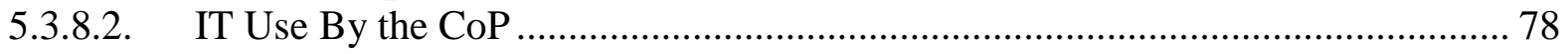

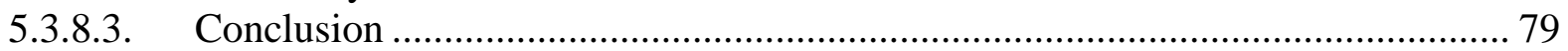

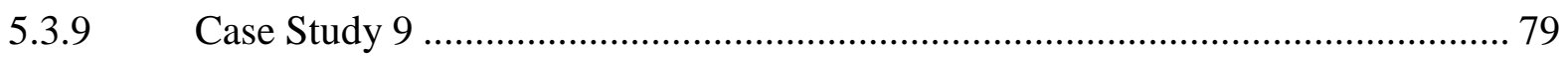

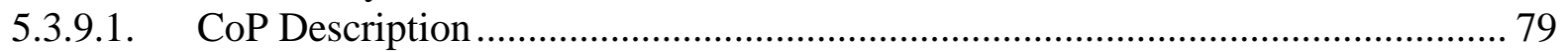

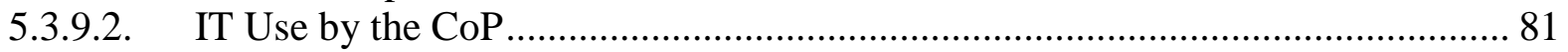

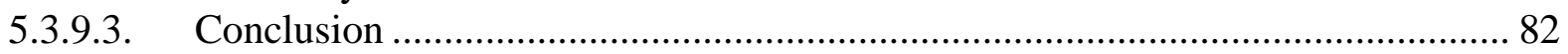

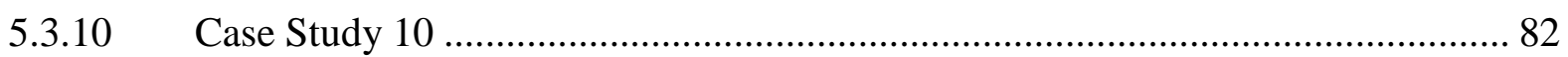

5.3.10.1. CoP Description .......................................................................................... 82

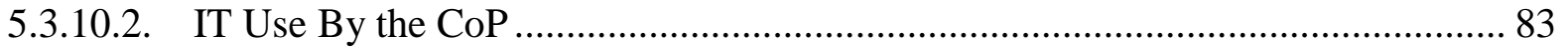

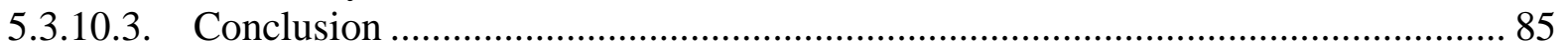

5.4 Comparison of All Cases In Terms of IT Use ..................................................... 85

5.4.1 Communities of Practice in the Potential Stage of Development .......................... 89

5.4.2 Communities of Practice in the Coalescing Stage of Development ...................... 89

5.4.3 Communities of Practice in the Active, Memorable, and Dispersed Stages ........ 90

5.4.4 Comparison Study of All Cases in the Coalescing Stage of Development .......... 91

5.4.5 Comparison Study of Cases in the Coalescing Stage of Development with Cases

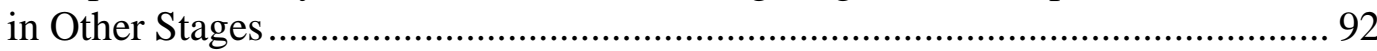

5.4.6 Impact of IT on the Role of a Moderator ............................................................... 93

5.4.7 Improvement Opportunities in Terms of IT Use by a CoP.................................... 94

5.4.8 Barriers in Terms of IT Use by a CoP ……….................................................... 98

5.4.9 Comparison of CoP Moderators’ versus Members’ Responses Regarding IT Use 


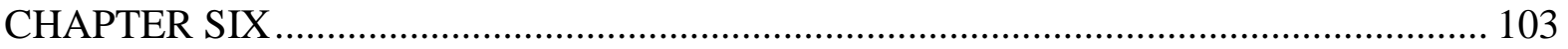

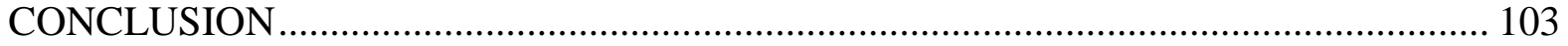

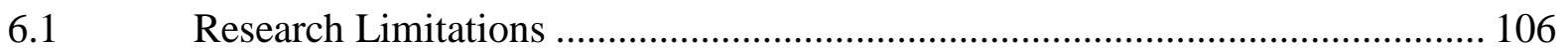

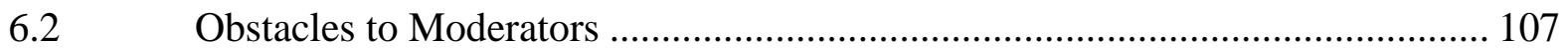

6.3 Obstacles to Moderators in Terms of Using IT ……….................................... 109

6.4 Recommendations for Companies with Various CoPs.......................................... 110

6.5 Drawbacks of Having a Company-Supported CoP ……………………........... 114

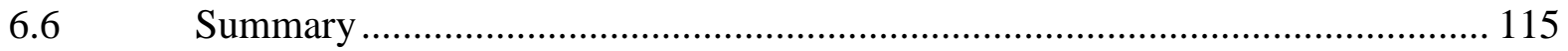

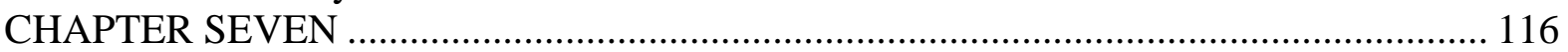

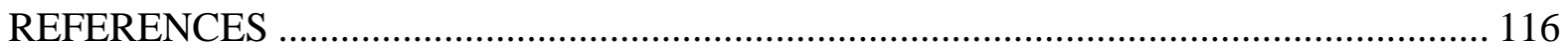

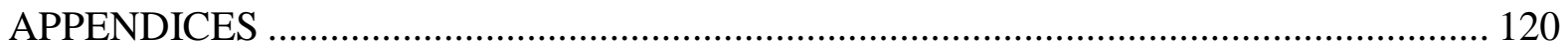

APPENDIX-A Institutional Review Board and Survey Consent Form ................................ 120

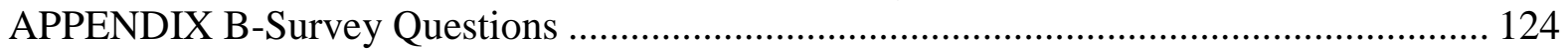

APPENDIX C-Sample Survey Responses..................................................................... 130

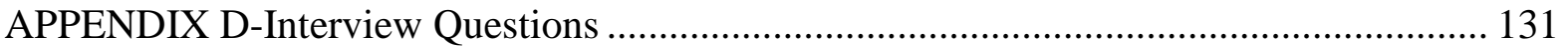

\section{Table of Figures}

Figure 1- Stages of Development of Communities of Practice -- Wenger (1998) ...........Error!

\section{Bookmark not defined.}

Figure 2- McDermott's view of Communities of Practice Dimensions................................... 15

Figure 3- Communities of Practice and Organizational Performance ...................................... 18

Figure 4-Knowledge Typology in a Community of Practice.................................................. 26

Figure 5-C5PE Framework, which indicates the elements influencing the effectiveness of a $\mathrm{CoP}$ 31

Figure 6-Impact of IT Use on the Role of a CoP Moderator ................................................. 54

Figure 7-Factors Determining Use of IT by a CoP Moderator ................................................. 92

Figure 8-Improvement Opportunities Stated by Moderators ................................................... 98

Figure 9-Barriers to CoPs' IT Use........................................................................................ 100

\section{Table of Tables}

Table 1-Teams, Virtual Teams, and CoPs by Dayan, Rony , Pasher, Yossi (2006)................ 34

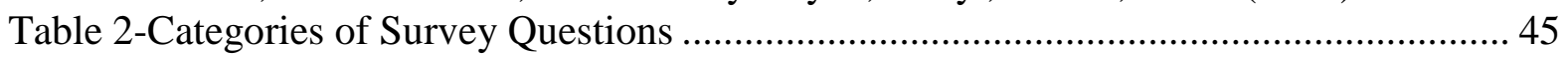

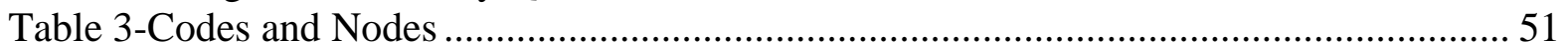

Table 4-Respondents' Breakdown .................................................................................. 52

Table 5-Breakdown of Interview Responses ................................................................... 54

Table 6-Summary of All CoPs.......................................................................................... 57

Table 7-List of IT Tools Utilized in Each Stage................................................................... 88 


\section{CHAPTER ONE INTRODUCTION}

Etienne Wenger (Wenger, 1990) defines communities of practice (CoPs) as an embodiment of competencies in an organization. (Wenger, p. 4) Wenger defines five stages of development for a CoP and lists a set of activities and outcomes for each stage. Although CoPs were conceptualized about two decades ago and while Information Technology (IT) is an important element in various types of organizational groups and teams (e.g., virtual communities), there is no research that explains how IT affects the role of a moderator of a $\mathrm{CoP}$ in the Coalescing stage of development. The purpose of this dissertation is to understand whether and in which ways IT effectively supports the Coalescing stage and how the role of a moderator affects the use of IT. Ten CoPs from a large corporation are the subjects of the analysis.

The first part of this dissertation provides a literature review of CoPs as defined by several learning theorists and practitioners and delineates the three dimensions of a community of practice as identified by Wenger, a learning theorist. The traditional view of learning rules out the relationship among learning, working, and innovation, and asserts learning and working are in conflict with change (innovation). Wenger (1990) believes "situated learning" brings all these aspects together and that learning takes place at work since both learning and working are social and act together to augment innovation. The first part also provides different practitioners' views on learning in the workplace, including the challenges both management and workers face. The second part of the document provides different views on the potential impact of IT on the role of a moderator of a community of practice. The research makes a detailed comparison of several communities of 
practice in a company. The research method section discusses the data collection and analysis methods. This dissertation concludes with a discussion of potential outcomes and future research and improvement opportunities. 


\section{CHAPTER TWO \\ A LITERATURE REVIEW OF COMMUNITIES OF PRACTICE}

Wenger (1991) coined the term community of practice by defining it as a way of explaining how competencies and human knowledge are "created, sustained and transformed.” (Wenger, p. 3) He views communities of practice as the embodiment of competencies (Wenger, p. 4) and believes communities of practice are created on their own and not by management. Wenger (1991) has provided a set of guidelines for managers who want to "leverage the power of the social communities within their corporations.” (Wenger, p. 4) The guidelines include the following,

- Focus on the social world and respect its informal, improvised, inventive, negotiated character.

- Remember that the social world is where work gets done; meaning is constructed, learning takes place every day, innovation originates, and identities are formed.

- View individuals as members of communities of practice in multiple and complex ways, and support their learning by opening possibilities for participation and membership.

- Think of any institution, such as a corporation or school, as encompassing an ensemble of interconnected communities of practice whose boundaries do not necessarily (or usually) follow the formal boundaries of the organization, both inside and outside.

- Understand that change implies new practices, but remain aware of the limits of anyone's external control over communities of practice.

- Understand that boundaries and peripheries are places where much happens and where there is high potential for change, create bridges, and allow peripheral yet legitimate forms of participation.

- Pay attention to any document or artifact that crosses community boundaries and become interested in people whose memberships overlap across business units or companies. 
- Become aware of the interaction of multiple local cultural practices instead of talking in abstract terms about a corporate culture because the organization's competencies are embodied in these living, overlapping, changing, and nonconforming communities of practice. (Wenger, p. 5)

Brown and Duguid (1991) view working, learning and innovating as different forms of human interaction. They consider this interaction contrary to the traditional view of learning which sees the three components as exclusive and deems work as resistant to change and innovation. Brown and Duguid believe this contradiction lies in work practice, which entails following sets of procedures rather than learning being abstracted from actual practice. (Brown and Duguid, p. 1) The authors agree with Wenger's practice-based theory of learning (Wenger, 1991) as "legitimate peripheral participation" (Wenger, p. 4) and from this viewpoint they find learning as a bridge between working and innovation.

Brown and Gray (1995) reaffirm the theory of interrelation between learning and work asserting that in a knowledge-era environment three principles can bring an organization into focus:

1. Processes do not work, people do. The challenge is to under-prescribe formal business procedures and create 'elbow room' for local interpretations and innovations.

2. Learning is about work, work is about learning, and both are social. Two ideas shape how most companies approach learning and knowledge, (1) learning means individual mastery, and (2) everything that is knowable can be made explicit. The more one explores real work, the more one appreciates the power of a different kind of knowledge, tacit knowledge. With individuals, tacit knowledge means intuition, judgment, and common sense -the capacity to do something without necessarily being able to explain it. With groups, tacit knowledge exists in the distinct practices and relationships that emerge from working together over time -- the social fabric that connects communities of knowledge workers. Recognizing the tacit and collective dimensions of work has significant implications for learning. From this 
perspective, learning is less about absorbing information than it is about becoming part of a community. It is a social process built around informed participation, people need information to do their work, but it is only through working that they get the information they need.

3. Organizations are webs of participation. Changing the patterns of participation changes the organization. At the core of the Twenty-first century company is the question of participation. At the heart of participation is the mind and spirit of the knowledge worker. Put simply, the organization cannot compel enthusiasm and commitment from knowledge workers. Only workers who choose to opt in -- who voluntarily make a commitment to their colleagues -- can create a winning company. When a company acknowledges the power of community, and adopts elegantly minimal processes that allow communities to emerge, it is taking a giant step toward the 21st century. (Brown \& Gray, pp. 2- 4)

Brown and Gray assert that communities of practice (CoPs), the "critical building block” (Brown \& Gray, p 4) of a knowledge-based company, convert these principles into action. People in CoPs are peers in the execution of "real work." (Brown \& Gray, p 4) What holds them together is a common sense of purpose and a real need to know what each individual member knows. There are many communities of practice within a single company, and most people belong to more than one of them. While most companies define competencies as discrete technologies, patents, trade secrets, and proprietary designs, a real-world competence -“a sustained capacity to outperform the competition” (Brown \& Gray, p. 4) -- is built as much on implicit know-how and relationships as on tangible products and tools. Competencies cannot be divorced from the social fabric that supports them.

Stewart (1996) defines communities of practice as "the shop floor of human capital, the place where the stuff gets made.” He notes, “A person's responsibilities to the communities which he/she is a member of sometimes conflict with each other, and with the rules and interests of the company he/she works for." (Stewart, p. 4). He 
proceeds to explain the nature of communities of practice as "cosa nostra”, and asserts, “Communities of practice are responsible only to themselves. No one owns them. There is no boss. They are like professional societies. People join and stay because they have something to learn and to contribute. The work they do is the joint property of the group.” Stewart believes managers can help communities of practice by recognizing them and letting them build an intranet, use a company conference room, or "put a gettogether on the expense account. There are many benefits in joining people who may unknowingly duplicate others' efforts or walk away from projects too big to tackle single-handedly.” (Stewart, p. 6) .

Schein (1996) attributes organizational learning failures to three types of “occupational cultures” by stating two of these cultures (engineering and executive) have roots outside the organization while the organization's internal culture is based on its operational or operator success. Schein asserts the lack of alignment among these three cultures leads to failures at organizational learning. Schein does not place much value in organizational learning and believes successful organizational learning either tends to be short-run adaptive learning — doing better at what is already being done — or, “if they are genuine innovations, tend to be isolated and eventually subverted and abandoned.” (Schein, p. 9) He believes that to remain competitive in an increasingly turbulent world an organization has to be able to create new organizational forms and processes, and innovate in both the technical and organizational arenas.

Snyder (1997) asserts that the CoP perspective significantly enhances the three main contributions to multinational firms facing issues such as a "firm boundaries, scope, and competence, which include mergers and acquisitions; joint ventures and 
alliances; leveraging core competencies and core products; disaggregating business units; and outsourcing." (Snyder, p.2) He indicates,

1. Organization capability consists of a configuration of coordinated competencies, which are generally applied in combination to enact recognized business processes (e.g., distribution, production, and product development).

2. Organization competence consists of a 'bundle of skills and technologies' or a 'knowledge set' including explicit know-that 'information', tacit know-that ('values'), explicit know-how ('routines'), and tacit know-how ('expertise'). Organization competence includes the ability to integrate all four dimensions within specific organization contexts to meet task requirements.

3. Each of the four components of organization competence -- information, values, routines, and expertise -- exist at individual, group, and organization levels; they are highly interrelated so it is difficult to separate them in practice. Know-that elements include what we know about (information, values), while know-how elements include both behavioral and 'intellective' abilities to perform a task (routines, expertise). Tacit components (values, expertise) are more difficult to codify, explain, or transfer than explicit components (information, routines). (Snyder, p. 2)

Per Snyder (1997), CoP research explains how competencies are combined to produce capabilities, "constellations of communities of practice” (Brown \& Duguid, 1991; Wenger, 1990). These constellations of interacting and overlapping CoPs coordinate with each other to enact capabilities that depend on multiple competencies. These constellations may include several "technical", and "administrative" competencies, to ensure that competencies are built, shared, and applied effectively. (Snyder, p. 7)

Sharp (1997) sees communities of practice as a special type of informal network that emerges from a desire to work more effectively or to understand work more deeply among a small group of a particular specialty or those who have worked together and 
have developed a common sense of purpose and a desire to share work-related knowledge and experience. (Sharp, p.1)

Sharp (1997) states that several factors provide fertile grounds for the development of CoPs including working and taking several training classes together, and otherwise being placed together through face-to-face meetings. Other such factors include style, trust, and mutual recognition of competence.

Sharp indicates practitioners can offer or benefit from services in a community of practice. These include, asking for help using a mailing list, sharing success stories, site-developed marketing collaborations (presentations, product reviews and benchmarks), sharing of statements of work, proposals, deliverables, and discussions of the nature of reality for this practice (which requires high trust, and perhaps off-line settings so others outside the group will not hear). (Sharp, pp. 3-8)

Snyder (1997) describes, “Communities of practice as a group of people bound by a shared interest in learning and applying a common practice. Their focus on learning, competence, and performance bridges the gap between organizational learning and strategy topics and generates new insights for theory and practice.” (Snyder, p. 1)

Snyder finds an interrelation between practice and learning, as did Wenger and Brown, asserting the two key words in the term “communities of practice” provide a convenient way to unpack the meaning of this complex, emergent construct. “Community” refers to the informality and personal basis of many relationships in typical communities of practice; it also suggests that community of practice boundaries do not correspond to typical geographic or functional boundaries in organizations but 
rather to practice- and person-based networks. A less obvious connotation of this word is the inclusion of community-based artifacts -- e.g., equipment, forms, and policies, which have little independent influence in the organization apart from their context-specific interpretation and enactment by community members. "Practice" indicates that communities of practice are centered on a shared purpose, which may or may not correspond to an established function in the organization. The term suggests that community "practitioners" identify with their work in personal ways, often in ways that recall a typical professional's purpose. A less obvious point is that "practice" connotes "knowledge-in-action” or "knowing”, and implies that practice is as much about learning as it is about doing. Snyder asserts, "communities of practice consist of people who are informally as well as contextually, bound by a shared interest in learning and applying a common purpose.” (Snyder, p. 1)

Snyder believes "communities of practice augur fresh streams of research on new concepts such as network leadership, individual-community dynamics, and virtual organization structures." He asserts, "community of practice studies now address research deficiencies related to learning and competence and may soon help organizations avoid or minimize the loss of valuable competencies and relationships as they disaggregate and outsource major business functions.” (Snyder, p. 3)

Wenger (1998) asserts communities of practice share information, insight, experience, and tools about an area of common interest. He identifies three dimensions of a community of practice, 
- What it is about (its domain) — its joint enterprise, as understood and continually renegotiated by its members. In other words, communities of practice develop around things that matter to people. As a result, their practices reflect the members' own understanding of what is important. Obviously, outside constraints or directives can influence this.

- How it functions - the relationships of mutual engagement that bind members together into a social entity. Communities of practice also move through various stages of development characterized by different levels of interaction among the members and different kinds of activities (see Figure 1, Stages of Development).

- What capability it has produced - the shared repertoire of communal resources (routines, sensibilities, artifacts, vocabulary, styles, etc.) that members have developed over time. (Wenger, p. 2)

Wenger also defines the five stages of development for communities of practice and the typical activities associated with each stage. As indicated in Figure 1, there is a bell curve association between the stages of development and typical CoP activities depicting the peak of activities in the Active stage of CoP development.

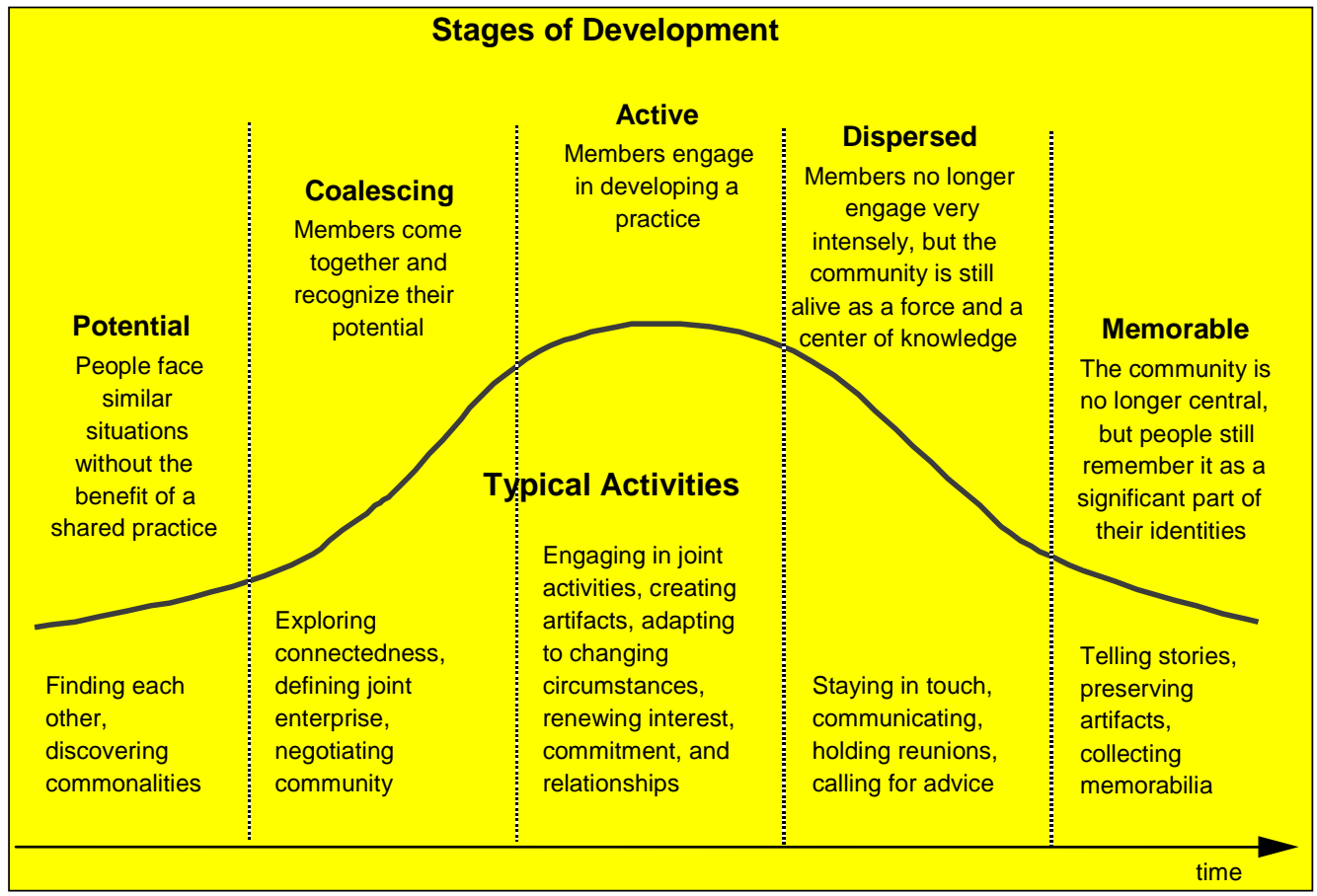

Figure 1-Stages of Development of Communities of Practice -Wenger (1998) 
McMaster (1998) asserts, "Communities of practice in corporations are also 'communities of commitment.' That is, they are formed around shared commitments to have the knowledge and practice be applied, effective and produce results that forward the interests of the whole. The practices are focused on performance in cooperative ventures in a competitive environment. These combinations of practice and commitment that are at the heart of CoPs allow for processes which are dramatically more effective than ordinary work practices.” (McMaster, p. 2)

McMaster describes one of the two best ways of learning as to "be engaged in teaching others while developing new approaches to old challenges. The other method is "to continually confront the marketplace, to be tested against reality, and to use that as learning for continued development." Sharing in a "Community of Practice” increases one's ability to learn individually and increases the knowledge of the whole community.” (McMaster, p. 1)

McMaster believes communities of practice face these challenges,

1. Development within the more formal and rigid structures of a normal corporate organization- These formal structures provide the environment for "Communities of Practice" and the resources required for their support. Yet they cannot make it occur, force it, or manipulate it.

2. A CoP, which is part of a corporation, requires some resources for its support, and in return for that, can be expected to make commitments for development and delivery of value. These commitments should be not so much promises for which they are held to account but more mutual expressions of commitment with reciprocal supporting structures. These structures will be for the development of the knowledge of the community; and the connection between that development and the intentions, interests and commitments of the business that supports it. 
3. To begin the formation of a CoP there needs to be a process that discovers what is going to happen, what is natural to existing interests, and what will emerge and prosper from the existing interests and commitments of competent and motivated individuals. These communities need to be provided a space to discover themselves and be nurtured in their early formative times.

4. Leadership understanding and commitment is missing within most corporations for this particular idea. Generally speaking, company leaders do not appreciate the potential benefits, and have not created the environment for growth of CoPs. The remedy for this is a basic understanding and an expression that these are to be nurtured by providing some alteration in structure that removes a few barriers and some small investment of resources to support a formulation phase; and, of course, some executive time to nurture by intention and attention. (McMaster, p. 2)

McDermott (1999) indicates that communities of practice are "loosely-knit groups driven by the value they provide to members, defined by the opportunities to learn and share what they discover and bounded by the sense of collective identity the members form.” (McDermott, p.2) He asserts that unlike teams, communities of practice rarely have a specific result to deliver to the organization but are often driven by the value they provide to individual members. Since knowledge sharing is the heart of communities of practice, they follow opportunities for sharing knowledge as it arises. Communities of practice frequently form around disciplines or topics in which community members have invested many years thinking about and developing. In the course of helping each other, sharing ideas and collectively solving problems, community members often form strong bonds. Communities of practice arise out of people’s natural desire to share ideas, get help, learn about new ideas, verify their thinking, and hear the latest "professional” gossip. They develop as people have regular contact with colleagues who share their interests. However, in team-based organizations, most day-to-day contact is with other team members. Since communities 
of practice are organized around knowledge and not outputs, traditional team-building activities of setting goals, dividing tasks and developing work plans are not appropriate. McDermott (1999) identifies a set of guidelines for starting and supporting communities of practice,

1. Build communities around a few important topics. To leverage knowledge effectively, it is best to start with a few communities of practice focused on topics important to the organization. Focusing on strategically important topics will make it considerably easier to expand beyond the original communities.

2. Find and build on natural networks. Communities of practice arise naturally in most organizations, whether an organization supports them or not.

3. Develop community coordinators and core groups. A key success factor for intentional communities is to have a coordinator (a well-respected and wellconnected community member) who organizes and maintains the community. The coordinator invites people to participate, links people together, finds exciting topics for the community to address, connects outside the community, and generally keeps the community vibrant. Coordinators usually rely on a core group of community members to contribute.

4. Initiate some simple knowledge sharing activities. Since intentional communities of practice are a new approach to organizational structure, they are difficult for people to understand and adapt to. The most effective way to convey a CoP's purpose (knowledge sharing in an informal setting) is to provide a regular forum, supported by a coordinator to support the knowledge sharing activities.

5. Support communities. If the organization values learning and sharing knowledge, it will provide a rich ground for growing communities of practice.

6. Create a community support team. Because they are organized and supported differently from teams, community of practice development requires a different set of tools and approaches than that of a team.

7. Be patient. Communities of practice often take time to develop. (McDermott, pp. 5-9). 
As teams have a specific, company approved, measurable set of goals (such as deadlines and schedules), and as a team is provided with company resources to achieve these goals (e.g., charge numbers, software, hardware, and other pertinent work environment) their knowledge sharing and interaction is different from that of a $\mathrm{CoP}$ as a CoP's main goal is knowledge sharing. . At Shell Oil company, the CoPs have the goal of sharing knowledge (both tacit and explicit) as defined by Wenger. However, while Wenger asserts CoPs are created by themselves, most CoPs at Shell Oil Co. are created by management and benefit from company resources (such as conference rooms, knowledge sharing tools, and charge numbers for the subject matter experts involved in knowledge sharing activities). (McDermott, p. 3)

McDermott (1999) argues that a CoP coordinator should refer to the three dimensions of communities of practice as identified by Wenger (its domain, its capabilities, and its members' relationships) when deciding what kind of community of practice to create. While Wenger believes communities of practice are created (or should be created) spontaneously without management approval, McDermott asserts CoPs could be created per management request as in the case with the Shell Oil Company’s CoPs. (McDermott, p. 2)

As depicted in Figure 2, McDermott theorizes all communities of practice, whether spontaneous or intentional, share both knowledge and information, have both individual and community relationships, and integrate with peoples' work in many different ways. But they vary a great deal in how much they focus on each of these dimensions. Some focus more on sharing tacit knowledge; others on explicit information. Some build relationships among individuals; others build a common identity. Some are tightly tied 
into people’s everyday work; others are distinctly separate from it. By understanding these dimensions, it should be possible to determine the kind of learning community that will likely be most effective for a given situation. None of these dimensions is mutually exclusive.

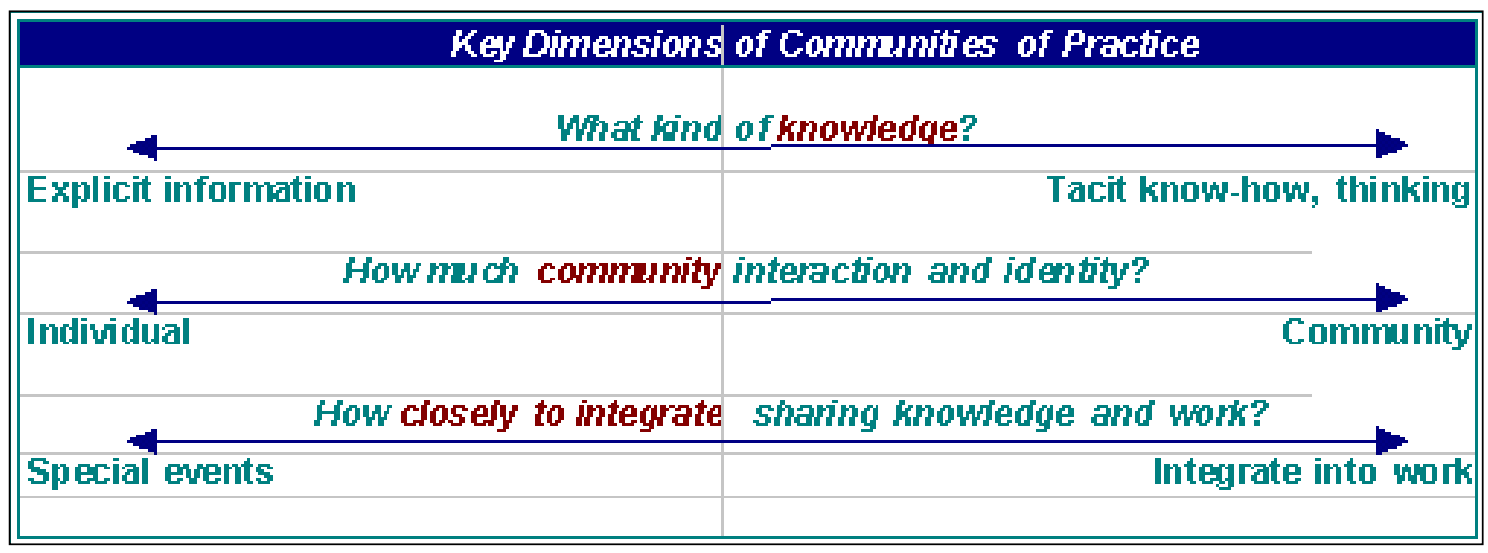

\section{Figure 2- McDermott's view of Communities of Practice Dimensions}

McDermott (1999) describes many types of communities of practice such as those that develop “official” best practices, create guidelines, have large knowledge repositories, or simply meet to discuss common problems and solutions. (McDermott, p. 1) He also asserts that communities connect in many different ways. Some meet faceto-face, and others have conferences; while others share ideas through a website. McDermott believes communities of practice are becoming prevalent mostly due to globalization, which forces companies to accelerate their innovation and ability to disseminate learning. (McDermott, p. 1)

McDermott (2000) believes ten factors are critical to the success of communities of practice. Without them, communities tend to flounder or fail. These factors are 
divided into four types of challenges: management, community, technical, and personal.

He provides a list of specific instructions regarding each type of challenge,

\section{Management Challenges}

1. Focus on topics important to the business and community members

2. Find a well-respected community member to coordinate the community

3. Make sure people have time and encouragement to participate

4. Build on the core values of the organization

\section{Community Challenges}

5. Get key thought leaders involved

6. Build personal relationships among community members

7. Develop an active passionate core group.

8. Create forums for thinking together as well as systems for sharing information

\section{Technical Challenge}

9. Make it easy to contribute and access the community's knowledge and practices

\section{Personal Challenge}

10. Create real dialogue about cutting-edge issues. It is difficult for many people to share ideas or to develop enough trust to share their ideas or knowledge with others. This personal challenge many hinder any knowledge sharing effort in a community of practice. (McDermott, p. 5)

Stamps (2000) asserts, "learning is social" and needs to be done on the job as corporate training is ineffective. Stamps shares Wenger's belief that communities of practice cannot be created out-of-the-blue by management fiat; they form of their own accord, whether management tries to encourage them or hinder them. Stamps believes some companies confuse communities of practice with competencies and go looking for them in hopes of cataloging skill sets and maybe even cataloging those skills into some sort of corporate knowledge base. Because knowledge is the cornerstone of communities of practice, a community member has to be able to give as well as take knowledge in order to remain a member in good standing. However, the knowledge that 
is passed around in these communities is not limited to the sort of explicit information that can be cataloged or computerized or bullet-pointed in a training curriculum. Quite often, it is implicit or tacit. (Stamps, p. 5)

Wenger, Brown, and Stamps deem the traditional view on learning which separates learning, social interaction, and innovation as outdated and not the best solution to a knowledge sharing effort. They believe knowledge transfer's social interaction aspect to be pertinent to the learning process and learning in a lecture/classroom setting to be outdated. They believe on the job, informal learning encourages a fresh stream of innovation as new ideas emerge from this exchange of ideas and knolwledge.

Lesser and Storck (2001) have described the advantages, connections, relationships, and common context derived from creation of a community of practice (see Figure 3). (Lesser \& Storck, p. 839) Their framework provides a set of principles consistent with both Wenger and Brown's theories in which leaning, working, and innovation are intertwined and cannot be separated. While Wenger believes communities of practice should be created on their own and without management intervention, Lesser and Storck include instructions on how to stay in accordance with the firm's principles. 


\begin{tabular}{|c|c|c|c|}
\hline Advantage & Connections & Relationships & Common Context \\
\hline $\begin{array}{l}\text { Decrease learning } \\
\text { curve }\end{array}$ & Find experts & $\begin{array}{l}\text { Mentor and coach } \\
\text { new employees }\end{array}$ & $\begin{array}{l}\text { Understand rules of } \\
\text { the firm }\end{array}$ \\
\hline $\begin{array}{l}\text { Reduce rework and } \\
\text { prevent reinvention }\end{array}$ & $\begin{array}{l}\text { Find commonalities } \\
\text { and the individuals } \\
\text { who developed them }\end{array}$ & $\begin{array}{l}\text { Establish positive } \\
\text { reputation }\end{array}$ & $\begin{array}{l}\text { Understand situational } \\
\text { nature of knowledge }\end{array}$ \\
\hline Increase innovation & $\begin{array}{l}\text { Leverage weak ties } \\
\text { that provide exposure } \\
\text { to new ideas }\end{array}$ & $\begin{array}{l}\text { Build safe environment } \\
\text { for brainstorming and } \\
\text { testing new ideas }\end{array}$ & $\begin{array}{l}\text { Understand which } \\
\text { problems are of } \\
\text { common interest }\end{array}$ \\
\hline
\end{tabular}

\section{Figure 3- Communities of Practice and Organizational Performance}

Zboralski (2006) believes communities of practice are intertwined with a formal organization and evaluates CoP activities including how knowledge generation efforts affect organizational-level performance. She also indicates that for a CoP to be successful the information it generates must be translated into primary tasks of organizations such as production or service. This point of view is contrary to Wenger's (2000) assumption of self-generating, self-organizing CoPs. (Zboralski, p. 4)

Daniels (2006) proposes that CoPs aim to “minimize redundant research efforts, enhance collaboration and exchange of ideas, and help leaders make timely and accurate decisions. The virtual porch provides a mechanism for individuals to keep each other current in the development of a shared discipline, and assists with better top-down communication by providing multiple and more-direct methods of disseminating information and ideas. Rather than being a detriment to individuality, this continuously updating baseline, once readily accessible, allows leaders to "focus their creative energies on the more advanced issues" (Daniels, p. 4). The key is the "socialization” of information dissemination; it is the manifestation of a long-accepted truism, "The 
perception of and the management of social networks is intrinsic to the leadership role” (Daniels, p. 4). Managed efficiently, those social networks can lead to tangible organizational improvements.

Archibald and Montgomery (2008) assert that despite the popularity and perceived contribution of communities of practice, their contribution to organization performance has been difficult to measure. They studied a large number of CoPs across a range of private industry sectors. They found that CoP leaders should invest time and money if they are looking to improve community performance and identify nine factors that contribute to individual and organizational performance in a community of practice,

1. Significant funding for face-to-face events

2. CoP activities addressing business issues

3. CoP leaders receiving training in community leadership

4. Sponsors with high levels of expectations

5. Members engaged in developing good practice

6. CoPs improving the usefulness of IT tools provided

7. Clearly stated goals

8. CoPs solving employees' daily work challenges

9. Leaders with sufficient time to perform the role (Archibald and McDermott, p. 17)

Wenger (2009) redefined communities of practice as social learning spaces, that is, places of genuine encounters among learners where they can engage their experience of practice. He indicates that although people's interactions such as books, web pages, and websites play a great role in sharing of information, "social learning spaces" provide a genuine environment for sharing of practical experiences. He indicates these social learning spaces require their members to have "learning citizenship” where people feel a belonging to participate or an ethics of learning by having a sense of personal responsibility and initiative. Wenger requires these social learning spaces to involve 
people, whom he calls "social artists", to provide inspirations to learning citizenship and address the social dynamics of learning. These social artists not only have a complete understanding of the discipline but the ability to connect with people and connect people with one another to maximize the learning process. Wenger believes that to better induce these "social learning spaces" there has to be a "learning governance" which participates in making decisions that affect the learning both locally and systematically. He indicates that the learning space of a community is built through a history of learning together over time. Commitment derives from identification with a shared domain of interest and with others who share that identification with the domain. Wenger indicates that in a social learning space, participants use their very beings - their personal history, relationships, and aspirations — as vehicles for learning. They pursue learning as a change in their ability to participate in the world, and as a transformation of their identity and engagement in an inquiry. Participants should see each other as learning peers and have a commitment to the practice in an open learning environment where no single person can direct the learning process. (Wenger, p. 2)

While Wenger emphasizes the learning aspect of communities of practice, Brown (2009) indicates that online games have changed the way learning takes place. He discussed a group of online gamers who formed a community of practice (which he defines as social and cultural institutions that imbue actions with meaning). These communities formed as guilds who meet online structure the meaning of activity within the game world. They also serve as the primary conduit of information between and among players, determining what has value and providing contexts for puzzle solving, organization, and social and task interaction. (Brown, p. 2) 
Dale (2009) identifies a community of practice as "a network of individuals with common problems or interests who get together to explore ways of working, identify common solutions, and share good practice and ideas.” He indicates a CoP,

1. Puts you in touch with like-minded colleagues and peers

2. Allows you to share your experiences and learn from others

3. Allows you to collaborate and achieve common outcomes

4. Accelerates your learning

5. Validates and builds on existing knowledge and good practice

6. Provides for opportunity to innovate and create new ideas (Dale, p. 2)

It is imperative to note "communities of purpose" defined by Litteton (2010) as an online community of people with a common, clear, defined goal such as stopping smoking or supporting or raising money (or awareness) for a particular cause. A community of purpose could be a Twitter group, a Facebook community, or increasingly - an online community created by a brand for a specific purpose, to be achieved over any given period of time. As there is a main goal for the group, members are very engaged and motivated. Littleton divides communities of purpose into two separate groups,

1. Groups with medium to long term goals such as WeightWatchers or Open University

2. Those created around a main event or a short-term goal.

Another variation of a community of practice is called a "virtual community of practice” (VCoP) intended for knowledge sharing efforts conducted by members of a CoP who are at different locations. Correia et al.(2010) believe VCoPs allow companies to better compete in a global business environment with accelerated market volatility and faster response times. While the above literature review outlines a variety of 
viewpoints on how a community of practice should (or could) be, there is little empirical research done in this field. This lack of empirical research provides an opportunity for research on several CoPs. By comparing these CoPs against Wenger's framework and stages of development of a community of practice, this dissertation can identify opportunities for improvement and evaluate how Wenger's framework and stages of development measure up in a real work environment. In addition, it is the goal of this dissertation to understand the role of IT in how a moderator manages a CoP. (Correia et al. p. 3) 


\section{CHAPTER THREE IMPACT OF IT ON A COMMUNITY OF PRACTICE}

As information technology (IT) is an integral part of our everyday work life, it would be valuable to understand the role it plays in shaping a community of practice's knowledge sharing efforts. Electronic networks have been found to support individuals interested in a specific practice, research, and development effort. Brown and Duguid (2000) assert despite the growing interest in online cooperation and virtual organizing, there is little empirical research on the communication and organization process of electronic networks, and how participation in these networks relates to sharing knowledge. They identify conferences as a good example of the potential contribution of integrating IT with the formal and informal knowledge sharing process because networks of practices often coordinate through professional associations.

While sharing explicit knowledge (knowledge that can be documented and shared using media) may be easier using an online/virtual community of practice, tacit knowledge needs to first go through the "externalization process" - be converted to explicit knowledge as defined by Nonaka (2004) in order to be shared using IT resources. Meanwhile, sharing of some time consuming, specific, and detailed explicit knowledge (such as a using a database system) may be similar to a lecture/class (traditional learning) environment and not the reciprocal knowledge exchange activities specific to a community of practice.

Wasko and Faraj (2005) built on Brown and Duguid‘s (2000) general description of networks of practice, and defined an electronic network of practice as a special case of the broader concept of networks of practice where the sharing of practice-related 
knowledge occurs primarily through computer based communication technologies. They defined electronic networks of practices as "computer mediated discussion forums focused on problems of practices that enable individuals to exchange advice and ideas with others with common interests.” They assert, an IT supported conference may enable people to obtain benefits from external network connections because they can gain access to new information, expertise, and ideas not available locally and can interact formally and informally free of the constraints of scholarly hierarchy and local rules. (Wasko \& Faraj p. 37)

Pan and Leidner (2009) conducted a year of study of knowledge management implementation by Buckman Labs and listed the following as the four main lessons learned from this case study,

1. To implement an effective communication process in a community of practice, an organization's technical solutions should be flexible enough to change with the dynamic knowledge sharing process. In other words, technology should not place a constraint on the process but should also be flexible with the CoP's culture and subcultures.

2. There should be different means of knowledge sharing tools/channels/forums available to the CoPs. In a global economy, an environment of communication/connection among existing CoPs should exist. The same knowledge sharing method cannot be used across all cultural boundaries.

3. Communities of practice should be encouraged to expand and the participants should share knowledge with the participants from other CoPs or communities to 
expand their communities. Most previous studies on CoPs have focused on the nature and nurture of an individual CoP while more research should be carried out to explore issues related to inter-CoPs. IT can play different roles in helping CoPs in these three phases,

1. IT as the overall knowledge infrastructure

2. IT as the linking mechanism between different Communities of Practice

3. IT as a support to different Communities of Practice

4. Issues and concerns regarding the changing role of IT should be addressed, a. An organization will have to re-adapt itself to different designs of KMS in order to bring out the best KM performance

b. Knowledge sharing in a CoP can only be effective if it is in accordance with existing practices rather than introducing new practices. IT can play the facilitator role if a new knowledge sharing practice is being introduced. (Pan \& Leidner, p. 2-4)

Pan and Leidner's case study involves a knowledge sharing effort on a global level where the teams located at remote or same locations contribute to the same project simultaneously. While most CoPs at the company are exclusive of other chapters (where no knowledge sharing activity takes place among different chapters), there are some CoPs with members at remote locations. All knowledge sharing efforts at the company (whether CoPs or organizational supported) must be conducted by the IT department's approved tools (different locations may have different lists of available and approved tools which may hinder the knowledge sharing efforts). This case study will evaluate the impact of IT on knowledge sharing efforts as well the impact of IT on advancement of a community of practice through the stages of development as defined by Wenger. (Pan \& Leidner, p. 1) 
Hara (2007) asserts that in a community of practice, three types of knowledge may be shared, cultural knowledge and the below two kinds of subject-matter knowledge (see the knowledge typology in Figure 4).

1. Book knowledge, which refers to factual knowledge, such as that gained by encyclopedic awareness of historical case laws and statutes (partly explicit so it can be shared through documents and electronic formats, such as messages on a listserv).

2. Practical knowledge, which refers to using the book knowledge in practice (part tacit, part explicit)

3. Cultural knowledge is tacit so the main mechanism of learning relies on observing experts' transfer of knowledge, which is a challenge in an online environment. (Hara, p. 9)

\begin{tabular}{|c|c|c|}
\hline $\begin{array}{c}\text { Professional } \\
\text { Identity }\end{array}$ & Cultural knowledge & Tacit \\
\hline \multirow{2}{*}{$\begin{array}{c}\text { Subject-matter } \\
\text { knowledge }\end{array}$} & Practical knowledge & \multirow{2}{*}{ Explicit } \\
\cline { 2 - 2 } & Book knowledge & \\
\hline
\end{tabular}

Figure 4-Knowledge Typology in a Community of Practice

There are conflicting perspectives on the role of IT in the knowledge sharing process, specifically in a community of practice. While some researchers view use of IT as beneficial and contributory to a community of practice, others find it as an impediment to a CoP's knowledge sharing process. The following viewpoints identify the possible constraints of using IT to the knowledge sharing effort in a community of practice.

Hara (2007) defines communities of practice as "informal networks that support professional practitioners in their efforts to develop shared understandings and engage in 
work - relevant knowledge building.” (Hara, p. 1) He asserts that reliance on IT use for communicative action may even weaken ties within a community. "Recognition of ways to foster professional identity" (having colleagues with whom to exchange ideas) is an important part of being a member of a community of practice. (Hara, p. 11)

Huysman (2002) identifies three constraints to a knowledge sharing process as applicable to a $\mathrm{CoP}$,

1. Those imposed by the management (sharing knowledge with members of competitor organizations may be limited to prevent knowledge leakage).

2. Those imposed by the individual (such as low willingness to share the knowledge, and lack of reciprocity and trust).

3. The constraints imposed by IT and the company communication system or network (not compatible with the CoP culture). (Huysman, p. 1)

Wang, Yang, and Chou (2008) list the possible reasons people do not share their knowledge as,

1. The technological architecture of such systems does not match human social behavior and work processes.

2. Knowledge workers do not want to give up their autonomy and anonymity. The design of KM systems needs to be consistent with the social processes of organization cognition, the way an organization thinks, creates, and operates. One difficulty in KM nowadays is how to bridge the gap between the technical architecture and human factors (i.e., behavior). (Wang et. al., p. 529)

These possible reasons can also apply to knowledge sharing efforts required as part of a community of practice. As indicated by McDermott (2000), personal challenges such as lack of initiative to share ideas, speak in public, and trust to share knowledge, are all obstacles to the knowledge sharing ideas associated with a community of practice. 
Correia et al. (2010) list the possible motivations and constraints in the knowledge creation and sharing process in a virtual community of practice as,

1. Intrinsic factors (Soft) - where members get motivated by factors related to their personality and the satisfaction they feel when sharing their knowledge with others

2. Extrinsic factors (Hard) - which involves financial rewards, direct or indirect, for sharing or creating knowledge

3. Organizational factors - which relate to the environment in which the group operates

4. Trust in the shared environment- as a facilitator of communication

5. Moral obligation - members feel the moral obligation to repay what they have gained from the organizational $\mathrm{CoP}$

6. Access to information and to specialists in a certain field

7. Organizational culture - a culture that motivates and rewards knowledge sharing creates advantageous conditions for the development of knowledge creation

8. Technological factors - among the constraint factors associated with technology, non-verbal communication (e.g., visual cues, rituals), so essential to tacit knowledge sharing, is not available to a VCoP. (Correia et. al p. 3)

While the above authors have listed the possible constraints to a knowledge sharing effort in a community of practice, results of a case study conducted by Gammelgaard (2010) at the Computer Sciences Corporation (CSC) indicates that employees' knowledge retrieval and access of documents written by colleagues in geographically distant units are managed. The company's virtual communities of practice facilitate the coordination of knowledge, and minimize contextual gaps between senders and receivers of knowledge. Furthermore, the knowledge sharing friendly culture of the case company quickly establishes swift trust, which enables receivers to 
directly approach the original, often previously unknown, author of a document for additional information. (Gammelgaard, p. 1)

According to Davenport and Prusak (1998), the idea of a knowledge market, a place where knowledge is exchanged or shared, is much like any other market where reciprocity and trust are two of the most significant factors. Wasko and Faraj (2000) confirm this theory and assert, "Knowledge sharing in electronic networks is facilitated by a strong sense of reciprocity - favors given and received along with a strong sense of fairness." In a community of practice setting where most of the knowledge sharing takes place using Web 2.0 tools, members may not feel enough trust to share their knowledge with those they do not know. Furthermore, the feeling of reciprocity may not be felt by those subject matter experts who continue to share their knowledge through the ITsupported media but not receive any input (and gain new knowledge) from their counterparts. (Davenport \& Prusak, p. 3)

Constant, Sproull, and Kiesler (1994) assert that the availability of electronic communication technology is no guarantee that knowledge sharing will actually take place, and one of the problems with accessing knowledge from acquaintances and unknown others is that it depends upon the "kindness of strangers" and "people’s selfexpressive needs”. (Constant, Sproull, \& Kiesler, p. 3)

Wang et al. (2008) provide three guidelines for a successful community of practice implementation, 1) remove barriers to individual participation, 2) support and enrich the development of each individual's uniqueness within the context of the community, and 3) link that uniqueness with the community's purpose. (Wang et al, p. 2) 
Lin, Hung, and Chen, (2009) suggest the norms of reciprocity and trust are treated as two major contextual factors influencing personal perceptions and a community member's behavior. Knowledge sharing self-efficacy, perceived relative advantage, and compatibility are seen as predictors of personal factors since they are all considered as the main influences shaping users’ behavior. (Lin et al, p. 3)

Lin et al. (2009) assert that in order to promote extensive and intensive knowledge flows in knowledge management, IT application research should be concerned primarily with three issues,

1. Comprehensiveness of IT construction- which provides various objectives and leads to employment of various tools to meet the diversity of objectives

2. Knowledge construction and maintenance-which requires IT achieve at least two objectives, reduction of uncertainties of knowledge loss, and reduction of dependence on specific personnel. (Bonora \& Revang, 1991) A considerable amount of knowledge may never be effectively exploited because of a lack of purposefully applied mechanisms.

3. Facilitation of knowledge creation, search, and diffusion, which are improved by IT, are resulting in increased transmission and response speed. In addition, IT facilitates creating, storing, and sharing of knowledge on a continuous basis. (Lin et al. p 3) 
In his Master’s thesis “Design of a CoP”, Oosting (2009) proposed a framework based around the core elements of a CoP as suggested by Hoadley and Kilner (2005). These elements, which facilitate knowledge sharing, are Content, Conversation, Connections, Context and Purpose (see Figure 5).

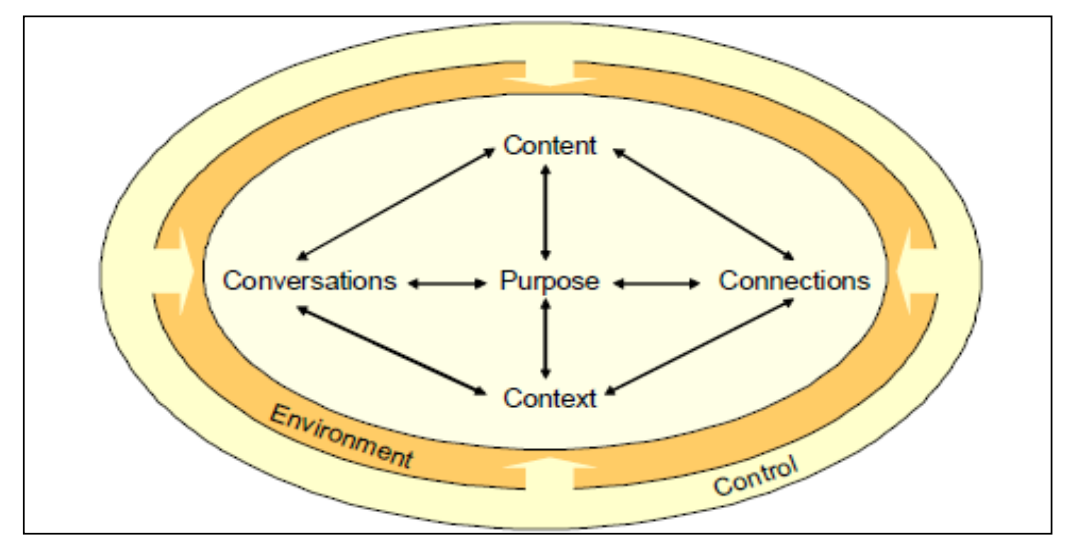

\section{Figure 5-C5PE Framework, Which Indicates the Elements Influencing the Effectiveness of a CoP}

In this framework named C5PE by Oosting (2009),

- Content refers to explicit, static knowledge objects (artifacts) and involves a one-way communication of information. Conversation refers to member discussions and includes at least a two-way exchange. Connections refer to the interpersonal contacts between community members that involve some level of relationship.

- Information context is, who, what, where, when, why, and how that enables community members to assess whether and how information is relevant to them. Finally, purpose is the reason for which the members come together and share their knowledge with others. (Oosting, p. 6)

There have been some questions about the differences between a team, a virtual team, a community of practice, and a community of purpose. While a team is created by an organization to support its operational goals and is hence provided with all available resources, its main characteristic is the locality of its members in which members have a 
day-to-day interaction. A virtual team differs from a conventional team as its members are dispersed at different locations. A community of practice is created without an organization's intervention and receives a limited (if any) amount of resources. A community of purpose is an online community created to achieve a specific goal such as smoking cessation or weight loss. Table 1 outlines the fundamental differences and similarities among a team, virtual team, and a community of practice. 


\begin{tabular}{|c|c|c|c|c|}
\hline & Traditional Team & Virtual Team & Community of Practice/VCoPs & $\begin{array}{l}\text { Communities of } \\
\text { Purpose }\end{array}$ \\
\hline Goals/Objective & $\begin{array}{l}\text { Accomplish specific } \\
\text { task }\end{array}$ & Accomplish a task & Knowledge sharing/learning & $\begin{array}{l}\text { A short term goal or } \\
\text { event }\end{array}$ \\
\hline $\begin{array}{l}\text { Company Support } \\
\text { (Resources) }\end{array}$ & $\begin{array}{l}\text { Company resources } \\
\text { (charge number, } \\
\text { conference rooms, } \\
\text { tools) are provided }\end{array}$ & $\begin{array}{l}\text { Company resources (charge number, } \\
\text { conference rooms, tools) are provided for } \\
\text { company set goals }\end{array}$ & $\begin{array}{l}\text { Company may or may not provide } \\
\text { support }\end{array}$ & N/A \\
\hline Member interactions & High & Less & High & High \\
\hline Member conflicts & Less Conflict & $\begin{array}{l}\text { Lack of face to face interaction leads to less } \\
\text { inhibited behavior (more conflict, better } \\
\text { decision making) }\end{array}$ & Less conflict & None \\
\hline Leader role & Project manager & Moderator & Moderator & Important \\
\hline Trust issue & More trust & Less trust & More trust & High \\
\hline Knowledge exchange & Low & High & $\begin{array}{l}\text { High (physical interaction among the } \\
\text { members of the network of experts) }\end{array}$ & Medium \\
\hline Decision making & Less satisfied & More satisfied & More satisfied & N/A \\
\hline Accomplishing task & Less time taken & More time taken & Knowledge sharing accomplished & High \\
\hline Satisfaction level & More satisfied & Less Satisfied & High if members joined voluntarily & $\begin{array}{l}\text { Depends on member } \\
\text { involvement }\end{array}$ \\
\hline Monitoring team activities & Low & High & High & High \\
\hline Amount of participation & Low & $\begin{array}{l}\text { High (due to asynchronous nature of } \\
\text { communication ) }\end{array}$ & High & High \\
\hline $\begin{array}{l}\text { Project management issues } \\
\text { (such as staying on schedule } \\
\text { or within the budget) }\end{array}$ & Low level of difficulty & High level of difficulty & N/A & High \\
\hline $\begin{array}{l}\text { Establishing a shared vision } \\
\text { or mission }\end{array}$ & Easy & Difficult (due to lower interaction) & $\begin{array}{l}\text { Moderate depending on participants' } \\
\text { views of the CoP }\end{array}$ & High \\
\hline $\begin{array}{l}\text { Members expressing their } \\
\text { opinion due to status effect }\end{array}$ & Lower & Higher & Highest & N/A \\
\hline $\begin{array}{l}\text { Acceptance of member } \\
\text { opinion }\end{array}$ & Higher & Lower & Highest & N/A \\
\hline Organizing the team & Easier & $\begin{array}{l}\text { Harder (difficult to access across division } \\
\text { boundaries) }\end{array}$ & Easy & High \\
\hline Life cycle & Duration of project & Duration of project & As long as value added & Short \\
\hline Membership fluidity & Solid for a period & Fluid membership & Semi-fluid membership & High \\
\hline $\begin{array}{l}\text { Group efficiency in relation } \\
\text { to group size }\end{array}$ & $\begin{array}{l}\text { Efficiency decreases } \\
\text { with group size }\end{array}$ & $\begin{array}{l}\text { Efficiency increases with group size (more } \\
\text { members means more ideas) }\end{array}$ & $\begin{array}{l}\text { Group size increases the knowledge } \\
\text { sharing effort (more heads = more ideas) }\end{array}$ & High \\
\hline $\begin{array}{l}\text { Impact of diminished } \\
\text { nonverbal communication }\end{array}$ & $\begin{array}{l}\text { Teams take less time } \\
\text { for decision making }\end{array}$ & $\begin{array}{l}\text { VTs take longer to make decisions, are less able } \\
\text { to make inferences about members' knowledge, } \\
\text { and are less able to anticipate other members' } \\
\text { responses }\end{array}$ & $\begin{array}{l}\text { N/A as members meet both in person and } \\
\text { online }\end{array}$ & N/A \\
\hline Role of location & $\begin{array}{l}\text { All members are at the } \\
\text { same location }\end{array}$ & $\begin{array}{l}\text { VTs can bring together individuals with the } \\
\text { needed knowledge, skills and abilities } \\
\text { regardless of their location }\end{array}$ & $\begin{array}{l}\text { Members should meet face to face to ease } \\
\text { the knowledge transfer effort }\end{array}$ & N/A \\
\hline
\end{tabular}


Table 1-Teams, Virtual Teams, and CoPs by Dayan, Rony , Pasher, Yossi (2006) 
While the above research has outlined the possible improvements and constraints provided by use of IT in a community of practice, the issue of "quality of transferred knowledge” has not been discussed by any of the authors. As use of knowledge transfer tools enables the knowledge sharing process, the question remains, "would the quality of transferred knowledge be the same as when the knowledge transfer and exchange is done on a 'one on one' basis?” Furthermore, "Would use of IT in a community of practice contribute to a change in a CoP moderator's role in each stage of development or is it vice versa, does the moderator influence the use of IT in a CoP?" To answer these questions, an interpretive research method will be used to observe selected CoPs and examine the possible role of IT in their effectiveness.

Another point to consider is that the above research provides a set of guidelines to improve knowledge sharing efforts in an organization (where management support and resources are provided to achieve an organizational goal). However, a community of practice may not benefit from this support and companies may not adhere to CoPs' requests to upgrade or change resources (such as tools).

\subsection{Typical Activities in Each Stage of Development}

\subsubsection{Potential Stage}

Important activities at this stage include providing various means for the need of more systematic interaction among community members. Each participant has several issues to consider at this stage including, define the scope of the domain, find people who already network on topics, and identify the common knowledge needs of the potential community (Wenger et al, 2002). In this stage, the members try to find commonalities with other members and try to meet others with the same interests. The 
members ask many questions to both other members and the moderator to identify a way to charter the group to convene and agree on a possible mission statement and a set of guidelines for the CoP. They also find a way to ensure their activities are aligned with not only the organization's culture (and possibly with its goals), but also with other CoPs.

\subsubsection{Coalescing Stage}

It is critical to initiate activities that encourage relationship building, trust and common interests and needs. The key issues for each element in this stage are establishing the value of sharing knowledge, exploring connectedness, defining joint enterprises, negotiating community, developing relationships and trust to discuss "sticky" practice problems, and discovering what knowledge should be shared and how this should be accomplished (Wenger, 1998). During this stage the members create more detailed plans on the knowledge sharing process such as identifying and contacting subject matter experts, setting up mentor-protégé tracking systems, composing meeting agendas and scheduling regular meetings. One of the main activities during this stage is promoting the CoP and its goals to recruit more interest among company members. The group also makes plans for making artifacts (such as training material and videotapes of lectures for future members' retrieval and use), creating CoP web pages and blogs, document repositories, and email lists. The Coalescing stage of a community of practice was selected as the focus of this study as it is the deciding factor for all subsequent stages of development as defined by Wenger. This is where the members come together and decisions regarding the CoP's main activities, policies, IT use, and knowledge sharing efforts are made. (Wenger, 1998) 


\subsubsection{Active Stage}

A shift from sharing tips to developing a comprehensive body of knowledge expands demands on community members. The key issues in this stage are, defining the community's role in the organization, managing the boundaries of the community, which has expanded beyond a network of professional friends, organizing the knowledge of the community and taking the stewardship seriously. (Wenger 1998)

\subsubsection{Dispersed Stage}

As the community closes its doors to new knowledge sharing efforts, it is imperative to maintain the artifacts created in the earlier stages of development and hold re-unions for the members. (Wenger 1998)

\subsubsection{Memorable Stage}

Key issues in this stage are telling stories, preserving artifacts, collecting memorabilia. (Wenger et al, 1998)

\subsection{Role of a Moderator in a Community of Practice}

Moderators help to cultivate a community of practice when they organize events and connect community members. They discover who talks to whom about what topics, issues of importance, obstacles and barriers. One method of discovering this information is through informal network analysis. A key role for the moderator is to help the community focus on its domain, maintain relationships through networking, and develop its practice. (Wenger et al., 2002)

Archibald and Montgomery (2008) note that at ConocoPhillips' CoPs (called Networks of Excellence), leaders learn what is expected of them; how to link to and engage members; how to influence outside their community; and how the support team 
can help the community achieve its goals. They conduct conference calls and send monthly newsletters highlighting the community activities’ statistics to all members to describe "what we see happening."

Dale (2009) emphasizes the importance of the Coordinator's role in building trust within a $\mathrm{CoP}$, and as a catalyst for turning conversations into active collaboration. He believes it is up to the facilitator to inspire the members to connect, collaborate and co-create.

Studying the Coalescing stage of development in a CoP is of importance because planning, coordinating, moderating, and establishing the network of knowledge sharing which normally takes place at this stage contributes to the success of a CoP in its Active stage and beyond. In other words, the Coalescing stage is where the CoP is set up for the remaining stages of its development.

The importance of the moderator's role is at its peak during the Coalescing stage as use of IT (knowledge sharing tools and communication tools such as blogs, email, newsletters, Instant Messaging) would typically be set up during this stage. As the moderator's role in the Active (and subsequent stages) is more involved in using the tools, it is imperative for the moderator to be proactive during the Coalescing stage.

\subsection{What is Information Technology (IT)?}

Information technology (IT) is the technology that deals with the use of computers and telecommunications to retrieve, store and transmit information. The role of IT is important in every organization since it defines both the internal and external 
communications among its members. In a community of practice, IT plays an even more important role since a CoP's main purpose is to share and transfer knowledge. By utilizing IT, a CoP can benefit from knowledge sharing tools such as a wiki, ShareCenter, SharePoint, blogs, instant messaging, online newsletters, and websites. Since the Coalescing stage is when a moderator sets up the knowledge sharing agenda (whether it is in person or virtual) for the CoP, it is important to evaluate the mutual impact of IT and role of a moderator at this stage.

\subsection{What does CoP Effectiveness Mean?}

CoP effectiveness refers to the intensity and value of knowledge sharing that takes place in a CoP. If there is a high amount of knowledge shared, and several off-line conversations or meetings are taking place concurrently, then the $\mathrm{CoP}$ is deemed as effective. If CoP members meet only sporadically and do not share their knowledge (whether it is due to the moderator or technological, cultural, or trust issues), the CoP is considered ineffective.

\subsection{What Are The Success Factors in a CoP?}

A community of practice's success is dependent upon several factors, including the diversity of the CoP members that may play a major role in member relations and knowledge sharing activities. The diversity may be derived from the geographic location, role of members in their own organization versus their roles in the CoP, and/or the tools available to each of the CoP members. Another major factor influencing a CoP's success is multiple reporting structures (as in a matrix organization), which may cause a conflict between a member's primary role versus his or her role in the CoP. A 
CoP's success may also be influenced by many factors. Such as, the role of the moderator and the support it receives from the champion (upper management), the possibility of incentives to motivate the moderator and team members, and the extent to which the company supports the CoP by providing it with resources (such as conference rooms, communication tools and devices, and charge numbers). (Correia et al. p. 14 ) (Davenport and Prusak p. 4). The success or effectiveness of a CoP in its Coalescing stage is determined by quality and quantity of knowledge sharing venues being developed by the moderator. If he or she is utilizing (or planning to utilize) all possible knowledge sharing venues, then the CoP is deemed successful (or effective). A CoP whose moderator is utilizing a limited number of available resources to achieve its mission is not found to be successful or effective.

\subsubsection{IT Culture In Each CoP at the Company}

As each division of the company has adopted a different set of communication tools, members of a CoP who span several divisions may have access to different tools. This may have hindered the knowledge sharing effort among these members. Furthermore, members from different divisions may not have access to the same set of documents due to issues such as consent decree, security, and exclusiveness of servers.

\subsubsection{Roles of Different Members of a CoP}

As each company CoP is supported (or initiated) by a different champion, there are several roles in CoPs. In other words, different CoPs have different roles for their

members. While in one CoP there may be a moderator, a development officer, a secretary, and a treasurer, another CoP may only have the moderator and member roles. 


\subsubsection{Why Does the Company Support CoPs?}

The company that hosts the CoPs studied in this dissertation has a Community of Practice Implementation Guide that lists several reasons to support a CoP,

- Leveraging capabilities faster than competition

- Replicating proven practices and sharing lessons learned

- Improving access to relevant and authoritative information sources

- Leveraging individual experience and expertise

- Fostering an environment of collaboration and knowledge sharing, that provides a fertile ground for business process innovation.

The company has provided the rationale to create and support a CoP, but needs to outline the specific support mechanism it plans to provide its CoPs. There should be a detailed guideline on resources, tools, and personnel support, each CoP is entitled to receive. The company should define the explicit role for the CoP moderator as well as the company policy regarding use of IT tools and other company-supported resources.

This research was conducted using a multi-dimensional approach by focusing on the stage of development the CoP is in, the role of the moderator in the CoP, and use of IT in conducting CoP activities or achieving CoP goals. The Coalescing stage of the CoP was selected as the focus of this study as it is the center stage of all CoP goals and activities. This is when the community of practice comes together, goals are set, activities are scheduled, and plans are made. 


\section{CHAPTER FOUR METHODOLOGY}

What sets this dissertation apart from other research on CoPs is that while other CoP-related literature has focused only on one CoP, this dissertation provides a comparison study among several CoPs in the same company. The present work not only offers an insight into how various CoPs in the same organization operate and overcome obstacles, but it also provides guidance to organizations with more than one CoP. For the purpose of this study, use of IT was selected as the main category and the focal point of all questions. In other words, the survey and interview participants were asked whether and how the moderators used IT to achieve the CoP goals and conducted activities (specific to the Coalescing stage as defined by Wenger).

\subsection{Research Questions}

Two research questions were posed based on the review and analysis of literature: How does IT affect the effectiveness of a CoP in the Coalescing stage, and how does the moderator influence the use of IT during this stage of development? I conducted a series of case studies to answer these research questions.

\subsection{Research Method}

The interpretive research method was used for the purpose of this dissertation. Neuman (2003) asserts, “Interpretive research focuses on studying, reflecting on, and examining people’s behaviors in their natural settings and often involves participation and personal contact with those being studied. The researcher is a passionate participant and involved with those being studied.” (p. 76) 
This dissertation study evaluates the impact of IT on the role of a moderator in the Coalescing stage of a CoP and the use of IT by the moderator. Several communities of practice at a large government contractor ("the company") were selected as case studies. The company's guidelines regarding creation and conduct of CoPs as well as each CoP's mission statement, wiki page, past meeting minutes, and list of activities were reviewed. As part of an interpretive study, the researcher participated as an active member in almost all of the CoPs. This participation included being a member of or joining the CoPs, attending their meetings, reviewing their mission statement and goals, and getting involved in their knowledge sharing and administrative activities when applicable. As a collateral benefit, the company's CoPs were evaluated against Wenger's CoP framework and activities and goals indicated in the Coalescing stage of a CoP's development.

\subsection{Case-Study Research}

A case study is a review of an entity to describe its nature, its behavior through one or more situations and provides a conclusion after analyzing the collected data against one or more questions. For the purpose of this study, several CoPs in a large technical firm were reviewed, and ten of them were selected to be used as case studies. To provide a broader perspective on the research, a variety of CoPs with different domains, locations, number of participants, moderator's competency in IT tools, and moderator influence in the company were selected. Some CoPs were bound to one company site while other CoPs had members from company sites across the U.S. All CoPs were part of a U.S. based company. 


\subsection{Case-Study Selection Method}

Yin (2003) indicates, “An explanatory case study presents data bearing on causeeffect relationships -- explaining how events happened” (p. 6) and asserts the case-study selection process needs to list the specific reasons why a particular group of cases was selected. The rationale may include selection of exemplary instances of the phenomenon being studied, or a group that includes contrasting outcomes. He points out the casescreening step should be included in the work plan and should include collecting sufficient data to decide whether a case meets the pre-established criteria. In this study, the impact of IT on the role of a moderator and the use of IT by the moderator in the Coalescing stage of development serve as the criteria to be met. The ideal screening process identifies a series of candidate cases without an extensive or expensive data collection session.

\subsection{Rationale for Survey Questions}

The survey questions were related to activities specific to a CoP's Coalescing stage of development. In other words, for the CoPs in the stage before Coalescing (Potential Stage), the questions aimed to learn how the moderator planned to achieve the goals and set up the knowledge sharing efforts and venues specific to the Coalescing stage. For a CoP in the Coalescing stage, the goal was to observe and evaluate how the moderator was achieving these goals. For the CoPs in the Active through Memorable stages, questions evaluated whether and how the moderator conducted or coordinated these activities. The questions were categorized into two main groups of objectives and 
activities specific to the Coalescing stage of CoP development as defined by Wenger (1998) as depicted in Table 2.

\begin{tabular}{|c|c|}
\hline $\begin{array}{l}\text { The Most Critical Coalescing Stage Objectives } \\
\text { (e. g., articulation of common interests) }\end{array}$ & CoP-members' activities related to the objectives \\
\hline $\begin{array}{l}\text { 1. Establishing the value of sharing knowledge } \\
\text { 2. Exploring connectedness } \\
\text { 3. Negotiating community } \\
\text { 4. Developing relationships and trust to discuss } \\
\text { "sticky" practice problems } \\
\text { 5. Discovering what knowledge should be } \\
\text { shared and how this should be accomplished }\end{array}$ & $\begin{array}{l}\text { 1. Identifying and contacting subject matter experts } \\
\text { 2. Setting up mentor-protégé tracking systems } \\
\text { 3. Composing meeting agendas and scheduling } \\
\text { regular meetings } \\
\text { 4. Making plans for making artifacts (such as } \\
\text { training material and videotapes of lectures for } \\
\text { future members' retrieval and use), creating CoP } \\
\text { web pages and blogs, document repositories, and } \\
\text { email lists } \\
\text { 5. Defining joint enterprises }\end{array}$ \\
\hline
\end{tabular}

\section{Table 2-Categories of Survey Questions}

\subsection{Communities of Practice at the Company}

The company’s Community of Practice Implementation Guide defines a CoP as "Groups of people who share a passion about a topic, and who deepen their knowledge and expertise by interacting on an on-going basis. Communities help knowledge flow across organizational and geographical boundaries.”

The company has adopted a more positive view of CoPs throughout the years and has realized their ultimate knowledge sharing benefits. Accordingly, it provides a positive environment for both the CoP moderators and members. Through the course of this study it was determined those CoPs created in previous years received less IT support from the company and were treated differently from those created more recently as they encountered more barriers in terms of IT use. The company's support of CoPs created recently includes allowing them to use company-approved IT tools such as 
conference call numbers, LiveMeeting, a wiki, SharePoint, and ShareCenter/TeamCenter (document repositories).

\subsection{Survey Method}

In order to ask for the necessary information from subjects, six sets of open- and closed-ended questions were created as part of a survey emailed to the participants. The survey was emailed to 8 moderators and 20 members of different communities of practice in their various stages of development. The intended participants were members and moderators of various communities of practice at the company. An introductory paragraph describing the purpose of the research, the endorsement by upper management, the intended participants, and a consent form were included along with the survey questions. The participants were assured that participation was voluntary and the survey results would be aggregated and not compromise the company's products, process, project information, their job title, the CoP's name, or the domain of the CoP. The Claremont Graduate University Institutional Review Board approved the consent form and the procedures (see Appendix A).

Due to the company's mass email restrictions, the moderators were asked to respond to their own sets of questions and forward another set of survey questions to their CoP members. While a few of the moderators refused to forward any non-workrelated emails to their CoP members, a couple of members indicated they moderated other CoPs and expressed an interest in participating, thereby responding to the survey intended for moderators as well.

A few of the moderators contacted the researcher and indicated the questionnaire provided them with a new perspective on CoP coordination and gave them a new 
direction on the goals they should achieve and activities in which they should participate, such as setting up mentor/protégé pairs or setting up a blog, newsletter, or a wiki page. A few participants, both members and moderators of different CoPs, also called the researcher to ensure their responses were confidential as they had provided specific references to company issues and wanted to make sure their responses could not be traced back to them. All respondents provided their contact information and hence agreed to be contacted for follow-up questions or to clarify answers. Several of the participants were contacted to clarify their survey answers and at least one participant preferred to be interviewed as opposed to responding to questions in an email message.

The questions for the moderators of CoPs in different stages of development were almost identical except for the verb tense. For example, for the moderators of CoPs in their Potential stage, the questions aimed to explore the moderators' plans for conducting the specified activities and achieving the goals; while for the moderators of CoPs in their Coalescing stage, the purpose of the questions was to explore whether and how the moderators were achieving goals and conducting activities. For those moderators coordinating CoPs in their Active, Memorable, or Dispersed stages, the questions intended to find out whether and how the moderators had achieved the goals and participated in the activities specific to the Coalescing stage. The same approach applied to the questions forwarded to the CoP members where the purpose of the questionnaire was to ask whether and how their moderators planned, met, or had achieved certain goals or conducted the activities specific to the Coalescing stage. For each specific activity and goal a set of questions was asked in order to establish whether and how the participants used IT to achieve the goal or conduct the activity. 


\subsection{Interview Method}

To clarify some of their questionnaire responses and analyze the moderators' views on the impact of IT on their role in their community of practice as well as possible barriers to use and improvement opportunities, a series of interviews were conducted with the moderators to ask three further questions. Eleven moderators participated in the interview portion of this study. The questions were,

1. What is the impact of IT on the role of the moderator in a community of practice?

2. What improvement opportunities, in terms of IT use, do you suggest for a community of practice?

3. What barriers, in terms of IT, have you encountered when conducting CoPrelated activities or planning to achieve CoP-related goals? 


\section{CHAPTER FIVE \\ FINDINGS}

Twenty-six participants (thirteen moderators and thirteen members) responded to the survey. To analyze the research result, a series of field notes, including the survey responses (provided to the researcher via a series of email messages), notes from follow up phone calls or meetings, and notes from in-person and phone interview sessions were reviewed. These notes also included moderators’ blogs, wiki pages, and meeting minutes to verify IT tools used to conduct each CoP activity and achieve each goal.

\subsection{Survey Analysis}

\subsubsection{Data Analysis Method}

This section includes review and analysis of survey results and comparison with the established frameworks (knowledge sharing and other efforts specific to a CoP's Coalescing stage of development), and provides possible improvement opportunities for the CoPs. While the grounded theory data analysis method as defined by Strauss and Corbin (1967) was not used in this research, the three coding steps outlined by Strauss and Corbin, Open Coding, Axial Coding, and Selective Coding were followed to conduct data analysis.

\subsubsection{Open Coding}

For the purpose of this study, a set of detailed notes was created from responses on both the questionnaire and interview. All these responses were composed in a Microsoft Excel spreadsheet to make it easier to verify the completeness and applicability of responses. The Excel spreadsheet was then converted into NVivo 9 before "open coding” was performed. During this process, segments of responses were 
flagged and several main concepts were selected and examined. These main concepts included IT use, achieving each goal, and conducting each CoP related activity.

\subsubsection{Axial Coding}

During this phase, the major categories were further evaluated and a series of nodes were defined to assess the major themes in the responses. IT uses to achieve each goal and conduct each activity were the main nodes, which allowed the researcher to categorize the ideas and explore the relationship between the nodes.

\subsubsection{Selective Coding}

"Selective Coding is the process of choosing one category to be the core category, and relating all other categories to that category. The essential idea is to develop a single storyline around which everything else is draped” (Borgatti, 2010). All cases were reviewed several times to find common concepts and codes by assessing and categorizing respondents’ remarks. The common theme of IT use in conducting CoP related activities and achieving goals was used to extract the possible factors related to determining use of IT by a CoP moderator, improvement opportunities as indicated by the moderators, and barriers to CoP's IT use. Table 3 outlines the results of cross-case analysis to find consistencies among the participants’ survey and interview responses. 


\begin{tabular}{|c|c|c|}
\hline $\begin{array}{l}\text { Concepts/ } \\
\text { Codes }\end{array}$ & Respondents' Remarks (examples) & $\begin{array}{l}\text { Categories/ } \\
\text { Nodes }\end{array}$ \\
\hline Goals & $\begin{array}{l}\text { Achieving CoP goals (setup knowledge sharing efforts), } \\
\text { "Make sure all members of the group have access to the same network, organize } \\
\text { information in user-friendly logical folders. Periodically remind group members } \\
\text { where information is located.” }\end{array}$ & $\begin{array}{l}\text { IT use to achieve } \\
\text { CoP goals }\end{array}$ \\
\hline Activities & $\begin{array}{l}\text { Conducting activities (tracking mentor/protégé activities), } \\
\text { "Planning to use monthly report of protégé's progress." }\end{array}$ & $\begin{array}{l}\text { IT use to conduct } \\
\text { activities }\end{array}$ \\
\hline Perception & $\begin{array}{l}\text { Moderator's perception of tool, } \\
\text { "Adoption of new tools is a major issue....if people find the new tool useful then } \\
\text { they are more apt to adopt it...the perception of people about tools is very } \\
\text { important.” }\end{array}$ & \multirow{4}{*}{$\begin{array}{l}\text { Factors } \\
\text { Determining Use } \\
\text { of IT by a CoP } \\
\text { Moderator }\end{array}$} \\
\hline Competence & $\begin{array}{l}\text { Moderator's competence in tool, } \\
\text { "Everyone has a different level of knowledge on tools... making more tools } \\
\text { training available...people don't want to learn the syntax of how to do it...our } \\
\text { tools need to be more intuitive and easier to use...now users don't use a lot of } \\
\text { tools because they are hard to use.” }\end{array}$ & \\
\hline Availability & $\begin{array}{l}\text { Availability of the tool to the moderator, } \\
\text { "SharePoint is powerful and making it available to all will help out a lot...it is } \\
\text { currently available to limited groups." }\end{array}$ & \\
\hline Location & $\begin{array}{l}\text { Location of CoP members (co-located or dispersed), } \\
\text { "We wouldn't have a CoP without a LiveMeeting or ShareCenter as our CoP } \\
\text { members are spread among several sites." } \\
\text { "Conducting meetings using LiveMeeting has some issues as people drop in and } \\
\text { out all the time. Meetings held at remote locations need to have video feed to } \\
\text { make them more efficient. Our community of practice members are at the same } \\
\text { location so this would be irrelevant to us but when we meet with other chapters } \\
\text { remotely we have the issues." }\end{array}$ & \\
\hline Network & $\begin{array}{l}\text { Provide a mobile network, } \\
\text { "We need to push for more mobile functionality such as iOS devices and } \\
\text { Android to connect to the company network...to get the job done...easier for } \\
\text { developer--decision makers on using new programs and environment is } \\
\text { important." }\end{array}$ & \multirow{4}{*}{$\begin{array}{l}\text { Improvement } \\
\text { Opportunities } \\
\text { Stated by } \\
\text { Moderators }\end{array}$} \\
\hline KM Tools & $\begin{array}{l}\text { Make more KM tools available, } \\
\text { "Use of Wiki to keep meeting minutes...would be a great help so everyone can } \\
\text { access it...true collaboration is not happening...we need to use the discussion } \\
\text { feature...for collaboration purposes...Google+ would be a great tool for us to } \\
\text { adopt...circles of people you specify to join a discussion...Use of SharePoint } \\
\text { would greatly reduce the cost of doing business.” }\end{array}$ & \\
\hline Connectivity & $\begin{array}{l}\text { Provide tools' connectivity, } \\
\text { "We need connectivity between different software tools." }\end{array}$ & \\
\hline Encourage & $\begin{array}{l}\text { Encourage CoP's IT use, } \\
\text { "Unified set of tools would help...setting up a conference call is difficult as the option } \\
\text { is not available to all CoPs who are not supported by upper management." }\end{array}$ & \\
\hline Security & $\begin{array}{l}\text { Security restrictions such as limitations on mobile devices, } \\
\text { "Using some of the software tools....security restrictions... We would like to use the } \\
\text { voice or video recording feature in LiveMeeting-connectivity between different } \\
\text { software tools... at times we find it as an overload of security.” }\end{array}$ & \multirow{3}{*}{$\begin{array}{l}\text { Barriers to } \\
\text { CoPs' IT Use }\end{array}$} \\
\hline Limitations & $\begin{array}{l}\text { Development environment/tools limitations such as use of MS products, } \\
\text { "There is a very strong push to stay with MS world and approved software." }\end{array}$ & \\
\hline Challenges & $\begin{array}{l}\text { Other challenges (decision-making process, lack of tools training, lack of } \\
\text { connectivity among tools), } \\
\text { "Everyone has a different level of knowledge on tools. We need to have more } \\
\text { tools training available, as people do not want to learn the syntax of how to do } \\
\text { it. Our tools need to be more intuitive and easier to use...now users don't use a } \\
\text { lot of tools because they are hard to use...” }\end{array}$ & \\
\hline
\end{tabular}

\section{Table 3-Codes and Nodes}




\subsubsection{Data Analysis}

While the study emphasizes those CoPs in the Coalescing stage in order to identify the impact of IT on the role of its moderator, several CoPs in other stages were also studied. Of the ten CoPs, there were six in the Coalescing stage, and one CoP each in the Potential, Active, Dispersed, and Memorable stages of development (see Table 4).

\begin{tabular}{|c|c|c|c|c|c|c|c|c|c|c|}
\hline $\begin{array}{l}\text { CoP Stage of } \\
\text { Development }\end{array}$ & \multicolumn{2}{|c|}{$\begin{array}{l}\text { Potential } \\
\text { (P) }\end{array}$} & \multicolumn{2}{|c|}{$\begin{array}{c}\text { Coalescing } \\
\text { (C) }\end{array}$} & \multicolumn{2}{|c|}{$\begin{array}{l}\text { Active } \\
\text { (A) }\end{array}$} & \multicolumn{2}{|c|}{$\begin{array}{l}\text { Dispersed } \\
\text { (D) }\end{array}$} & \multicolumn{2}{|c|}{$\begin{array}{c}\text { Memorable } \\
\text { (M) }\end{array}$} \\
\hline Number of & \multicolumn{2}{|c|}{1} & \multicolumn{2}{|c|}{6} & \multicolumn{2}{|c|}{1} & \multicolumn{2}{|c|}{1} & \multicolumn{2}{|c|}{1} \\
\hline & Mod & Mem & Mod & Mem & Mod & Mem & Mod & Mem & Mod & Mem \\
\hline $\begin{array}{l}\text { Number of } \\
\text { Respondents }\end{array}$ & 2 & 4 & 6 & 4 & 2 & 3 & 1 & 2 & 2 & 0 \\
\hline
\end{tabular}

Table 4-Respondents' Breakdown

\subsubsection{Survey Results}

All participants’ responses were entered in an Excel spreadsheet, where each row represented a respondent's record to make the comparison of responses easier. A copy of the spreadsheet was made and an identification code was assigned to each participant. The code was based on the CoP's stage of development ( $\mathrm{C}$ for Coalescing, $\mathrm{P}$ for Potential, A for Active, M for Memorable, and D for Dispersed), the CoP letter Id (A, B, C, etc.), the participant's role in the CoP ("Mod" for a moderator vs. "Mem" for a member), and their number ID. For example, the first moderator of $\mathrm{CoP} \mathrm{C}$ in the Coalescing stage is identified as Co_CoP_C-Mod_1. A sample set of survey 
responses by members and moderators of CoPs in different stages of development is given in Appendix B.

After reviewing and redacting (removal of all references to the company name, CoP title, domain, location, or moderator name, and coding), the survey results were processed using the NVivo 9 software. NVivo is analysis software used to process qualitative, unstructured data such as surveys, interviews, or pictures. The data were imported into separate datasets in a format similar to an Excel worksheet. As a result, the following six sets of answer groups were created,

1. Members of CoPs in their Potential stage

2. Moderators of CoPs in their Potential stage

3. Members of CoPs in their Coalescing stage

4. Moderators of CoPs in their Coalescing stage

5. Members of CoPs in their Active, Memorable, or Dispersed stages

6. Moderators of CoPs in their Active, Memorable, or Dispersed stages

\subsubsection{Interview Results}

The Respondents were all moderators of CoPs in various stages of development as shown in Table 5. A sample set of interview responses by moderators of CoPs in different stages of development is given in Appendix C. 


\begin{tabular}{|l|l|l|l|l|l|}
\hline $\begin{array}{l}\text { CoP Stage of } \\
\text { Development }\end{array}$ & $\begin{array}{l}\text { Potential } \\
\text { (P) }\end{array}$ & $\begin{array}{l}\text { Coalescing } \\
\text { (C) }\end{array}$ & Active (A) & $\begin{array}{l}\text { Dispersed } \\
\text { (D) }\end{array}$ & $\begin{array}{l}\text { Memorable } \\
\text { (M) }\end{array}$ \\
\hline $\begin{array}{l}\text { Number of } \\
\text { Respondents }\end{array}$ & 1 & 5 & 1 & 0 & 2 \\
\hline
\end{tabular}

\section{Table 5-Breakdown of Interview Responses}

The interview data indicated that IT has a reciprocal effect on the role of a CoP moderator and the CoP's goals and activities. In other words, while IT use affects the role of a moderator by providing the knowledge-sharing infrastructure and acting as a facilitator, it is impacted by the decisions made by the moderator. As the CoP moderator decides which tools are used to conduct certain activities and achieve specific goals, her or his role also impacts whether and how a certain tool is utilized; making the IT use and CoP moderator's role a reciprocal relationship. These findings are depicted in Figure 6.

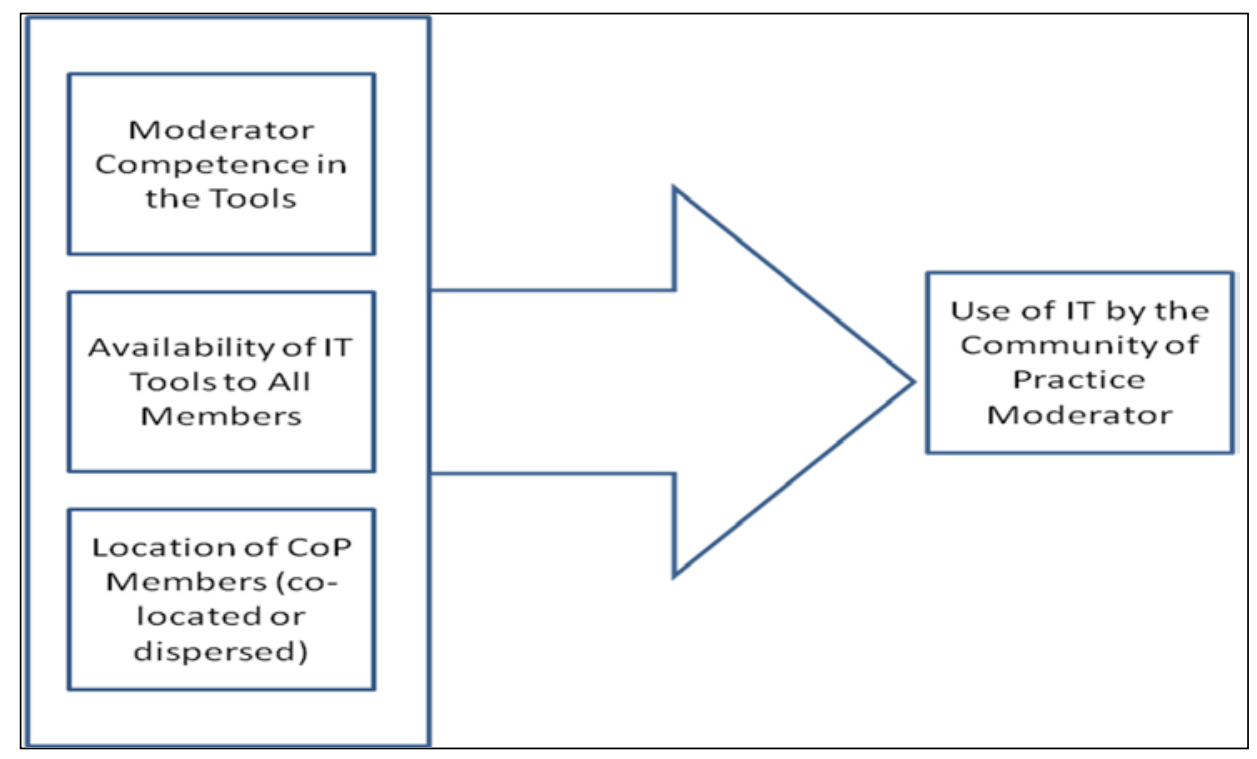

Figure 6-Impact of IT Use on the Role of a CoP Moderator 
It was determined there was a consistency regarding the moderators' perception of IT's impact on their roles for CoPs in the all stages of development. IT use is not related to the present stage of development of a CoP. The moderator of a CoP in one stage may use a specific tool or group of tools, which may or may not be used by CoPs of the same or different stages of development.

\section{$5.2 \quad$ Overview of Cases}

About fifteen CoPs were considered for inclusion in this study, of which ten were qualified to be part of this research. The criteria for this selection process was the group's domain (whether it was practice-related or not), its members, and its capabilities (plans to produce artifacts such as training material, web sites, and wiki pages). Being part of a large technical firm, most of the company CoPs are related to engineering/technical domains and the activities include knowledge sharing practices; most CoP participants are highly technical. Almost all CoPs were created to promote knowledge sharing efforts among more senior and less experienced personnel.

The communities of practice were in various stages of development as defined by Wenger and had different domains, locations, and moderators. While only one CoP in the Potential stage and one $\mathrm{CoP}$ in the Dispersed stage were identified, there were several CoPs in the Coalescing, Active, and Memorable stages, however only one CoP in the Active and Memorable stages qualified for the study. The study included CoPs with domains in technical, process improvement, earned value/financial analyst, KM, an application used to conduct a specialty task such as conducting a search or a design tool and a suite or group of applications used for a variety of purposes. 
The following case studies include an introductory section describing the case including its history and moderator's background, use of IT by the CoP moderator, results of both survey and interview questions, and a conclusion section summarizing the IT use by the CoP moderator. When referring to $\mathrm{CoP}$ goals or $\mathrm{CoP}$ activities in each case, the CoP goals specific to the Coalescing stage of CoP development, as listed in Section 5.5, are being discussed. The first sub-section of each case outlines its history, moderator (s), and participants. This section also provides a detailed insight into the CoP's domain, goals, and activities. The second part of each case provides the moderators' and CoP members' responses to various IT related questions regarding the IT use to achieve goals or conduct activities, possible improvement opportunities, and barriers to the CoP's IT use. The third part of each case provides the concluding remarks regarding the case. Table 6 gives a summary of all cases' specifications including the CoP's code, start and end date (if applicable), stage of development, rationale for classifying the $\mathrm{CoP}$ in a specific stage, number of moderators and participants, and whether the CoP is location-specific or cross-location. 


\begin{tabular}{|c|c|c|c|c|c|c|c|c|}
\hline CoP Code & $\begin{array}{l}\text { Start } \\
\text { Date }\end{array}$ & $\begin{array}{l}\text { End Date } \\
\text { (if } \\
\text { applicable) }\end{array}$ & $\begin{array}{c}\text { Stage of } \\
\text { Development }\end{array}$ & $\begin{array}{l}\text { Activities specific to this Stage of } \\
\text { Development as Defined by Wenger }\end{array}$ & $\begin{array}{l}\text { The Criteria/Rationale for Classification in the } \\
\text { Stage }\end{array}$ & $\begin{array}{c}\text { Number of } \\
\text { Moderators/ } \\
\text { Number of } \\
\text { Moderator } \\
\text { Respondent } \\
\text { s }\end{array}$ & $\begin{array}{c}\text { Number of } \\
\text { Participant } \\
\text { s/Total } \\
\text { Number of } \\
\text { CoP } \\
\text { Members }\end{array}$ & $\begin{array}{l}\text { Location- } \\
\text { specific/ } \\
\text { Cross- } \\
\text { Location }\end{array}$ \\
\hline Po_CoP_A & 2007 & & Potential & $\begin{array}{l}\text { 1. Define the scope of the domain } \\
\text { 2. Find people who already network on topics } \\
\text { 3. Identify the common knowledge needs of the } \\
\text { Potential community } \\
\text { 4. The members try to find commonalities with other } \\
\text { members and try to meet others with the same } \\
\text { interests } \\
\text { 5. The members ask many questions from both other } \\
\text { members and the moderator to identify a way to } \\
\text { charter the group to convene and agree on a possible } \\
\text { mission statement and a set of guidelines for the } \\
\text { CoP }\end{array}$ & $\begin{array}{l}\text { This CoP is recruiting members, does not have a specific } \\
\text { agenda, and has not been involved in any knowledge } \\
\text { sharing activities. }\end{array}$ & $2 / 2$ & $4 / 45$ & $\begin{array}{l}\text { Location- } \\
\text { specific }\end{array}$ \\
\hline Co_CoP_A & 2008 & 2011 & Coalescing & \multirow{6}{*}{$\begin{array}{l}\text { 1. } \\
\text { Establishing the value of sharing knowledge } \\
\text { 2. Exploring connectedness } \\
\text { 3. Defining joint enterprises } \\
\text { 4. Negotiating community } \\
\text { 5. Developing relationships and trust to discuss } \\
\text { "sticky" practice problems } \\
\text { 6. Discovering what knowledge should be shared and } \\
\text { how this should be accomplished } \\
\text { 7. Creating more detailed plans on the knowledge } \\
\text { sharing process such as identifying and contacting } \\
\text { subject matter experts, setting up mentor-protégé } \\
\text { tracking systems and composing meeting agendas } \\
\text { and scheduling regular meetings } \\
\text { 8. Promoting the CoP and its goals to recruit more } \\
\text { interest among company members. Make plans } \\
\text { for making artifacts (such as training material and } \\
\text { videotapes of lectures for future members' } \\
\text { retrieval and use), creating CoP web pages and } \\
\text { blogs, document repositories, and email lists }\end{array}$} & $\begin{array}{l}\text { This CoP has just finalized its member recruitment and } \\
\text { is planning some of its knowledge sharing activities. } \\
\text { A strong sense of trust has been developed among } \\
\text { community members. }\end{array}$ & $1 / 2$ & $0 / 9$ & $\begin{array}{l}\text { Cross- } \\
\text { located }\end{array}$ \\
\hline Co_CoP_B & 2010 & & Coalescing & & $\begin{array}{l}\text { This CoP has just finalized its member recruitment and } \\
\text { is planning its activities and meeting agenda. }\end{array}$ & $1 / 1$ & $1 / 150$ & $\begin{array}{l}\text { Cross- } \\
\text { located }\end{array}$ \\
\hline Co_CoP_C & 2009 & & Coalescing & & $\begin{array}{l}\text { This CoP has just finalized its member recruitment and } \\
\text { is planning its activities and its meeting agenda but has } \\
\text { not participated in any knowledge sharing or generating } \\
\text { artifacts activities. }\end{array}$ & $1 / 1$ & $2 / 47$ & $\begin{array}{l}\text { Cross- } \\
\text { located }\end{array}$ \\
\hline Co_CoP_D & 2011 & & Coalescing & & $\begin{array}{l}\text { This CoP has just finalized its member recruitment and } \\
\text { is planning its activities and its meeting agenda but has } \\
\text { not been involved in generating artifacts or a specific } \\
\text { schedule of meetings. }\end{array}$ & $1 / 1$ & $0 / 17$ & $\begin{array}{l}\text { Cross- } \\
\text { located }\end{array}$ \\
\hline Co_CoP_E & 2010 & & Coalescing & & $\begin{array}{l}\text { This CoP has just finalized its member recruitment and } \\
\text { is planning its activities, finalizing its domain, and } \\
\text { bringing the members together. }\end{array}$ & $1 / 1$ & $0 / 14$ & $\begin{array}{l}\text { Cross- } \\
\text { located }\end{array}$ \\
\hline Co_CoP_A & 2011 & & Coalescing & & $\begin{array}{l}\text { This CoP has just finalized its meeting agenda and is } \\
\text { planning its knowledge sharing development of artifact } \\
\text { activities. This CoP has initiated a wiki page. }\end{array}$ & $1 / 2$ & $1 / 10$ & $\begin{array}{l}\text { Cross- } \\
\text { located }\end{array}$ \\
\hline Ac_CoP_A & 2007 & & Active & $\begin{array}{l}\text { 1. Defining the community's role in the organization } \\
\text { 2. Managing the boundaries of the community which } \\
\text { has expanded beyond a network of professional } \\
\text { friends } \\
\text { 3. Organizing the knowledge of the community and } \\
\text { taking the stewardship seriously } \\
\text { 4. Maintaining the artifacts created in the earlier } \\
\text { stages of development }\end{array}$ & $\begin{array}{l}\text { This CoP is actively conducting knowledge sharing and } \\
\text { artifact (training material, website, wiki page) activities } \\
\text { and has a defined meeting agenda and CoP mission. }\end{array}$ & $1 / 1$ & $2 / 8$ & $\begin{array}{l}\text { Cross- } \\
\text { located }\end{array}$ \\
\hline Dis_CoP_A & 2008 & & Dispersed & $\begin{array}{l}\text { 1. Maintaining the artifacts created in the earlier } \\
\text { stages of development } \\
\text { 2. Holding reunions for the members }\end{array}$ & $\begin{array}{l}\text { This CoP has very few scheduled meetings and the CoP } \\
\text { members do not conduct a cohesive set of knowledge } \\
\text { sharing activities. The moderator is involved in } \\
\text { coordinating the training activities, maintaining the wiki } \\
\text { site and CoP artifacts. }\end{array}$ & $2 / 2$ & $3 / 8$ & $\begin{array}{l}\text { Cross- } \\
\text { located }\end{array}$ \\
\hline $\begin{array}{l}\text { Mem_CoP_ } \\
\text { A }\end{array}$ & 2008 & 2010 & Memorable & $\begin{array}{ll}\text { 1. } & \text { Telling stories } \\
\text { 2. } & \text { Preserving artifacts } \\
\text { 3. } & \text { Collecting memorabilia }\end{array}$ & $\begin{array}{l}\text { This CoP does not meet anymore and most of its } \\
\text { members have moved on to other tasks or left the } \\
\text { company. The CoP has achieved the goals it was set out } \\
\text { to achieve and has conducted the activities it was } \\
\text { cheduled to complete. }\end{array}$ & $2 / 6$ & 0 & $\begin{array}{l}\text { Location- } \\
\text { specific }\end{array}$ \\
\hline
\end{tabular}

Table 6-Summary of All CoPs 


\subsection{Case Studies \\ 5.3.1 Case Study 1 \\ 5.3.1.1. CoP Description}

This CoP started in 2007 and both its moderators participated in this study. One of the CoP moderators was a founding board member of this CoP while the other joined the $\mathrm{CoP}$ in 2009. The CoP is composed of those interested in contributing to women engineers' career development by providing professional workshops and career improvement lectures and seminars. While there are occasional meetings held, there are no scheduled recurring meetings nor is there a specific agenda for the chapter meetings. Group membership is extended to both men and women. This CoP was chosen as it is quite new and is still in the Potential stage of development. Each company site has its own chapter, which acts on its own behalf with no direction from and little communication with sites at different locations. Different site chapters meet each other on a quarterly basis to share their past activities and upcoming events. Only one chapter of this CoP was the subject of this study.

This CoP holds membership drives, posts recruiting advertisements, and sends email to managers and potential members to pique their interest in joining the group. To develop relationships between its members, the CoP sporadically holds various games and events. There are several roles in this CoP, including those of moderators, members, treasurer, and webmaster, all volunteered by the members and/or assigned by the moderators. Because the local chapter of this CoP benefits from the company's resources (budget for lunches, events, and conference rooms), its events are attended by more people than other CoPs at this company site. The researcher is a casual participant of this CoP. 
This CoP was classified in the Potential stage of development as it is recruiting members, does not have a specific agenda, and has not been involved in any knowledge sharing activities.

\subsubsection{IT Use by the CoP}

The CoP has a wiki site, which is updated by its webmaster as needed. The group uses email to provide updates (such as meeting notices) to its members and utilizes a set of shared folders to store meeting minutes, past presentations, and other informative material. This CoP does not use any IT tools (such as LiveMeeting or conference calls) to conduct its meetings as all its participants are at the same location.

The CoP moderators have used IT tools to send emails, gather information, assign action items, collect feedback to moderators, and keep meetings on track. They also use various tools to keep members informed of certain events and activities such as membership recruitment, professional development for the members, and scheduling community outreach programs. When asked about the impact of IT on achieving the CoP goals, the moderator said,

We have a wiki page that is updated bi-weekly and is viewed by over 50 members. The wiki page contains information such as past, present, and future activities. We also have archives of Power Point Presentations and other information from past speakers to bring new members up to date.

As one of the main goals of this CoP is to identify Subject Matter Experts (SMEs) and invite them to speak at the meetings, a managers' mailing list is used to ask managers to identify possible members and possible presenters. 
One moderator indicated that she uses an email distribution list to contact potential and current members. She named IT as the most essential part of the CoP because she uses mailing lists, web pages, and a wiki to bring the members together as part of the knowledge sharing effort of the CoP. Another of the CoP members indicates the CoP uses IT to share best practices and maintain the schedule.

The other moderator listed IT as a somewhat essential part of her role as the moderator and indicated the CoP has used IT tools to send emails, gather information, assign action items, collect feedback to moderators, and keep meetings on track. They also use various tools to keep CoP members informed of certain events and activities such as membership recruitment, professional development for our members, and scheduling community outreach programs.

The CoP moderator provided CoP-specific improvement opportunities in terms of IT,

CoPs should use videoconferencing (currently only available for organizational meetings with the customer) as opposed to the current combination of LiveMeeting and conference calls. Conducting meetings using LiveMeeting has some issues as people drop in and out all the time. Meetings held at remote locations need to have video feed to make them more efficient. Our meetings are at the one location, so this would be irrelevant to us but when we meet with other chapters remotely, we have the issues. It would also help us to use document/software review software so people do not use pen and paper to add their comments and notes, which is very inefficient.

As part of the knowledge sharing efforts conducted by the CoP, engineers of the same discipline often review and comment on each other's work to help them present better quality work. As some of the CoP members are software 
engineers, they tend to review each other's programming code. One moderator indicated,

The members are currently using pen and paper to comment on each other's codes and it would be more efficient if a software review application was available to the CoP members (as it is to the organizational teams).

She also indicated the engineers in other disciplines encountered the same issue in terms of reviewing each other's work as design review software was only available to do "actual work" related to a team project and not "extra-curricular activities.”

\subsubsection{Conclusion}

This CoP is one of the three case studies whose members are located at the same site and do not utilize IT tools to conduct their meetings or activities, except when they meet with other chapters. While the CoP uses PowerPoint to provide presentations, the use of LiveMeeting and conference calls is limited to the occasions when the colleagues from remote locations express an interest in the topic or the CoP is conducting its quarterly meeting with other chapters. This is also the only CoP with a chapter at each different company site, independent from one another.

\subsubsection{Case Study 2}

\subsubsection{CoP Description}

The CoP was created in August 2008 and was led by one moderator until June

2010. Another moderator took over until March 2011 when the CoP was disbanded by the company's vice president (CoP's champion). The reason for disbanding was that the 
upper management initiated another company-supported CoP that encompassed the whole division and absorbed all this CoP's members.

This CoP was composed of at least one representative from each of the company sites across the U.S. to discuss the company's knowledge sharing efforts. The council met once a week using LiveMeeting and conference calls and led the company's knowledge management/knowledge transfer activities. These activities included updating and maintaining a succession plan for the sector's SMEs and a scheduled plan to create training material on the approved knowledge transfer tools. One of this CoP's major objectives was to communicate the availability of various knowledge management tools and measure the tools' effectiveness through user surveys and usage metrics. These metrics were updated monthly by the team's metrics-coordinator and by the tools' owners.

This CoP was chosen as its moderator was planning for major activities and was in the Coalescing stage. This CoP used LiveMeeting, ShareCenter, and TeamCenter for member interaction and planned to create a wiki page, conduct demos, invite guest speakers, and provide other venues to continue its knowledge sharing efforts. The researcher believes this would be one of the most productive CoPs studied as part of this dissertation as it had already initiated developing a variety of artifacts, knowledge sharing activities, a wiki page, article writing, and meeting with various members of upper management. Different members of the CoP volunteered for a variety of roles contributing to the CoP's efforts. The researcher was an active member as the training lead for this CoP; different members were responsible for launching the wiki page or maintaining the ShareCenter and TeamCenter document repositories. The CoP 
moderator stated that the CoP was very successful in planning to create artifacts and conducting other knowledge sharing efforts.

This CoP was classified in the Coalescing stage of development as it had just finalized its member recruitment and is planning its activities.

\subsubsection{IT Use by the CoP}

When asked about the use of IT in achieving CoP-related goals, the moderator indicated the CoP used a number of IT tools such as Net Meeting and LiveMeeting to share information during group meetings. They also used conference calling for discussions, emails to communicate, and TeamCenter to store and share artifacts. The CoP had a wiki site, which allowed anyone from the company to share in what the $\mathrm{CoP}$ is doing. It also composed a list of all knowledge sharing efforts conducted by each CoP member at their respective sites to share best practices among its members. The CoP was instrumental in implementing a talent identification tool across the company division.

This CoP utilized IT for various activities such as tracking the SMEs' knowledge sharing efforts with their nominated successors. These activities are tracked using an Excel spreadsheet, which has a list of predefined activities that the SMEs are to participate in with one or more of their successors. This effort was one of the most successful activities conducted by this CoP, which truly augured an environment of trust suitable for knowledge sharing. The CoP has created several artifacts and training materials, which are kept in a document repository. 
With regard to the impact of IT on the role of a moderator, the moderator

indicated how essential the role of IT was to this CoP,

IT is important to our CoP because it gives them a mechanism for communication and its tools facilitate the communication. IT is an important facilitator that gives it an infrastructure.

The moderator indicated,

There are so many different methods to be used...to do the same thing... which is nice...but it gets confusing...one CoP uses TeamCenter while another uses wiki for the same activity. There should be a standard tool.

The moderator cited two main barriers to IT use by this CoP,

Getting permission for people to get into the right folders because of all the methods...training is not available for people to learn how to use all these knowledge-sharing methods.

\subsubsection{Conclusion}

In terms of IT use, this is the most efficient CoP of those studied. It utilized every possible IT tool and other resources available to its members and conducted its activities with high efficiency. Its members participated in a variety of knowledge sharing activities such as creating artifacts, conducting training sessions, meeting with various SMEs at their respective sites, preparing detailed knowledge sharing plans for their sites, and meeting offline to provide fellow $\mathrm{CoP}$ members private tutoring sessions on specific tools or processes when needed. As noted above, its champion disbanded this CoP during the process of this study. 


\subsubsection{Case Study 3 \\ 5.3.3.1. CoP Description}

This CoP was created by upper management to replace the smaller knowledge management CoP (subject of Case Study 2), and to govern all knowledge sharing efforts such as lessons learned, best practices, and developing or updating knowledge sharing tools for the whole division. While the mission of this CoP is defined and its members are identified and recruited, the CoP has met only a few times since its inception in November 2010. There are not any scheduled meetings and its members have conducted very few activities. This CoP was selected to be a part of this study because it is moving away from the Potential to the Coalescing stage. It does not have a specific agenda but the members, all of whom are the knowledge management leads at their respective sites, have discussed their ideas and barriers to their knowledge sharing efforts. This CoP does not have a wiki page, blog, newsletter or any plans to create artifacts or conduct other knowledge sharing efforts. The CoP moderator defines the goal of this CoP as not to share knowledge but rather to solve specific problems. The researcher is an active member of this CoP, although there have not been many activities conducted by it.

This CoP was classified in the Coalescing stage of development as it has just finalized its member recruitment and is planning its activities, finalizing its domain, and bringing the members together. 


\subsubsection{IT Use by the CoP}

In response to the question regarding the use of IT to achieve CoP-related goals the moderator responded,

Yes, we use IT in correspondence of all forms - e-mails, phone calls, LiveMeeting - that increases individuals' knowledge of one another and the amount of knowledge sharing that is conducted.

The moderator indicated IT has an essential role to play in a CoP and has a great impact on the role of a moderator,

These tools are essential to make our meetings possible because we are all not at the same location but are communicating by phone, ShareCenter, conference calls. IT is very important in sharing the content.

The moderator cited use of collaboration tools as a major improvement opportunity and indicated,

SharePoint 2010 will provide a lot of communication...flow of communication will be a lot better... In general our collaboration tools could use an upgrade.

The moderator did not encounter any barriers in terms of IT use and indicated that only after a software or hardware tool was improved, then the CoP members realized what the tool had been missing because it was difficult for the moderator and CoP members to envision the tool's possible improvement opportunities. 


\subsubsection{Conclusion}

This CoP is the most unstructured of all the case studies. It was created by the direction of a top-level company manager. While the members of this CoP utilize conference calls and LiveMeeting to conduct their sporadic meetings, they are not utilizing many of the IT resources available to them such as a wiki page, website, blog, document repositories, or SMEs. The CoP moderator was nominated by upper management and does not seem to be enthusiastic to encourage knowledge sharing efforts.

\subsubsection{Case Study 4 \\ 5.3.4.1. CoP Description}

This CoP was created in February 2010 to provide a venue for those who conduct financial analysis related activities such as processes, future projects, and training in the company. It now has scheduled recurring meetings for its 150 members (50 people meet in person at the division's headquarters and the remainder dial in from remote locations). This CoP was introduced by one of its core members as a suitable candidate for this study during a conversation with the researcher as it is in the Coalescing stage of development. The moderator plans to inspire more knowledge sharing efforts as opposed to conducting the meetings as classroom type sessions as is the current norm. To do so, he has requested that the homeroom manager at each site identify the SMEs at each location to develop specific artifacts such as training material,

manuals, and demos for the CoP. He also indicates that due to the sheer number of participants (and each campus calling in as a group), it is difficult to determine how 
many side meetings and knowledge-sharing activities are held. This researcher is not a member of this CoP. However, she has attended a few of its meetings.

This CoP was classified in the Coalescing stage of development as it has just finalized its member recruitment and is planning its activities and meeting agenda.

\subsubsection{IT Use by the CoP}

The moderator of this very large CoP named LiveMeeting as the tool of choice to achieve the CoP-related goals,

The Forum has been held monthly with participation (attendance) of about 150 people each session... about 50 people meet in person and the remainder participate via Live Meeting/telephone.

The moderator named LiveMeeting as the only tool used for the purpose of CoP related activities. The moderator's response is below,

IT plays a major role for our CoP...we have so many members without IT we could not do anything (conduct any activities).

The moderator cited "more training and easier to use tools" as the possible improvement opportunities and cited "getting permissions to obtain tools that are not approved at specific locations as well as the security issues brought up by the IT Department” as the major barriers this CoP faces. 


\subsubsection{Conclusion}

In terms of IT use, the CoP conducts its meetings by use of conference calls and LiveMeeting and is in the process of creating its own blog, wiki page, and website, which would be a great help in tracking, maintaining, and updating the CoP's efforts. It is a large CoP requiring several tools to coordinate its activities. It would be beneficial if different CoP members (SMEs) were assigned to each tool's activities. However, when a task is assigned to a person, a charge number should accompany the task's instructions. If the $\mathrm{CoP}$ moderator has no authority over the CoP members, he or she cannot assign any tasks such as being responsible for a specific tool for the CoP. As the upper management does not always support a CoP's activities and does not provide the moderator with a charge number (even though the company is the ultimate beneficiary), a moderator cannot assign any tasks to the members.

This CoP's large number of participants makes it difficult to track its efforts whether by IT tools or other resources. While this CoP has a lot of potential, it may be difficult for one moderator to manage all its knowledge sharing/transfer (mentor/protégé), or knowledge creation, which is the cornerstone of a CoP. It would be more practical to track participants' activities and create specific artifacts if there were more than one moderator (one for each group of sites or for a certain activity) to be able to effectively utilize the CoP's IT and brainpower resources. The moderator and members of this CoP are competent in specific tools to conduct their financial analysis activities which is the CoP domain, but are neither comfortable nor competent in using the knowledge sharing tools (such as wiki, web pages, or SharePoint) available to them and used by other CoPs. 


\subsubsection{Case Study 5 \\ 5.3.5.1. CoP Description}

This CoP was created in March 2011 by a specialty-engineering manager interested in discussing possible improvement opportunities in design, process, and methods related to her project and specialty. This CoP meets regularly and has encountered various barriers created by the upper management. The CoP was selected because the moderator (a fellow CoP member with the researcher in another CoP) learned about and expressed an interest in participating in this study as the CoP is in the Coalescing stage. The moderator would like to focus the CoP's efforts on sharing knowledge, documenting lessons learned and best practices, and identified improving the internally-developed software tools they utilize to conduct their tasks as one of their main discussion topics. The group currently uses desktop PCs to conduct their specialty engineering/design tasks and manages the database containing product life cycle information, but is considering using more web-based solutions in the future. One of this CoP's initiatives was to identify the SMEs' areas of expertise and provide their contact information to all members. The researcher is not a member of this CoP and has not attended any of the meetings. Only those who conduct specific tasks or work on specific projects are entitled to join this CoP.

This CoP was classified in the Coalescing stage of development as it has just finalized its member recruitment and is planning its activities and its meeting agenda but has not been involved in generating artifacts and has not created a specific schedule. 


\subsubsection{IT Use by the CoP}

The CoP utilizes LiveMeeting and conference calls to achieve its goal of meeting with its members. The moderator indicated the CoP utilizes several IT tools to collect its artifacts and provided the following response,

We already use documents and demos to provide training to program users. The CoP discusses more cost-effective ways of providing training such as SnagIt! and the company's version of YouTube.

The moderator believes the role of IT is essential in a CoP as "almost all CoPs

meetings are held virtually.” She provided several improvement opportunities and indicated,

Being able to multitask is very important...letting people do things while attending the meetings because there is no charge number associated with it...Use of wiki to keep meeting minutes would be a great help so everyone can access it as true collaboration is not happening... We need to use the discussion feature for collaboration purposes. Google+ would be a great tool for us to adopt as it involves circles of people you specify to join a discussion. Use of SharePoint would greatly reduce the cost of doing business.

The moderator identified the company members' resistance to change (in terms of IT use) as her major barrier. Some managers and employees would like to continue using the tools they have used for a long time and have the "if it is not broke, don't fix it” attitude.

\subsubsection{Conclusion}

This is one of the smallest and more specialized CoPs in this dissertation study. The moderator is not only tech-savvy, but also focused on improving both process and 
IT tools utilized by the CoP members in their practice. The main issue the moderator faces is the barriers imposed by upper management. This CoP uses very limited tools such as LiveMeeting and telephone to hold its meetings and plans to create a wiki page. Because this CoP's domain focuses on a specific set of tools and processes, and due to limited resources and upper management's support, it is difficult for the moderator to use common IT tools such as wiki, document sharing repositories, or web pages. The domain of this CoP is very limited to an inclusive group of members and only those who work on the specific task attend the meetings.

\subsubsection{Case Study 6}

\subsubsection{CoP Description}

This CoP was created in 2009 by one of the members of upper-management who is responsible for a large portion of the company's process improvement efforts. This community aims to facilitate the sharing of ideas and strategies about the practice of model-based process improvement across the company.

While this CoP emphasizes the ways for each company site to implement the same process improvement methods imposed by a specific framework, general processrelated topics are also discussed in the meetings. The moderator identified the CoP as being in the Coalescing stage of development, which was verified after the meeting agendas, plans, and activities were reviewed. What sets this CoP apart from others is that it receives a lot of company support as its moderator is a member of the upper management team. The CoP's members have all met in person not necessarily at the CoP meetings, but at various conferences or occasions. An interesting point about this 
CoP is this is the only one in the present study whose moderator indicates a non-formal mentor/protégé relationship among some of its members. The researcher is not a member of this CoP and has attended two of its meetings. This is the second largest CoP whose members conduct demos and hold their meetings using the latest IT tools. The CoP also encourages its members to meet for knowledge sharing sessions among them and attend conferences to learn the new topics, methods, processes, and tools used for their jobs.

This CoP was classified in the Coalescing stage of development as it has just finalized its member recruitment, activities and meeting agenda; but has not participated in any knowledge sharing or generating artifacts activities.

\subsubsection{IT Use By the CoP}

The moderator indicated the CoP utilizes LiveMeeting and conference calls to achieve its knowledge sharing goals; and has created a document repository with various permission rights to allow CoP moderators, members and those interested to have access to the multiple artifacts and distribution lists. This document repository allows the members to share knowledge on process improvement activities, appraisal preparation, implementing best practices within an organization, conducting appraisals, analyzing findings and implementing corrective actions and process improvements.

The CoP moderator videotapes the monthly sessions conducted by various speakers, and posts them on the CoP website and is planning to create a wiki site and use various distribution lists to recruit SMEs and create mentor/protégé relationships among its members. This activity will be tracked using either the company’s mentor tracking software or an Excel worksheet depending on the members’ comfort level. 
The moderator indicated IT was the most essential part of this CoP and without it the $\mathrm{CoP}$ would not exist. As the $\mathrm{CoP}$ grows and expands, it uses more IT tools to conduct its activities and achieve its goals. The moderator provided the following improvement opportunities,

Essentially, we would like to have webcams, as voice quality is not good when using conference calls. Videoconferencing should be used to capture our SMEs' lectures.

In response to the question regarding IT related barriers, the moderator asserted,

Not having Internet access at all times is the major barrier to this CoP's knowledge sharing efforts.

He indicated his division's IT department has brought down the site network to upgrade the system during work hours several times and some of the members attending the CoP meetings while offsite or on travel do not always have access to the Internet when calling in from remote locations.

\subsubsection{Conclusion}

The CoP has used NetMeeting, Meet-Me, and now LiveMeeting and phone calls to conduct its meetings and utilizes a distribution list to inform its members of future conferences, presentations, and training opportunities. This is of interest as the moderator is a part of a division other than most of the CoP members and has access to a variety of tools available to all divisions. In other words, members of the CoP who work for another division may or may not have access to Meet-Me as LiveMeeting is the company-approved teleconferencing tool. The moderator cites IT as the essential part of this CoP and indicates the CoP could not exist without use of IT tools. The moderator indicated the research questions prompted him to create more knowledge sharing 
opportunities for the CoP. The members of this CoP are software, systems, and webpage developers making it one of the most tech-savvy CoPs in this study.

\subsubsection{Case Study 7 \\ 5.3.7.1. CoP Description}

This CoP was created in March 2011 by a group of enthusiasts who are interested in implementing, maintaining, and using a specific knowledge sharing (research) tool at the company. The CoP was selected for this dissertation as its moderator, a fellow member with the researcher at a different $\mathrm{CoP}$, volunteered to participate in the study. This CoP is in the Coalescing stage of development and all its members have previously worked together or were co-members of other CoPs. Most members of this CoP are located at the same site. The researcher is a non-active member of this CoP but attends the meetings regularly. The members of this CoP are tech-savvy and have all been involved in developing, updating, or maintaining one of the company’s main knowledge-sharing tools.

This CoP was classified in the Coalescing stage of development as it has just finalized its meeting agenda and is planning its knowledge sharing development of artifact activities.

\subsubsection{IT Use by the CoP}


When asked about use of IT to conduct its activities, the moderator indicated the CoP uses document repositories to host its contents and LiveMeeting for its virtual meetings.

We use ShareCenter to host our contents, LiveMeeting for virtual meetings. As the main domain of this $\mathrm{CoP}$ is to improve a specific search tool, one of the members indicated the CoP uses IT to conduct its meetings in two ways, 1) presenting topics and soliciting discussion; 2) asking participants to identify needs, process problems, and pain points (they have with the tool). The CoP also utilizes IT to establish an environment of collaboration and knowledge sharing among its members by providing them with their own digital workspace.

The moderator provided the following input regarding the impact of IT,

IT has a lot of impact on our CoP. We use voicemail (to conduct conference calls) and use LiveMeeting to collaborate online...CoP repository to store documents newsletters, manuals and share with others.

When asked about the barriers to IT use the moderator indicated the CoP has had some security restrictions using some software tools. The members would like to use the voice or video recording feature in LiveMeeting. He continued by indicating,

While ShareCenter is great, it has to connect with the company's networking paradigm so all status tools connect together...tools enable us with data such as SharePoint-Mobile devices so the members can stay in touch...different tools need to integrate together... We have the tools, but have to fine-tune security to make them work together. 


\subsubsection{Conclusion}

This CoP is benefiting from the fact that it focuses on using, and improving a certain knowledge sharing, research tool created using an open-source language and based on a vendor's data mining Commercial Off-the-Shelf Software (COTS). This has generated many brainstorming/knowledge sharing sessions conducted during meetings. The members are ready, willing, and able to utilize the IT tools available to them. Although this is the smallest of the CoPs studied for the purpose of this dissertation, it seems to be the most efficient in terms of holding sessions, creating artifacts, making plans, and meeting with various members of upper management. As the CoP members are tech-savvy, the group has plans to expand its knowledge sharing efforts by creating a wiki page, inviting SMEs to conduct lectures, and creating newsletters.

\subsubsection{Case Study 8}

\subsubsection{CoP Description}

This CoP was created in 2007 and tracks the production and use of companygenerated Web 2.0 tools such as wikis, blogs, message boards, the company's version of Craigslist, and other similar tools. As the group members are located at different U.S. locations, the group meets electronically on a bi-weekly basis and the topics of interest include company-specific as well as public Web 2.0 tools. Off-line meetings are scheduled often to discuss specific questions. This CoP was chosen as it provides an effective learning environment for the participants and is in the Active stage of a CoP's development. 
As members of this CoP belong to various divisions and are of different technical, professional, and educational backgrounds, they tend to benefit from each other's knowledge of specific tools, As a result, members report that meetings are very informative. Almost all members of this CoP are SMEs who created the CoP and the moderator was a member of the CoP for three months before becoming the moderator. The researcher is a non-active member of this CoP who attends the meetings regularly. This CoP has the highest total number of tech-savvy members. They are comfortable using, teaching, and updating various knowledge sharing tools both approved by the company and those available but not approved by the company.

This CoP was classified in the Active stage of development as it is conducting knowledge sharing and artifact (training material, website, and wiki page) activities and has a defined meeting agenda and CoP mission.

\subsubsection{IT Use By the CoP}

The moderator indicated,

A wiki is the company's main asynchronous tool for its communication.

His comment indicates how important the role of introducing various tools is in providing an open knowledge-sharing environment for company members.

The moderator also stated that the CoP uses LiveMeeting and conference calls to conduct its demos and knowledge sharing activities. 
IT plays an essential role in our communication and collaboration efforts. Use of wiki, LiveMeeting, and e-mails allow us to communicate with the CoP members.

When asked about improvement opportunities, the moderator indicated that having a unified set of tools would help as setting up a conference call is difficult for some CoPs who are not supported by upper management because only a certain number of employees have access to conference call codes.

The moderator noted the following barrier to IT use,

Adoption of new tools is a major issue...if people find the new tool useful then they are more apt to adopt it...the perception of people about tools is very important.

\subsubsection{Conclusion}

This CoP was created so its members could learn about a variety of Web 2.0 tools and uses of these tools for its knowledge sharing efforts. While this CoP is very active, the knowledge sharing effort is now saturated (i.e., people are running out of tools to demo or learn from one another). This CoP has accomplished a lot in terms of developing artifacts and its members have repeatedly provided tools support to other CoPs, some of which are subjects of this study.

\subsubsection{Case Study 9}

\subsubsection{CoP Description}

This CoP, created in 2008, helps define and refine implementation of a companydeveloped wiki, an open-source tool, and one of the main knowledge transfer tools used across the company's divisions. It is an informal users group made up of enthusiastic 
expert wiki users with the purpose of improving the company's wiki version and promoting its use among fellow employees. While reviewing and standardizing the wiki templates and boilerplates, this CoP also provides ways to make the wiki more userfriendly and helps users by answering questions. One of this CoP's main activities involved offering various training/help sessions on the wiki and holding question/answer sessions both as part of CoP meetings and at each individual site. This CoP is leaning away from the Active stage and entering the Dispersed stage of development.

While this CoP has monthly scheduled meetings, it meets sporadically, and the topics are dwindling as the company's open source tools seem to be in place and everyone has access to online or instructor-led training without the CoP's intervention. The scheduled meetings are cancelled intermittently due to lack of topics and the meetings that are held are short also due to lack of topics. The CoP does have a wiki page, which is updated only occasionally due to lack of interest since the CoP has met most of its original objectives. Due to the consent decree between two different sites, until recently, the CoP's activities were limited. The consent decree required different divisions to maintain separate wikis, which resulted in instantiation of multiple versions. Each division had to establish their own guidelines, boilerplates, and templates. As this issue was just resolved, the CoP's efforts are now focused on merging the two instances of the wikis together and ensuring that the standards are implemented throughout the company in a short amount of time. This can be a daunting task as the two different divisions of the company used different standards, templates, and tag systems. The researcher is a non-active member of this CoP and attends the meetings regularly. As the CoP members are tech-savvy, they use various tools (both company-approved and otherwise) to create its artifacts such as training material, web pages, or wiki pages. 
Several members of this CoP are also members of the CoP that focuses on Web 2.0 tools, leading to more knowledge sharing efforts among the members as they meet each other more often and have better opportunities to discuss various topics and hence share their knowledge.

This CoP was classified in the Dispersed stage of development as it has very few scheduled meetings and the CoP members do not conduct a cohesive set of knowledge sharing activities. The moderator is involved in coordinating the training activities, maintaining the wiki site and CoP artifacts.

\subsubsection{IT Use by the CoP}

When asked whether and how IT was used to achieve CoP goals the moderator responded,

All members are added to an email distribution list, and then added to our monthly meeting notices. Members are also encouraged to add a "membership badge" to their profile page on the wiki.

The moderator also indicated use of IT has allowed the CoP to create help manuals, tutorial videos, brown bag presentations, and email distribution lists,

Scheduling meetings through Outlook is super-easy, and even lets me add the LiveMeeting option.

The moderator indicated IT has had a positive impact on his role and asserted,

IT plays an essential role in our communication and collaboration efforts. Use of Wiki, LiveMeeting, and e-mails allow us to communicate with the CoP members. 
When asked about possible improvement opportunities in regards to IT use, the moderator responded,

Having a unified set of tools would help...setting up a conference call is difficult, as the option is not available to all CoPs who are not supported by upper management.

The moderator cited the following barriers to use of IT for this CoP,

Adoption of new tools is a major issue...if people find the new tool useful then they are more apt to adopt it...the perception of people about tools is very important.

\subsubsection{Conclusion}

This CoP has utilized the company's version of a wiki to its fullest and has provided a great amount of support in governing its standards. The CoP utilizes LiveMeeting and conference calls to conduct its activities and has its own wiki page that provided a great amount of information (learning material, tutorials, videos, and examples) to wiki site visitors. Because this CoP's recent meetings have been short and few, it will be transitioning into the "maintenance mode" of a Memorable CoP in the near future.

\subsubsection{Case Study 10}

\subsubsection{CoP Description}


This CoP was created in January 2008 to improve the overall quality and efficient use of engineering resources across the company and thereby benefit the entire engineering community by generating new tools and identifying upcoming technologies.

Originated by a group of young engineers with strong technical (software and system development) backgrounds, this CoP was created by upper management and hence benefited more than some other company CoPs from company support in terms of charge numbers, tools, and other resources. The team subsequently grew and recruited a large number of people passionate about these technologies. This CoP is in the Memorable stage and was disbanded in 2010 by upper management. It does not meet anymore and only one of its original founders still works for the company and maintains the $\mathrm{CoP}$ wiki page and artifacts. The $\mathrm{CoP}$ is not involved with any new activities as it does not have any set objectives and does not receive any support from the company. This CoP's members were located at the same site and used instant messaging and “developing” sessions to create several new tools for the division where they worked. The researcher, who is not a member of this CoP, did not attend any of its meetings.

This CoP was classified in the Memorable stage of development as it does not hold any meetings anymore and most of its members have moved on to other tasks or left the company. The CoP has achieved the goals it was set out to achieve and has conducted the activities it was scheduled to complete.

\subsubsection{IT Use By the CoP}

When asked about the use of IT tools in achieving CoP goals the moderator responded, 
IT was most useful in terms of using telecom numbers, also riding on IT projects to incorporate voice into OCS was useful, using a shared space (ShareCenter) was also useful to collect minutes and documents, and LiveMeeting was also a great tool to have real time shared working spaces.

In regards to whether IT was used in conducting CoP activities, the moderator asserted,

Yes, with the use of LiveMeeting/teleconference. Also, the IT department was usually involved with our monthly COP meetings, but at times could hijack conversations for their own purposes or shoot down ideas early before further development was allowed to proceed.

When asked about the IT use by the moderator to achieve CoP goals, the moderator responded,

It depends on what the moderation is for...You might have a lot of tools but they are not good enough...efficient or usable for the use it is not beneficial...MS products are not always the best for the uses we are using it for...it will hurt us in the long run...

The moderator indicated it would be helpful if the CoP members had an ecosystem for all engineering organizations to develop tools in the environment they want and all tools, which the CoP developed should be available to the whole company and not to a specific division. There should be a push for more mobile functionality such as an Initial Operating System (iOS) device and Android to connect to the company network to help people get the job done and make it easier for developers to get the decision makers’ approval on using new programs and environments is important as accountability is not always defined. He indicated the developers should know who the decision maker/accountable person is for what program/tool/environment, which will be used. 
The moderator's response to the question regarding the IT-related barriers is below,

We have all these tools but the IT department puts a stop to it because they are not MS tools. .Net is not the environment we should be using ... it is limited ... other companies such as Google, Facebook have environments other than .Net ... we are so rigid in choosing our environment. We cannot use PHP across the company while Facebook is written in PHP ... we need to adopt more programming languages....

\subsubsection{Conclusion}

This CoP was chosen as it is leaning away from the Dispersed stage and has

entered the Memorable stage. Almost all CoP members have left the company or changed positions within the company. This CoP has utilized a document repository, instant iessaging, and an internally developed document collaboration tool used for software development.

\subsection{Comparison of All Cases In Terms of IT Use}

While all moderators who were approached responded to the survey, due to the company email distribution policy, only a few moderators forwarded the survey to their CoP members. As a result, an equal number of CoP moderators as members participated in this study. The common factor is the moderator's competence in using various knowledge sharing tools.

After reviewing the responses, it was determined that the CoPs created earlier (those now in their Memorable/Dispersed stages) received less company approval and support (with an exception of CoP 10 which was created by but not subsequently supported by the upper management). However, the newer CoPs (those in their Potential and Coalescing stages) received more company support in the form of charge numbers, 
conference rooms, and operating budgets. This could be because the organization has realized the value of knowledge sharing and wants its employees to find a more time efficient, practical, and less expensive way to receive the training needed to conduct their tasks better. While knowledge hiding is a ubiquitous phenomenon in organizations, providing incentives such as bonuses, promotions, and acknowledgements to the more experienced members of the organization who actively participate in a CoP provides an easy way to incent them to train less experienced members in conducting a specific task. The knowledge sharing efforts prevalent in CoPs also prove to be a timeefficient, cost-effective way of providing on-the-job training to new hires. These efforts also increase employee morale by engaging the new employees in decision making in process improvement, guideline development, or other activities resulting from a CoP. They also provide a less structured and intimidating environment for employees to express their concerns and opinions than in a standard workplace environment.

While most of the moderators and members in CoPs in Potential, Coalescing, and Active stages expressed less stress and encountered fewer obstacles, those who participated in CoPs in Memorable and Dispersed stages expressed common frustration and obstacles such as resistance to change, lack of management support, low quality and quantity of organizational resources, and lack of incentives for the participants.

While almost all CoPs utilized Microsoft LiveMeeting and conference calls to conduct their meetings, the use of other IT tools depended on the CoP moderator's interest and experience in using Web 2.0 tools. Similarly, all CoPs used a document repository; however, using the company's version of an open source wiki was not ubiquitous due to its difficulty for some moderators. It was determined that IT 
contributes to achieving most goals and conducting certain activities specific to the Coalescing stage (such as setting up meetings, including items on the agenda, establishing knowledge sharing methods (such as use of blogs, newsletters, web pages, and creating the training material). However, it does not play a role in other activities such as auguring an environment of trust, tracking of quality of knowledge shared between the mentor and protégé, or defining the CoP domain.

The moderator's use of IT in any stage of development was driven by the perceived value of the tool and how comfortable he or she was to utilize that tool. Also, the more tech-savvy the moderator, the more apt he or she was to use IT communication tools, hardware, and software in the coordination of CoPs. Another major factor contributing to the CoP success and use of IT as a resource in conducting CoP activities was the position of the CoP moderator and his or her access to various IT tools. The more prominent the CoP's moderator, the easier the access to IT tools, which meant that it was a great deal easier to make the tools available to the CoP members regardless of the fact that the member's site had adopted the tool. For example, a moderator who is a member of upper management can provide specific training for a member located at a different site, reporting to another organization, and working on a different project. Also, those CoPs that were supported even if not created by upper management benefitted from more resources and opportunities (to suggest process or project improvement) than those created in later stages.

Table 7 provides a comparison of IT tools used for the CoPs in each development stage. 


\begin{tabular}{|c|c|c|c|c|c|}
\hline & Potential Stage & Coalescing Stage & Active Stage & Memorable Stage & Dispersed Stage \\
\hline \multicolumn{6}{|l|}{$\begin{array}{l}\text { The most critical Coalescing } \\
\text { stage objectives (e.g., } \\
\text { articulation of common } \\
\text { interests) }\end{array}$} \\
\hline $\begin{array}{l}\text { 1. Establishing the value of } \\
\text { sharing knowledge }\end{array}$ & $\begin{array}{l}\text { Yes. By using wiki, email, } \\
\text { document repository }\end{array}$ & $\begin{array}{l}\text { Email, Net } \begin{array}{r}\text { Meeting, LiveMeeting, } \\
\text { document repository (two types } \\
\text { including TeamCenter), } \\
\text { TeamCenter, GoldFire }\end{array} \\
\end{array}$ & $\begin{array}{l}\text { Wiki and LiveMeeting, } \\
\text { and IM. }\end{array}$ & $\begin{array}{l}\text { Wiki, web-based tools, } \\
\text { and ShareCenter }\end{array}$ & $\begin{array}{l}\text { teleconferencing, } \\
\text { IM, LiveMeeting, } \\
\text { wiki }\end{array}$ \\
\hline 2. Exploring connectedness & Yes, using email invites & Meet Me and LiveMeeting & $\begin{array}{l}\text { Sent an electronic survey } \\
\text { via email }\end{array}$ & $\begin{array}{l}\text { Email, } \\
\text { teleconferences, }\end{array}$ wiki, & ShareCenter \\
\hline 3. Negotiating community & Yes, to advertise meetings & Email & $\begin{array}{l}\text { e-mail, IM, Livemeeting, } \\
\text { and the wiki }\end{array}$ & Wiki & $\begin{array}{l}\text { Email to managers } \\
\text { to recruit members }\end{array}$ \\
\hline $\begin{array}{l}\text { 4. Developing relationships } \\
\text { and trust to discuss "sticky" } \\
\text { practice problems }\end{array}$ & Yes, using email & $\begin{array}{l}\text { Email, Net Meeting, LiveMeeting, } \\
\text { Wiki, TeamCenter, videos, } \\
\text { ShareCenter }\end{array}$ & No IT Tools & No IT Tools & ShareCenter \\
\hline $\begin{array}{l}5 . \text { Discovering what } \\
\text { knowledge should be shared } \\
\text { and how this should be } \\
\text { accomplished }\end{array}$ & No IT Tools & $\begin{array}{l}\text { Email, Net Meeting, LiveMeeting, } \\
\text { Wiki, TeamCenter }\end{array}$ & No IT Tools & Wiki & $\begin{array}{l}\text { Teleconferencing, } \\
\text { IM }\end{array}$ \\
\hline \multicolumn{6}{|l|}{$\begin{array}{l}\text { CoP-members' activities } \\
\text { related to the objectives, }\end{array}$} \\
\hline $\begin{array}{l}\text { 1. Identifying and contacting } \\
\text { subject matter experts }\end{array}$ & $\begin{array}{l}\text { Email to managers to identify } \\
\text { SMEs and then to SMEs to } \\
\text { request their input }\end{array}$ & $\begin{array}{lll}\text { Email, } & \text { company's } & \text { internal } \\
\text { resume/profile repository }\end{array}$ & No IT Tools & No IT Tools & $\begin{array}{l}\text { Email to executives } \\
\text { to recruit members }\end{array}$ \\
\hline $\begin{array}{l}\text { 2. Setting up mentor-protégé } \\
\text { tracking systems }\end{array}$ & No & $\begin{array}{l}\text { Excel (used by one CoP, the only one } \\
\text { who implemented a system) }\end{array}$ & $\begin{array}{l}\text { No IT Tools as this effort } \\
\text { was not implemented }\end{array}$ & $\begin{array}{l}\text { No IT Tools as } \\
\text { effort was } \\
\text { implemented }\end{array}$ & $\begin{array}{l}\text { No IT Tools as this } \\
\text { effort was not } \\
\text { implemented }\end{array}$ \\
\hline 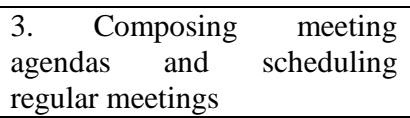 & Yes. Via Outlook & $\begin{array}{l}\text { Outlook, wiki to compose meeting } \\
\text { agendas }\end{array}$ & Outlook & Outlook & $\begin{array}{l}\text { LiveMeeting/ } \\
\text { Teleconference. }\end{array}$ \\
\hline $\begin{array}{l}\text { 4. Making plans for making } \\
\text { artifacts }\end{array}$ & $\begin{array}{l}\text { Yes, webmaster posts past } \\
\text { meeting minutes, lecture } \\
\text { material on wiki }\end{array}$ & 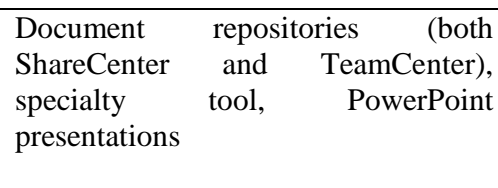 & wiki & 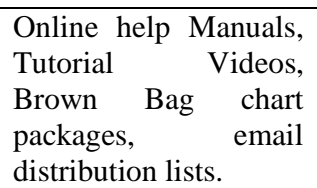 & $\begin{array}{l}\text { ShareCenter, wiki, } \\
\text { blog }\end{array}$ \\
\hline 5. Defining joint enterprises & None & Conference call and NetMeeting & Use mobile devices & telecon and wiki & telecon \\
\hline
\end{tabular}

Table 7-List of IT Tools Utilized in Each Stage 


\subsubsection{Communities of Practice in the Potential Stage of Development}

There was only one $\mathrm{CoP}$ in the Potential stage of development. As members of this $\mathrm{CoP}$ are at the same location, almost all their meetings are held at the site without the help of IT tools. The CoP meets with other chapters quarterly and uses webcasts, LiveMeeting and conference calls to conduct the meetings. The CoP utilizes document repositories, email lists, and wiki pages to share its activities and post the meeting minutes. While the moderators utilize these tools to conduct CoP activities and achieve goals, the members list only PowerPoint presentations as the means to conduct the meetings and are not aware of (or mention) other IT tools used by the moderator. The moderator of this CoP believes videoconferences would be a great help in conducting their meetings.

\subsubsection{Communities of Practice in the Coalescing Stage of Development}

Six of the CoPs studied as part of this research were in the Coalescing stage of development. The moderators of CoPs in this stage have a wide spectrum of competence in terms of IT use. Some are very comfortable in using various IT tools while others only use LiveMeeting, conference calls, and document repositories to conduct their CoP related activities.

Only one of the six CoPs had a moderator and several members who were competent in (and utilized) several knowledge-sharing tools for various CoP activities. This particular CoP, which was composed of members of the technical division of the 
company, utilized all knowledge sharing tools such as LiveMeeting, conference calls, wiki pages, document repositories, and web sites. The remaining CoPs in the Coalescing stage utilized some but not all of the aforementioned tools.

Two of the CoPs in the Coalescing stage are specific to their sites and all members meet in person, eliminating the need to use the combination of LiveMeeting and conference calls to conduct their meetings. One of these two CoPs is comprised of members of the technical team and is focused on developing, upgrading, and using a specific search tool for the division. This CoP utilizes a wiki, webcasts, web sites, and document repositories to conduct its business. Although the CoP has started planning for various activities, it still does not have any scheduled meetings and is still recruiting new members. For those who moderated the CoPs with members across the country, use of IT tools was essential to conduct their CoP related activities while for those who coordinated all activities at the same location use of the IT tools was a privilege but not a necessity. In other words, use of IT is the cornerstone of virtual CoPs while a traditional CoP whose members are at the same location is less dependent on IT tools.

\subsubsection{Communities of Practice in the Active, Memorable, and Dispersed Stages}

There is only one CoP studied here in each of the Active, Memorable, and Dispersed stages of development. The CoP in the Active stage of development focuses on governing the company's wiki standards and is comprised of a group of technical enthusiasts who are competent in using various knowledge sharing tools. This CoP uses web-based training, LiveMeeting, conference calls, wiki pages, and document repositories (as a backup to the wiki pages) to conduct its CoP-related activities. 
The CoP in the Memorable stage of development focuses on learning about various Web 2.0 tools and has a wiki page, document repository, live and videotaped demos, web-based training, and a combination of conference calls/LiveMeeting to conduct its activities. Its moderator and members are the most competent of any CoP in using various IT tools. The members of this $\mathrm{CoP}$ provide the same view as the moderators in terms of IT use, planning, and executing various CoP-related activities.

The CoP in the Dispersed stage is comprised of very highly technical personnel located at the same company site. This eliminated the need for LiveMeeting and conference calls but increased the need for a shared document repository, instant messaging, and many face-to-face meeting sessions.

\subsubsection{Comparison Study of All Cases in the Coalescing Stage of Development}

After reviewing the responses from all CoPs in the Coalescing stage of development, it was concluded that there is an inconsistency in terms of IT use among these CoPs. In other words, a CoP's IT use is not related to the stage of development the CoP is in presently. While some CoPs utilized several IT tools to conduct their activities, others used only LiveMeeting/conference calls and document repositories. The three main determining factors were the moderator's competency in using IT tools, whether the CoP members are all at the same location or dispersed across several sites, and whether the same tools were available across all participating sites. As different divisions develop their own tools or use COTS, it is common among members of the same CoPs not to have access to the same tools. This relationship is depicted in Figure 7. 


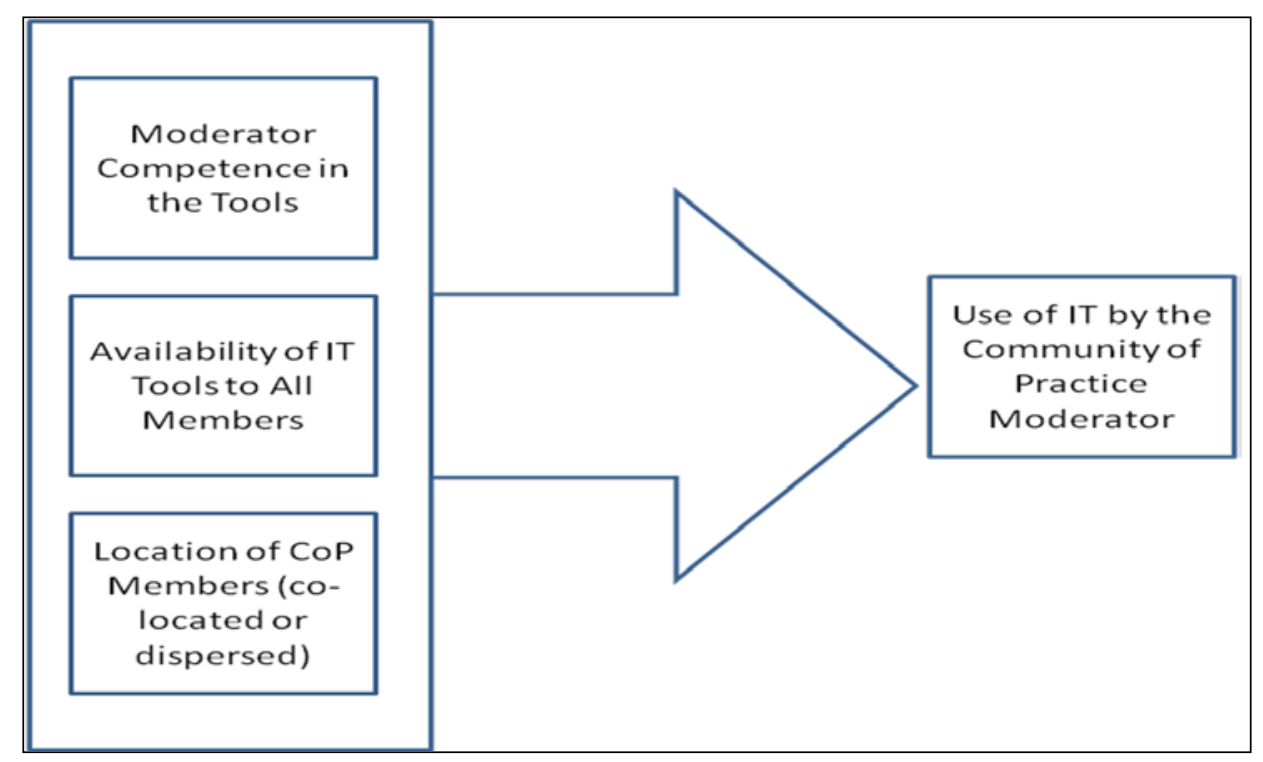

\section{Figure 7-Factors Determining Use of IT by a CoP Moderator}

\subsubsection{Comparison Study of Cases in the Coalescing Stage of Development with Cases in Other Stages}

As CoPs in all stages of development utilize a variety of IT tools to conduct their CoP-related activities, there is no consistency among CoPs in each specific stage of development in terms of IT use. For example, all CoPs in Coalescing, Active, and Dispersed stages of development use conference calls and LiveMeeting to conduct their meetings and utilize various document sharing repositories to store their artifacts such as meeting minutes, agenda, and announcements. All CoPs in Potential, Coalescing, Active, and Dispersed stages of development either plan to or already do use a wiki page or a website to post their announcements. Since a CoP in the Coalescing stage of development utilizes the same tools as a $\mathrm{CoP}$ in an Active or Dispersed stage of development, it is not clear that the use by and impact of IT on a moderator's role is consistent for moderators across stages of development. The data in this study suggest that a CoP's stage of development is not the deciding factor in its moderator's IT use, 
rather it is the availability of the tool and the moderator's competency in the tool that appears to be the main factors.

\subsubsection{Impact of IT on the Role of a Moderator}

When asked the question about the impact of IT on their role, one of the two moderators of the $\mathrm{CoP}$ in its Potential stage answered,

We have used IT tools to send emails, gather information, assign action items, collect feedback to moderators, and keep meetings on track. We also use various tools to keep our members informed of certain events and activities such as membership recruitment, professional development for our members, and scheduling community outreach programs.

The moderators of CoPs in the Coalescing stage of development provided a number of key responses to the impact of IT question. The moderator of a CoP in the Coalescing stage stated,

We wouldn't have a CoP without LiveMeeting ... IT is the essential part of a $\mathrm{CoP}$ as it gives them a mechanism for communication and its tools facilitate the communication. IT is an important facilitator, that gives it an infrastructure to communicate by phone, and conference calls, and the ShareCenter document repository to store and share documents such as newsletters and manuals.

Another moderator did not have a completely positive view of IT's influence and asserted, "It depends on how the CoP is managed ... almost all our CoPs meet virtually."

He also noted that,

The CoP moderator's decision in adopting IT tools, influenced by his or her competency, and availability of the tool to the $\mathrm{CoP}$ are the main factors influencing IT use.

A moderator of a CoP in its Active stage indicated,

IT makes my job as a moderator a lot easier ... email list, wiki page ... meeting minutes ... SharePoint team site ... We do not use a document repository/sharing 
system as all our members are at the same site and have access to the same folders.

The moderator of the CoP in its Dispersed stage responded,

IT plays an essential role in our communication and collaboration efforts. Use of wiki, LiveMeeting, and e-mails allow us to communicate with the CoP members.

One of the moderators of a CoP in its Memorable stage of development provided this response to the question regarding the impact of IT on the role of the moderator,

"Use of a web-enabled collaboration tool would let us communicate effectively." Another moderator of the CoP in its Memorable stage of development indicated,

It depends on what the moderation is for ... You might have a lot of tools but they are not good enough, not efficient or usable for the use or not beneficial.

There was a consistent set of responses provided by the moderators as all cited IT as the cornerstone of their CoPs and several indicated the CoPs would not exist without the use of IT.

\subsubsection{Improvement Opportunities in Terms of IT Use by a CoP}

When asked to suggest improvement opportunities in terms of IT use by communities of practice, the two moderators of the CoP in its Potential stage of development noted,

Conducting meetings using LiveMeeting has some issues as people drop in and out all the time. Meetings held at remote locations need to have videoconferencing to make the meetings more efficient. 
As the CoP in the Potential stage of development is composed of the site's women engineers, as part of their knowledge sharing efforts the members reviewed each other's work. The moderators of this CoP also indicated,

It would help us to use document/software review software so people do not use pen and paper to add their comments and notes, which is very inefficient.

Moderators of CoPs in the Coalescing stage of development noted several improvement opportunities regarding IT use. These suggestions included use of SharePoint, "SharePoint 2010 will provide a better flow of communication. In general, our collaboration tools could use an upgrade.” Another moderator suggested a specific tool for each of the CoP's activities and indicated,

So many different methods are used which do the same thing and it is nice to have choices but it gets confusing. One $\mathrm{CoP}$ uses TeamCenter, the other one wiki, for the same task. There should be a standard tool.

Another moderator cited multitasking as being the cornerstone of moderating a

CoP and noted,

Being able to multitask is very important...letting people to do things while attending the meetings because there is no charge number associated with it.

One moderator would like to be able to use a wiki to keep meeting minutes, as it would be a great help if everyone could access it because a true collaboration is not happening right now. He asserted, "We need to use the discussion feature on wiki for collaboration purposes.” A moderator suggested Google+ would provide an excellent collaboration environment because it uses the concept of "circles of people".

One moderator indicated the need for integration,

While the ShareCenter document repository is great, it has to connect with other status tools such as mobile devices to enable us with data sharing so the members can stay in touch.

He suggested, 
Different tools need to integrate together as several tools exist, we have the tools, but have to get approval from the security to use them.

Moderators of CoPs in the Active/Dispersed/Memorable stages provided a series of improvement opportunities in terms of a CoP's IT use including use of specific knowledge management tools. For example, one moderator suggested the company adopt a tool that provides real-time interactive document updates such as the new version of MS Office. Another moderator suggested the use of Microsoft's OCS R2 (Office Communications Server Release 2), a voice-enabled solution which helped their group tremendously when conducting their meetings. A third moderator suggested enabling corporate email communication on iPhones although he suggested that there will be some security issues with the IT department regarding the logistics.

The moderators in these stages also provided a set of improvement opportunities in terms of the company's policy on use of IT. Several moderators expressed some concerns regarding the removal of Blackberries across the company to reduce the cost associated with their use,

Different company divisions are pushing to reduce use of Blackberries across the company. This would reduce the cost to the company but people cannot call in to work when offsite.

More than one moderator suggested the company install or adopt a mobile network and social networking choices to make it easier for the participants to approach peer-to-peer relationships. They named specific tools and asserted the need for, “

IOS devices and Android to connect to the company network to make it easier for developers to connect and produce.

Others indicated the company’s talent identification software was used by managers to assign specific tasks to employees with specific talents required for those 
tasks, but this it does not offer a peer-to-peer relationship and needs to be less structured than what is currently available. One moderator indicated,

SharePoint is powerful and making it available to everyone will be very helpful. It is currently available to a selected few but needs to be available to more people.

One moderator proposed that the company adopt a "virtual world" to implement tools to use by employees to submit and vote on ideas, provide a budget to buy the tools and get the word out so that people see its usefulness and use it.

Two of the moderators suggested use of an open environment, or as one of them called it an "eco-system”, for all engineering groups to develop tools in the environment they want; while a third moderator suggested the company adopt a policy to allow different divisions to embrace tools developed by each other. Other moderators suggested that the CoPs would benefit if the company adopted a policy to assign accountability of and responsibility for making decisions regarding specific issues to specific people. They noted the importance of being able to find who makes the decision on adopting or using new tools/environments/programs. This group of moderators suggested the company develop or adopt a better search tool. The researcher is part of a company division which has adopted a powerful search/research tool, but this tool is not available to other divisions and the link was not available to the moderators to provide that improvement opportunity.

In general, there was a consistency found among the responses provided by moderators of communities of practice in various stages of development. While most suggested the company should make more development environments and tools available to CoPs, others suggested the company should improve its policies and provide a specific policy on use and adoption of different tools since currently different CoPs are 
forwarding their tool requests to different managers who may or not be the actual decision-makers on this issue. The main improvement opportunities provided by the moderators are depicted in Figure 8

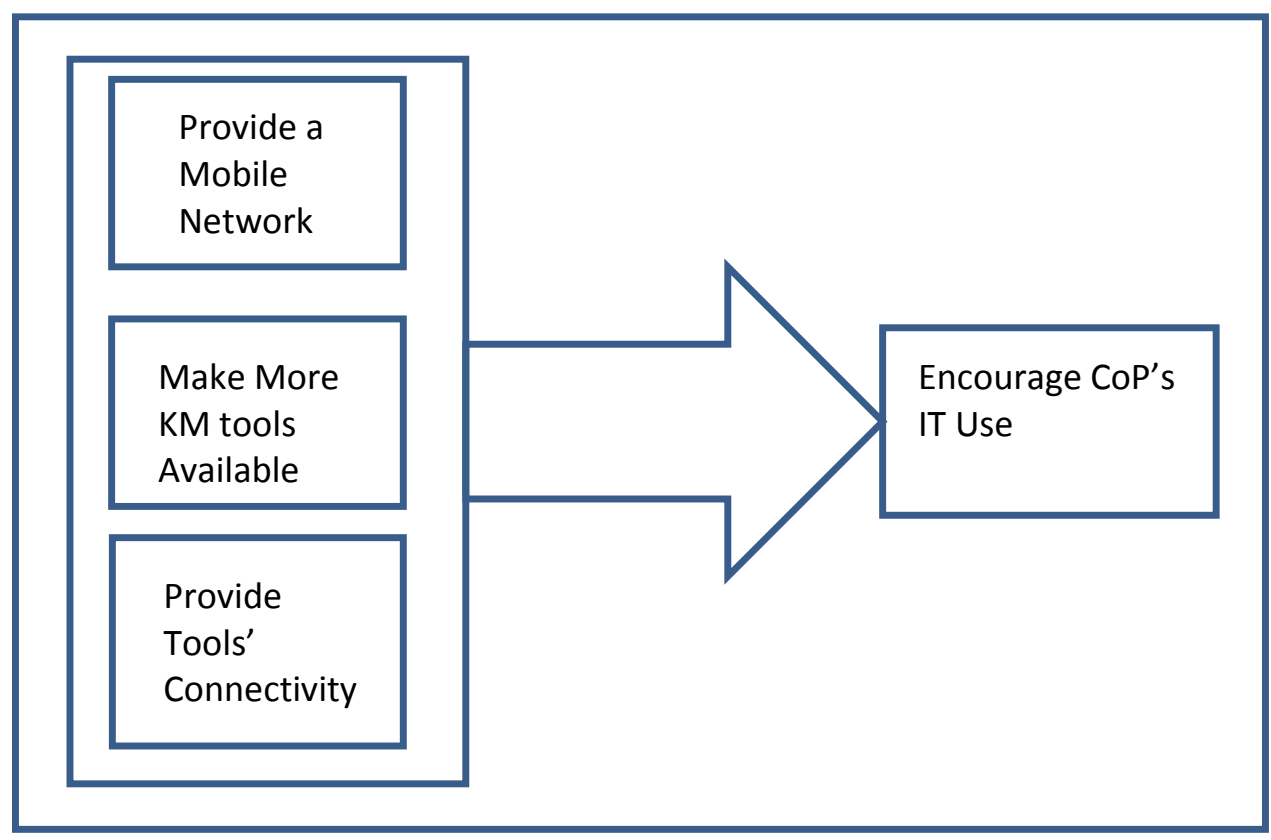

Figure 8-Improvement Opportunities Stated by Moderators

\subsubsection{Barriers in Terms of IT Use by a CoP}

A few moderators did not encounter any barriers to using IT. The moderators in the Potential stage of development did not encounter any barriers but they have just started their CoP activities. One of the moderators in the Coalescing stage of development indicated she has not encountered any barriers and did not realize what her IT tool set was missing until the tools were improved.

A moderator in the Coalescing stage asserted the main barrier to use was, "getting permission for people to get into the right folders because of all the permission 
and security methods/issues." Another moderator cited lack of sufficient training for different knowledge-sharing tools as his CoP's main barrier to IT use and indicated,

There are several great knowledge-sharing tools available but there is no formal training available for any of them

More than one moderator cited security restrictions as the major barrier to their CoP's use of IT. One indicated his $\mathrm{CoP}$ was planning to use the voice or video recording feature in LiveMeeting but met security restrictions. Another moderator indicated he often felt he had encountered "an overload of security”.

Several moderators listed lack of connectivity between different software tools as a barrier while another cited lack of internet connectivity when $\mathrm{CoP}$ members are travelling or are off-site as a major issue for the CoP. One indicated having internet access is a necessity for today's CoPs although it was not an issue several years ago. He also indicated his CoP has difficulties as some work sites have had system outages in the middle of workday.

The moderators in the Active/Dispersed/Memorable stages of development shared their CoP's barriers in terms of IT. Several moderators in these stages of development noted that security issues enforced by the IT department are preventing many projects they worked on to be realized. This is an issue even in terms of tool use.

Another moderator indicated the company has a "very strong push to stay with MS tools and approved software” which prevents the CoPs from developing and testing new tools. He indicated,

MS products are not always the best for the uses we are using them for but they are mandated by the company and this policy will hurt us in the long run.

Other moderators indicated that due to cost consciousness and cost reduction methods the IT department's decision to reduce laptop use has stifled the CoP's ability 
to develop creative solutions to their IT challenges. One moderator cited difficulty of use of tools as the major barrier to his CoP's IT use and indicated,

Our tools need to be more intuitive and easier to use ... now users don't use a lot of tools because they are hard to use.

In conclusion, the moderators of CoPs in all stages of development cited three major barriers to their CoP's activities. These barriers included restrictions imposed by the company's IT department as the major barrier and lack of connectivity among various tools available by the company as the second barrier. The third barrier cited by the moderators was lack of suitable environments (both system and software tools) which prevents the techno-savvy members of CoPs from developing new solutions. These barriers are depicted in Figure 9.

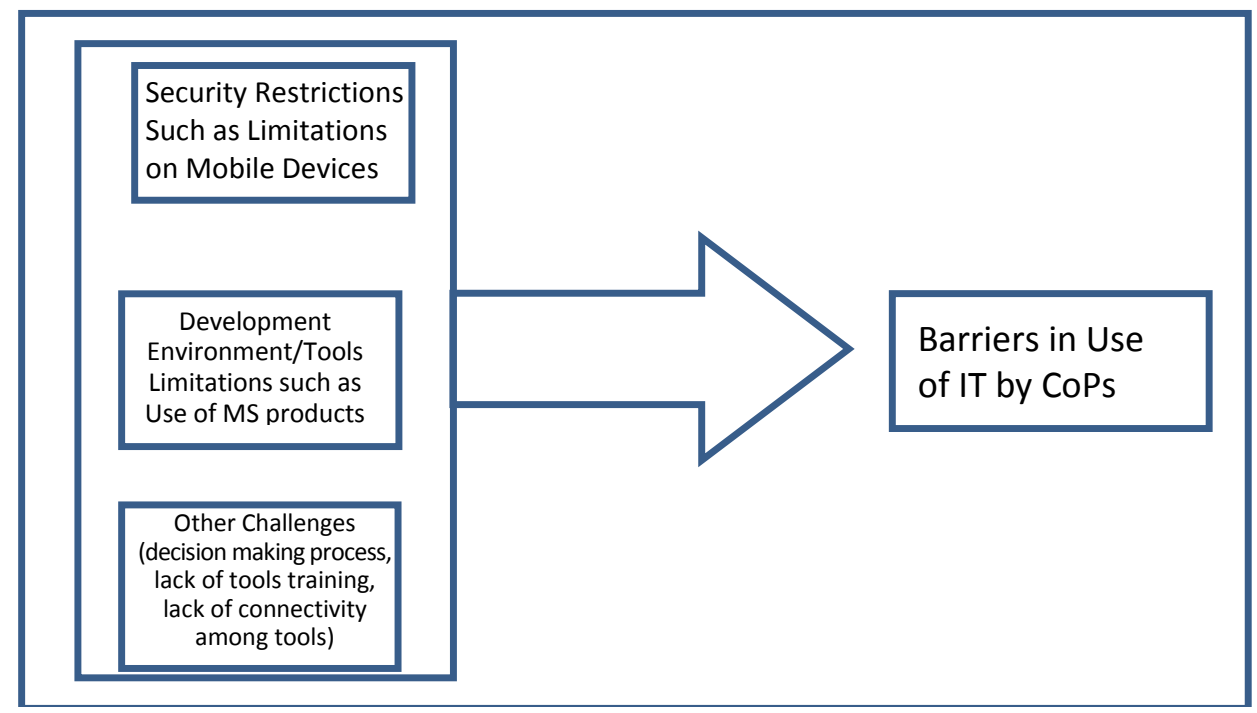

Figure 9-Barriers to CoPs' IT Use 


\subsubsection{Comparison of CoP Moderators' versus Members' Responses Regarding IT Use}

In total, thirteen members of various CoPs responded to the survey questionnaire and provided their perceptions regarding the use of IT by their CoPs. After reviewing the moderators and members' responses, it was determined that the moderators and members of each CoP had a consistent perception of use, impact, and effectiveness of IT tools on the CoP activities. It was also determined that the use of IT tools was not directly related to the tools used for each stage of development. In other words, a specific tool may be used by some, but not all CoPs in each stage of development. For example, a wiki, an open-source tool, is used by the CoP in its Potential stage, some (but not all) CoPs in their Coalescing stage, and some (but not all) CoPs in the Active/Dispersed/Memorable stages.

One of the members of the CoP in its Potential stage of development indicated the use of PowerPoint presentations as the major IT tool used in the CoP meetings, as all members of this CoP are located at the same site. Another member indicated the CoP moderator utilizes emails to coordinate various activities and distribute announcements to the members.

A member of a CoP in its Coalescing stage of development cited use of LiveMeeting and conference calls as the most important IT tool used by the moderator as the CoP's membership spans across several sites. A member of another CoP in its Coalescing stage cited use of document repositories as the main IT tool as several of the members participate in unofficial reviews of their peers' work and use this tool to share the documents. A member of a third CoP in its Coalescing stage named MS. SharePoint 
as the main tool used by the CoP moderators and members as it allows a variety of knowledge sharing options to the participants. It is important to mention that SharePoint has not been available to all company sites yet.

A member of the $\mathrm{CoP}$ in its Active stage named email, wiki, and instant messaging as the main IT tools utilized by the CoP moderator and participants. The members of the CoP in its Dispersed stage of development indicated use of email, LiveMeeting and conference calls, wiki, and document repositories as the main IT tools used by this CoP. The CoP in its Memorable stage was established in a way that all members co-moderated the CoP. One of the respondents indicated the IT tools used by members of this $\mathrm{CoP}$ were instant messaging and knowledge-sharing tools as all members of this $\mathrm{CoP}$ were located at the same site. 


\section{CHAPTER SIX CONCLUSION}

This dissertation evaluated the impact of IT use on the role of a moderator in the Coalescing stage of a community of practice. Several communities of practice were subjects of this dissertation and a series of questionnaires and interviews including both open and closed ended questions were given to the CoP moderators and members. After reviewing the survey responses, it was determined that the use of IT tools leads to success of CoPs in achieving some goals and conducting some activities but not all (such as defining the domain of the CoP or auguring an environment of trust conducive to knowledge sharing).

Use of IT is mostly related to how tech-savvy (comfortable with using new tools, software, and hardware) the moderator is, how many resources he or she has available, and how much support, in terms of resources, are provided by upper management. Those CoPs whose members are located at the same site are also less likely to use IT tools such as conference calls/LiveMeeting, instant messaging, and other tools.

Almost all CoPs in all stages used conference calls/LiveMeeting and various document repositories to conduct their knowledge sharing efforts; depending on the availability of the tools, resources, and the moderator's skills, some used an open source knowledge-sharing tool as well. During the follow-up conversations with some of the moderators, it was revealed that this dissertation data collection process generated ideas for the moderators to conduct certain activities or achieve certain goals. Some moderators indicated that they have included such activities and goals in their recent agendas. For example, one CoP has started a newsletter while another has started a 
mentor-protégé tracking system. In other words, some of the moderators have already implemented the improvement opportunities provided by this dissertation in their CoP operation. What seems to be a consistent issue for all CoPs is the lack of an efficient mentor/protégé plan or other systematic knowledge transfer effort launched by the moderators. While the SMEs may conduct a knowledge sharing session, there is no measure to ensure the knowledge was transferred and the participants can conduct the tasks as well as the SME. Furthermore, after reviewing the survey responses, conducting the follow-up interviews, and observing the CoPs, it is concluded those CoPs with the most amount of enthusiasm are the ones who are met with the most barriers imposed by the upper management. The use of company-approved IT tools by the CoP is acceptable as long as the CoP does not come up with any ideas or plans to make any changes to the processes, tools, or methods. What seems to be a common barrier for those $\mathrm{CoP}$ moderators who express concerns is that they lost upper management's support when they provided improvement opportunities or conducted tasks not approved by everyone involved. This is true even if the CoP suggested software improvements, which would save the company millions of dollars. In other words, politics plays a major role in how successful a CoP becomes (whether in use of IT or otherwise). While one site might not be as "political" as other sites, the levels of management that need to approve a tool, activity, or improvement opportunity are what make the CoP's goal viable.

In conclusion, use of IT provides both new opportunities and obstacles to a CoP's knowledge sharing effort and may make it harder for the moderator to coordinate the $\mathrm{CoP}$ activities due to those obstacles. There are several possible future research 
opportunities related to this topic. As the literature review indicates, almost all researchers outline the dimensions, characteristics, and requirements for a community of practice within an organization. What seems to be missing is a study on measuring the effectiveness of existence of a community of practice on productivity or efficiency of service. While most CoP researchers (whether learning theorists or practitioners) have assumed the members of a $\mathrm{CoP}$ are all located at the same site, with today's work environment (flexible schedules, telecommuting, and other options available to the knowledge or service workers), many CoPs meet as a virtual group and not in person. A comparison study of CoPs with the same domain but in various communities of practice would provide a more thorough result on how IT impacts the role of a moderator in a community of practice.

Since this study focused on a service/learning environment, future research could study CoPs in manufacturing/technical environments where the workers may spend more time together on a project as opposed to a service/learning environment where most people work on their own. Another research opportunity is to provide a comparison study of the inter-relationship between people, work, and innovation in CoPs in various industries as some industries (such as aerospace and military) require their members to follow a specific procedure in doing things and frown upon straying off course. Identifying an alternative or updating Wenger's and Brown's frameworks is called for since both have identified a community of practice as the group of practitioners who meet in person and have not mentioned those groups that do not have the opportunity to meet in person or have interpersonal relationships. What Sharp (1997) calls a community of discourse (a CoP in which its members meet electronically) 
is not mentioned or included in any other research. A new, more detailed framework for communities of practice who are involved with both tacit and explicit knowledge would be a useful research opportunity. Communities of practice as defined by Wenger and Brown have provided one knowledge sharing framework for both tacit and explicit knowledge. It would be more effective if there were separate frameworks for tacit knowledge (for which learning is acquired through continuous knowledge sharing sessions such as on the job training and discussion sessions) and explicit knowledge (for which training/learning is achieved through training sessions and following procedures and guidelines).

\subsection{Research Limitations}

Several research limitations were identified due to a variety of factors. One of these limitations was the low sample size. The lack of response to the survey by members may have been because different sites encouraged their members to attend the CoP meetings while others limited their activities. For example, some CoPs did not benefit from having charge numbers and members did not want to use their own time to respond to the survey. Due to the lack of resources, some moderators indicated that as the CoP attendance could not become mandatory (as they could not provide the attendees with charge numbers), they did not benefit from all possible knowledge sharing opportunities that SMEs could have provided (lack of incentives led to low level of attendance by the SMEs). This spanned across CoPs so members of the same CoP also had different resources available to them. The same inconsistency issue applied to different CoP moderators where due to mass-email limitation guidelines imposed by the 
company, most moderators forwarded the email survey sent to them to only a few and not all CoP members.

Some moderators and members expressed concerns about the ramifications of the responses they provided if upper management learned about them. They were assured their responses would be anonymous (even though it was indicated in the survey). Therefore, it is possible that some respondents provided biased responses.

Another limitation of this research is the fact that only one company from one specific industry was studied so that the results may have been different if several CoPs across different companies of different industries were studied. Another issue to consider is the fact that due to the very technical nature of this company, the CoPs studied had very tech-savvy, educated moderators and members. Less tech-savvy moderators may be impacted differently in their use of IT than was the case in this company.

\subsection{Obstacles to Moderators}

The moderators cited several obstacles to their CoPs' knowledge sharing efforts that were not related directly to IT. Some of the moderators stated that upper management had a negative reaction towards their CoPs because managers had not initiated these CoPs. The moderators also felt that the ultimate knowledge sharing value of their communities of practice was not maximized. That is, this lack of support contributed to lower levels of knowledge sharing and other activities associated with a CoP. In a few cases, lack of support was through withholding IT resources. As part of 
the knowledge sharing efforts in a community of practice, new ideas, suggestions for process improvement, and more efficient, up-to-date tools were suggested, but not approved by the upper management as so implementing the change would deviate from the contract with the customer. This resistance to change lowered some moderators' morale and caused them to lose interest in conducting CoP related activities, thinking even if they came up with better solutions, their solutions would not be accepted and implemented.

Other moderators indicated there was an inconsistency in resource allocation among different sites and CoPs. While some moderators enjoyed having charge numbers, conference rooms, food, and other resources others had to use their personal time to attend a CoP meeting or create wiki pages. This was also true with members of the same CoP at different sites. While members of some sites were able to charge the time spent on CoP related activities, some others were instructed to use flextime (their own time) to attend the CoP meetings, develop the training material, or create the wiki pages. This lack of consistency caused a feeling of resentment among some CoP members who realized their fellow members were given more opportunities than they had received.

The moderators found knowledge hiding to be a major impediment to the knowledge sharing efforts of a CoP. Some Subject Matter Experts (SMEs) were hesitant to share their knowledge, fearing others would use their ideas as their own. The SMEs cited three reasons to resist sharing their knowledge: due credit was not always bestowed upon those who had originated the idea, lack of incentives provided by the company to the SMEs to encourage them to share their knowledge, and sharing their knowledge 
might hinder their chances of retiring with the company and returning to work as a contractor. However, the moderators did not suggest ways in which IT could help to resolve this obstacle.

\subsection{Obstacles to Moderators in Terms of Using IT}

Several moderators cited inconsistency of tools among different locations as a major obstacle to their knowledge sharing efforts. Different divisions of the company use different tools for the same purpose such as the resume/profile repository used to identify mentors or SMEs. Some moderators indicated that finding SMEs throughout the company was impossible as different divisions of the company used different tools as their resume/profile repositories. That meant the moderators could only search for SMEs in their own division. Also, some managers did not wish to share their SMEs with other departments and did not fully utilize the tool (so others would not request the services of the SMEs in their departments). The moderators cited different divisions of the company as a feudal system where one division does not share (or even communicate) tools with other sites; and different divisions often create similar tools. Some moderators felt they were forced to use specific, company approved tools and platforms, which they did not always find the most suitable for the purpose. For example, some CoPs were interested in using an open source platform but were forced to use the MS platform approved by the company. This caused more of an issue with the tech-savvy, younger moderators who tried different tools and were familiar with newer techniques and applications. These moderators felt frustration in being forced to use tools they did not deem the best in the industry. 
Difficulty of using some IT tools was listed as another obstacle to moderators. They indicated some knowledge sharing tools (wiki, web pages, blogs, etc.) were hard to use for some moderators and there were no SMEs (or help) available to coordinate this effort for the moderators. There was a lack of ubiquitous training, help center, or other resources available to moderators who were interested in utilizing such knowledge management tools.

In their responses, the moderators divided the barriers of IT use into three different categories:

1. Organizational barriers -- such as users' access to certain tools or compatibility (to the platform imposed by the organization)

2. Management barriers -- such as providing one tool to a group of users in a pilot study while other users are unable to access the tool itself, training, or other information.

3. User barriers -- such as users' resistance to use a certain tool whether due to personal reasons such as its perceived lack of effectiveness or efficiency when conducting an activity, or its difficulty of use as perceived by the user.

\subsection{Recommendations for Companies with Various CoPs}

As a participant of several of the studied CoPs, and based on the research presented here, I have observed the following additional improvement opportunities for "the company", which may be applicable to similar companies. These recommendations are outlined below. 
It appears that companies with several CoPs could benefit from have a mechanism to provide company-wide support, guidelines, and resources, including IT, to their moderators and members. They mechanism could be in the form of a companywide guideline applicable to all divisions outlining the company's long term and short term strategy, resource allocation and application, and other details for both members and moderators to follow. This guideline could provide all possible CoP members with both the expectations and benefits of participation in a community of practice.

Based on the results of this research, it could be beneficial for a company with various CoPs to use a set of tools ubiquitous to all divisions instead of implementing a feudal system where each division uses different tools for the same purpose. For example, the same resume/profile repository, the same conferencing, and the same document repository should be used across all divisions. Such a policy provides both a more cost-efficient way of developing or acquiring tools and allows members of different divisions to contribute their expertise to the effort and hence feel ownership of the tools.

To maintain consistency in terms of a CoPs' operation, the company could assign a principal CoP coordinator to help with all moderators’ resource needs (a webmaster, charge numbers, conference rooms, Wiki SME) and allocation. This coordinator can ensure the implementation of the strategies outlined in the company-wide CoP guide and help the moderators better manage the operations of the CoPs. Those companies with several CoPs should educate middle and lower level management on the benefits of supporting CoPs such as cost savings on formal and informal training, externalization of knowledge by SMEs, and opportunities to solicit expertise when working on a project. 
These benefits could be included in the managers' yearly meetings, encouraging the managers to support the CoPs in their organizations.

A company should best benefit from its CoPs by engaging the new employees by involving them in the decision making process as part of CoP participation. When a new employee shares his or her opinion in adopting novel (or changing existing) IT tools or processes, or implementing innovative, more effective IT tools, he or she feels an ownership to the process and becomes more loyal to both the process and the company. This approach helps "flatten" the knowledge hierarchy and enables the company to benefit from newer ideas. To better promote the knowledge sharing efforts of the CoP, companies should encourage SMEs to moderate CoPs to auger an environment of trust (so members share their ideas without worrying about whether their ideas would be stolen). Assigning SMEs as moderators provides an opportunity for them to recruit other SMEs into the CoP (and hence resolve the issue of trust as the barrier to knowledge sharing) and allows moderators to rotate the leadership of the CoP with other SMEs and hence benefit from the CoP, both as a recipient, and a contributor, of the knowledge sharing effort. Encouraging the SMEs and moderators to adopt the company IT tools to share their knowledge (such as the company's mentor-protégé and talent identification tools) would be a great way to promote these tools among not only CoP members, but also other employees.

Organizations should not only involve SMEs, but also new employees by providing mutual mentor/protégé opportunities for the new and experienced employees where the experienced employees mentor new hires in their discipline and the new hires mentor the experienced employees on the new and emerging technologies. This 
reciprocal mentoring provides more credibility to new hires and makes it easier for the SMEs to trust and share their knowledge with their mentees. The mentor/protégé activities could include (but not be limited to) writing articles together, composing course material to teach classes, working on a project, writing manuals, and presenting at conferences. The knowledge sharing/transfer should be assessed using the appropriate IT tools. As part of this knowledge sharing/transfer effort, moderators should promote use of company IT tools to not only develop the CoP artifacts such as the training material and manuals, but also assess the quality of knowledge transferred. These tools can range from document repositories, video-making tools, wiki pages, or web sites to develop the artifacts to an Excel spreadsheet to track the knowledge sharing efforts.

Companies with various CoPs should provide the qualified CoP members a development environment separate from the company's network to not only allow those members to create new concepts and designs, but also to protect the company network from the threat of cyber-attacks, an important issue for today's large corporations. The company's security measures should allow CoP members to call in to this separate network from home to creatively develop the new tools, products, or ides outside work hours.

While employees interested in sharing their practice create CoPs, a company is the ultimate beneficiary of a CoP's knowledge sharing efforts, and investing in CoPs benefits the organization. As a result, a company should create an environment more conducive to the knowledge sharing effort, the cornerstone of a CoP. This knowledge 
sharing ultimately saves the company in training, employee attrition, and contractor costs.

\subsection{Drawbacks of Having a Company-Supported CoP}

While there are several benefits to having a company supported CoP, there are possible drawbacks, which stem from the company's intervention with the CoP efforts. For example, some employees may not express their opinions in a CoP environment, as they may fear upper management would reprimand them for not following the company's established process or approved tools. This is contrary to Wenger's belief that CoPs should not be initiated by management but should be created on their own.

If the company initiates a CoP, then it would also have to support the tools, processes, and artifacts resulting from the CoP activities which leads to higher operations cost. If the company provides charge numbers, SMEs' support, and intranet space, it means more expenditure; one commitment the company may not be prepared to make. Also, if the company supports hiring a CoP moderator, it has to provide a rationale to justify this cost increase as the results (return on investment) of a hiring a CoP moderator are not immediate and predictable. Another drawback to having a company-supported $\mathrm{CoP}$ is the rules and standards imposed by the supporting organization. When CoP meetings are held outside the company facility and/or working hours, the company guidelines in terms of using specific environments, software, and tools are not enforced and the members have the opportunity to easily create or discuss their practice. Receiving company approval to implement a new set of standards, install a development environment, or test and practice a new tool is an issue only when the company approves the CoP. 


\subsection{Summary}

This dissertation research studied ten CoPs in a large company in the aerospace industry to evaluate the impact of IT on the role of a CoP moderator in its Coalescing stage of development as defined by Wenger (1990). After conducting a survey and a series of interviews, it was concluded that a reciprocal relationship exists between IT and the role of a CoP moderator regardless of the CoP stage of development. In other words, use of IT provides a positive impact on the role of a moderator in achieving goals and conducting activities, but the moderator's perception of IT affects how the CoP utilizes IT.

Several recommendations were derived from the research. Barriers to use of IT including those imposed the company, upper management, and the IT department were also listed as possible future improvement opportunities. Future research should address ways in which barriers can be eliminated and investigate the generalizability of the findings reported herein. 


\section{CHAPTER SEVEN REFERENCES}

Archibald, Douglas, McDermott, Richard (2008). Benchmarking the Impact of Communities of Practice on Organizational Performance - with Douglas Archibald Knowledge Management Review | Volume 11 Issue 5 | November/December 2008 pp 14-19

Bonifacio, M, Cuel, R. G. Mameli, Nori, M. (2002). A peer-to-peer architecture for distributed knowledge management, Proceedings of the 3rd International Symposium on Multi-Agent Systems Large Complex Systems, and E-Businesses MALCEB

Bonora, E. A., \& Revang, O. A. (1991). Strategic framework for analyzing professional service firm-developing strategies for sustained performance. InStrategic management society inter-organizational conference. Toronto, Canada.

Borgatti, S. (2010) Introduction to Ground Theory Discussions drawn from Glaser and Strauss. 1967. The Discovery of Grounded Theory and Strauss and Corbin. 1990. Basics of Qualitative Research. http,//www.analytictech.com/mb870/introtoGT.htm and https,//sites.google.com/site/ba762researchmethods/handouts

Brown, John Seely \& Duguid, P. (2000). The social life of information. Boston, Harvard Business School Press(johnseelybrown.com)

Brown, John Seely and Thomas, Douglas (2009). Why Virtual Worlds Can Matter.International Journal of Media and Learning, Vol. 1, No. 1, January 2009

Brown, John Seely, Duguid, Paul (1991). "Organizational learning and communitiesof-practice, Toward a unified view of working, learning, and innovation The Institute of Management Sciences (now INFORMS)

Brown, John Seely, Gray, Esther (1995). The People Are the Company How to build your company around your people. johnseelybrown.com

Constant, D., Kiesler, S., \& Sproull, L. (1994). What's mine is ours, or is it? A study of attitudes about information sharing. Information Systems Research, 5(4), 400421

Cook, Scott. D. N., \& Yanow, Dvora (1993). Culture and organizational learning. Journal of Management Inquiry vol.2 373-390

Correia, Ana Maria, 3, Paulos Alice, Mesquita Anabela (2010). Virtual Communities of Practice, Investigating Motivations and Constraints in the Processes of Knowledge Creation and Transfer Electronic Journal of Knowledge Management Volume 8 Issue 1 (pp11 - 20) www.ejkm com 
Dale, Steve (2009). Communities of Practice, Conversations to Collaboration. http,//steve-dale.net/2009/01/25/communities-of-practice-conversations-to-collaboration/

Daniels, Christopher, Grove, Don, and Mundt, Ed (2006) Command and Communities of Practice, Air \& Space Power Journal - pp 4-21

Davenport, Thomas. H., \& Prusak, Lawrence (1998). Working knowledge, How organizations manage what they know Boston, Harvard Business School Press.

Gammelgaard, Jens (2010) Knowledge retrieval through virtual communities of practice Behaviour \& Information Technology; Jul/Aug 2010, Vol. 29 Issue 4, p349-362

Hara, Nokia (2007). Information Technology Support for Communities of Practice, How Public Defenders Learn About Winning and Losing in Court Journal of the American Society for Information Science and Technology 58(1)pp. 76-87

Hara, Nokia (2009.) Communities of practice,Fostering Peer to Peer Learning and Informal Knowledge Sharing in the work place, Information Science and Knowledge Management, , Volume 13, pp 1-6

Hoadley \& Kilner (2005). "Using Technology to Transform Communiteis of Practice into Knowledgebuilding Communities”, SIGGROUP Bulletin, Vol. 25, No. 1, pp. 31-40.

Huysman, M. (2002). Knowledge Sharing in Practice. SAP Design Guild Editions http://www.sapdesignguild.org/editions/edition5/km_mh.asp

Lesser, Ed.L. and Storck, John(2001). “Communities of Practice and organizational Performance. IBM Systems Journal 40 no 4 p 839

Lin, Ming-Ji James, Hung, Shiu-Wan, Chen, Chih-Jou (2009). “Fostering the determinants of knowledge sharing in professional virtual communities" Computers in Human Behavior 25 issue 4 July pp 929-939

Littleton, Tamara, Cooksley, Ashley (2010) Communities of Purpose A guide for Brands and Community Managers emoderation

McDermott, Richard (1999). Learning Across Teams, The Role of Communities of Practice in Team Organizations. Knowledge Management Review, May/June

McDermott, Richard (1999). Nurturing Three Dimensional Communities of Practice, How to get the most out of human networks. in Knowledge Management Review,

McDermott, Richard (2000). Knowing in Community, 10 Critical Success Factors in Building Communities of Practice. IHRIM Journal

McMaster, Michael (1998). “Communities of Practice, An Introduction” http,//www.coi-l.com/coil/knowledge-garden/cop/mmintro.shtml 
Nonaka, Ikujiro. (1994). A dynamic theory of organizational knowledge creation Organization Science volume 5, pp. 14-37.

Oosting, Wesley(2009). Design and evaluation of a Community of Practice to support IT implementation/migration processes School of Management and Governance, University of Twente

Orr, Julian (1990). Talking about machines, An ethnography of a modern job. Unpublished doctoral dissertation, Cornell University.

Schein, Edgar. H. (1996). “Three cultures of management, The key to organizational learning” Sloan Management Review, Vol. 38, Iss. 1; p. 9

Shan L. Pana,, Dorothy E. Leidnerb (2003). Bridging communities of practice with information technology in pursuit of global knowledge sharing” Journal of Strategic Information Systems vol.12 pp.71-88

Sharp, John (1997). “Communities of Practice, A Review of the Literature” March 12, http,//www.tfriend.com/cop-lit.htm

Singer, D.L. (1982). Professional socialization and adult development in graduate professional education. In B. Menson (Ed.), New directions for experiential learning, Building on experiences in adult development, San Francisco, JosseyBass. No. 16 (pp. 45-63).

Snyder, William 1997 Communities of Practice, Combining Organizational Learning and Strategy Insights to Create a Bridge to the 21st Century presented at the Academy of Management Conference, Boston, MA, August

Stamps, Thomas (2000). Communities of Practice. Learning Is Social, Training Is Irrelevant? TRAINING Magazine. Feb 26, 2000

Stewart, Thomas (1996). The Invisible Keys to Success Fortune, Vol. 134 Issue 3p173175, http,//money.cnn.com/magazines/fortune/fortune_archive/1996/08/05/215440/in dex.htm

Strauss, Anselm; Corbin, Juliet (1990). BASICS OF QUALITATIVE RESEARCH, GROUNDED THEORY PROCEDURES AND TECHNIQUES Newbury Park, CA, SAGE Publications, p19. Jg, S. 418 ff.

Walton, Richard E. (1985). From control to commitment in the workplace Harvard Business Review, Mar/Apr1985, Vol. 63 Issue 2 p77-84

Wang, Chen-Ya, Yang, Hsin-Yi Chou, Seng-Cho T. (2008). Using peer-to-peer technology for knowledge sharing in communities of practices Decision Support Systems 45 528-540 Available online at http,//www.sciencedirect.com/

Wasko, M. M., \& Faraj, S. (2000). It is what one does, Why people participate and help others in electronic communities of practice. Journal of Strategic Information 
Systems, 9(2-3), pp.155-173.

Wasko, M. M., \& Faraj, S. (2005) Why Should I Share? Examining Social Capital and Knowledge Contribution in Electronic Networks of Practice

MIS Quarterly; Mar 2005; 29, 1 pp. 35-57

Weedman, J. (1999). Conversation and community, The potential of electronic conferences for creating intellectual proximity in distributed learning environments. Journal of the American Society for Information Science, 50(10), pp. 907-928.

Wenger, Etienne C. (1990). Toward a theory of cultural transparency, Elements of a social visible and the invisible. Unpublished doctoral dissertation, University of California, Irvine.

Wenger, Etienne (1991). “Communities of Practice, where learning happens” Institute for Research on Learning Benchmark Magazine, Fall

Wenger, Etienne (1998). “Communities of Practice, Learning as a Social System” in The Systems Thinker, Vol 9 No. 5

Etienne Wenger, Etienne, Foote, Nathaniel, Matson, Eric, Weiss, Leagh (2002) "Leveraging group knowledge for high-performance decision-making" Organizational Dynamics, Volume 31, No. 3.

Wenger, Etienne (2009). Social learning capacity Four essays on innovation and learning in social systems. www.ewenger.com/pub/pubpapers.htm

Yin, Robert K. (2003). Applications of Case Study Research Second Edition Sage Publication International Educational and Professional publisher ISBN 0-76192551-1 Thousand Oaks, California, U.S. pp 5-13

Zboralski, Katja (2006) Organizational Benefits Of Communities Of Practice, A TwoStage Information Processing Model” Cybernetics and Systems, Volume 37, Issue 6, pages 533 - 552 
APPENDICES

\section{APPENDIX-A Institutional Review Board and Survey Consent} Form

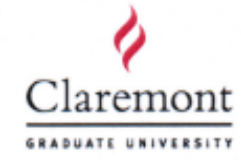

Institutional Review Board

March 28, 2011

RE: Expedited approval of IRB\# 1562

Title of Study: Communities of practice: The Impacts of IT and the Community Moderator on the Coalescing State

Dear Ms. Piepkorn:

Thank you for submitting your research protocol to the IRB at Claremont Graduate University. Your protocol has been approved as indiçated on the coversheet that you provided when you submitted the protocol. Your signed cover sheet is being returned with this letter.

Your protocol is approved for a period of one year from the date on this letter. At that time you must send a brief report on your progress-to-date to the IRB and have your protocol renewed if necessary. Be sure to submit your report in time for a renewal to be issued before this one expires. Include in your report any changes that should be made to the originally approved protocol for the renewal.

Please note that before data may be collected from research participants in any particular institution, a letter of approval from the authority for that institution must be obtained.

If your research is completed before this protocol expires you must notify the IRB that your research has been completed and identify any problems encountered that will assist the Board in approving future research of the type you conducted.

If any injuries or unanticipated problems are encountered in the conduct of your research that are related to risks to participants or others it is your responsibility to notify the Chair of the IRB and the Office of Research and Sponsored Programs as soon as practical but in no more than five days of the occurrence (phone: 909-607-9406 or via email to irb@cgu.edu ).

If, during the conduct of your research, you discover changes that should be made to the procedures in the approved protocol you must promptly report the proposed changes to the IRB. The proposed changes must not be implemented without IRB approval except where necessary to eliminate immediate hazards to participants.

The entire Institutional Review Board of Claremont Graduate University wishes you well in the conduct of your research project.

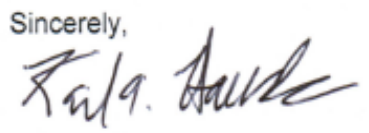

Karl Haushalter, IRB Representative Institutional Review Board 


\section{Form Revised 5/22/2008}

Claremont Graduate University

Institutional Review Board

\section{Application for Review}

\section{Do not exceed cheracter length restrictions indicated}

Please submit to Harper Hall Room 152 Attention: IRB Secretary

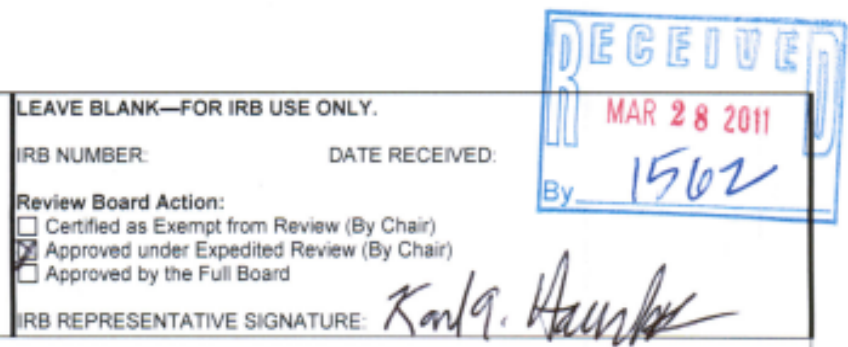

Please submit with this form a description of the proposed project, along with other required materials, following the guidelines in Procedures for the Review of Research Protocols. The investigator should allow sufficient time for review before initiation of the project.

PRINCIPAL INVESTIGATOR: Farnaz (Farah) Piepkorn DEPARTMENT: Information Sciences

MAILING ADDRESS:

Street: 2697 Woodacre St.

City: Brea State: CA Zip Code: 92821

E-MAIL ADDRESS: farnaz.piepkorn@cgu edu TELEPHONE: (714) $396-8594$ CO-PI (If applicable):

AFFILIATION

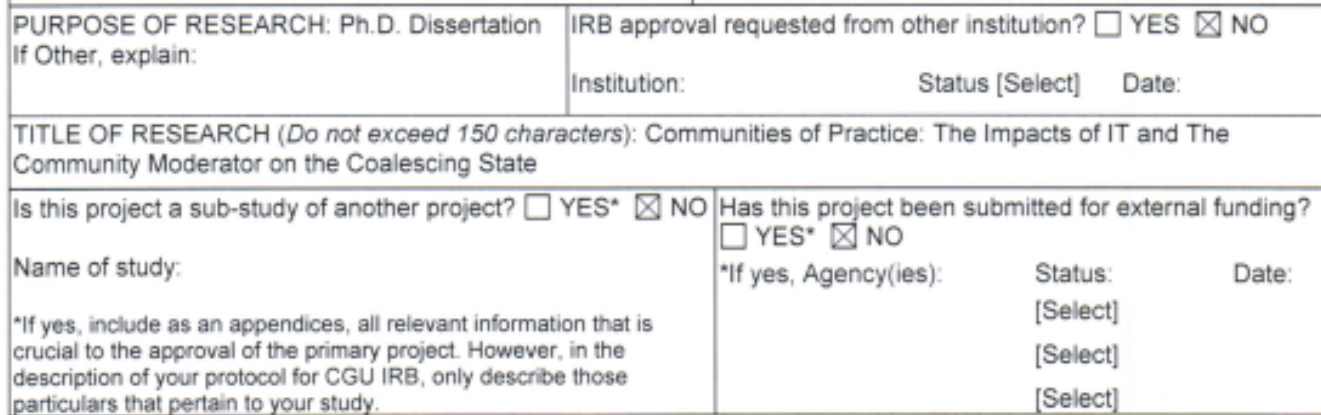

description of your protocol for CGU IRB, only deseribe those

LOCATION OF STUDY: Northrop Grumman Corporation Communities of Practice

PROJECT PRÉCIS OR SUMMARY (Two sentences): The potential impact of IT on a community of practice's outcomes in the coalescing stage of development, taking into account the role of the CoP moderator.

The Institutional Review Board (IRB) reviews all research projects involving human participants. Research means a systematic investigation designed to develop or contribute to generalizable knowledge. It includes research development, testing, and

evaluation, but does not typically include class-related exercises or demonstrations. Human participants are living individuals alone, whom an investigator obtains data through intervention or interaction with the individual or identifiable private information from some other source (e.g., a third party, medical records, etc...).

PARTICIPANTS (check all that apply):

$\triangle$ Adults (18 years or older)

Minors (Less than 18 years)

Patients

Non-English Speaking

Mentally Disabled

Prisoners, Parolees, or Incarcerated

Elected or Appointed Officials or Candidates in

Public Office

TYPE OF DATA (check all that apply):

\Interviews

Questionnaires or Surveys

$\square$ Existing Data Banks, Archives or Documents

$\square$ Physiological Measurements or Blood Samples

$\square$ Observations/Record of Public Record

Educational Tests (e.g. Cognitive, Aptitude, or

Achievement)

CGU IRB Application for Review-page 1 of 5

APPROVED

MAR 282011

CLAREIROMT GRADUATE

UWversm

wa 


\section{Informed Consent Form for (Impact of IT on the role of a moderator in a Coalescing stage of a community of practice's development)}

You are being asked to participate in a research project conducted by Farah Piepkorn, a doctoral student in the School of Information and Technology, Claremont Graduate University (CGU) and an employee of Northrup Grumman Corporation (NGC). You are being asked to participate because you are a member or a moderator of one of NGC's Communities of Practice.

PURPOSE: The purpose of this study is to explore the coalescing stage activities of several of NGC's CoPs using a framework developed by the researcher who first defined the concept of "Communities of Practice".

PARTICIPATION: You will be asked to answer several survey questions. I will also follow up with you to ask a number of open-ended questions. I expect your participation to take about 20-30 minutes of your time.

RISKS \& BENEFITS: There are no potential risks associated with this study. I expect the project to provide improvement opportunities to Northrop Grumman's guidelines on creating and maintaining communities of practice.

COMPENSATION: You will receive no compensation for your participation.

VOLUNTARY PARTICIPATION: Please understand that participation is completely voluntary. Your decision whether or not to participate will in no way affect your current or future relationship with CGU or its faculty, students, or staff nor with NGC employees. You have the right to withdraw from the research at any time without penalty. You also have the right to refuse to answer any question(s) for any reason, without penalty.

CONFIDENTIALITY: I cannot guarantee the confidentiality of your responses to the questionnaire because NGC retains the right to access the data from online questionnaires and emails. However, I do guarantee to maintain the confidentiality of the responses I gather from individual interviews. I will also maintain your individual privacy in all publications or presentations resulting form this study. I will separate your name from the data (survey responses and interview answers) after I have coded it. The survey and interview data will be summarized without any references to the company, community of practice, or member names. As the report results are aggregated, the names, status, and other information regarding to the survey participants will not be included in the report.

If you have any questions or would like additional information about this research, please contact me (Farah Piepkorn) at (626) 812-2270, Northrop Grumman, 1100 West

Hollyvale St., Azusa, CA 91702, email:_farnaz.piepkorn@ngc.com You can also contact my research advisor, Dr. Lorne Olfman, at (909) 621-8209, School ffPPROVED
Information Systems and Technology, $130 \mathrm{E} 9$ th St., Claremont, CA 91711, emain? lorne.olfman@cgu.edu. 
The CGU Institutional Review Board, which is administered through the Office of Research and Sponsored Programs (ORSP), has approved this project. You may also contact ORSP at (909) 607-9406 with any questions.

A signed copy of this consent form will be given to you.

I understand the above information and have had all of my questions about participation on this research project answered. I voluntarily consent to participate in this research.

Signature of Participant

Date

Printed Name of Participant

Signature of Researcher Date

\section{APPROVED}

MAR 282011

CLAREIAOIUT GRADUATE

UAIVERST:

ing 
APPENDIX B-Survey Questions

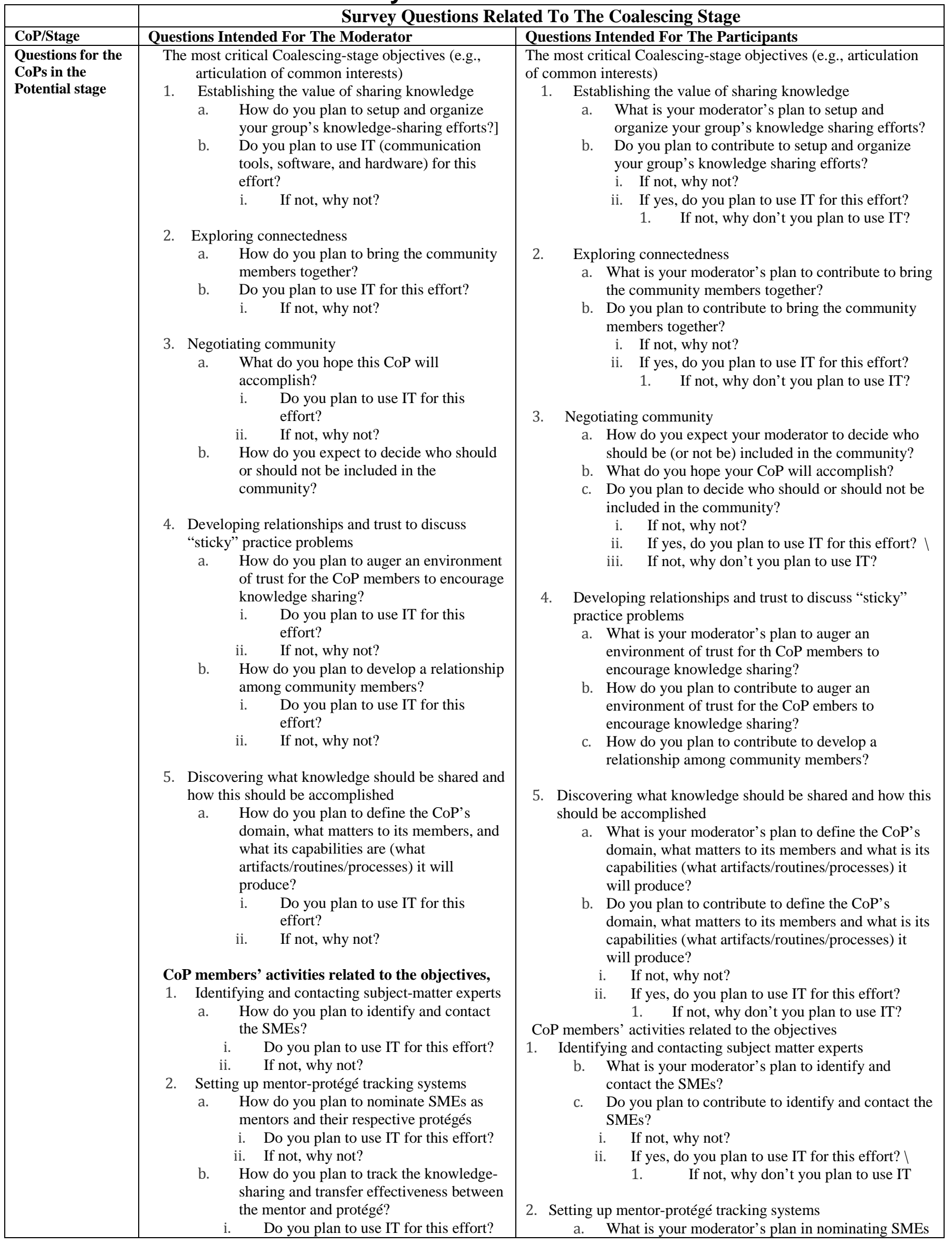




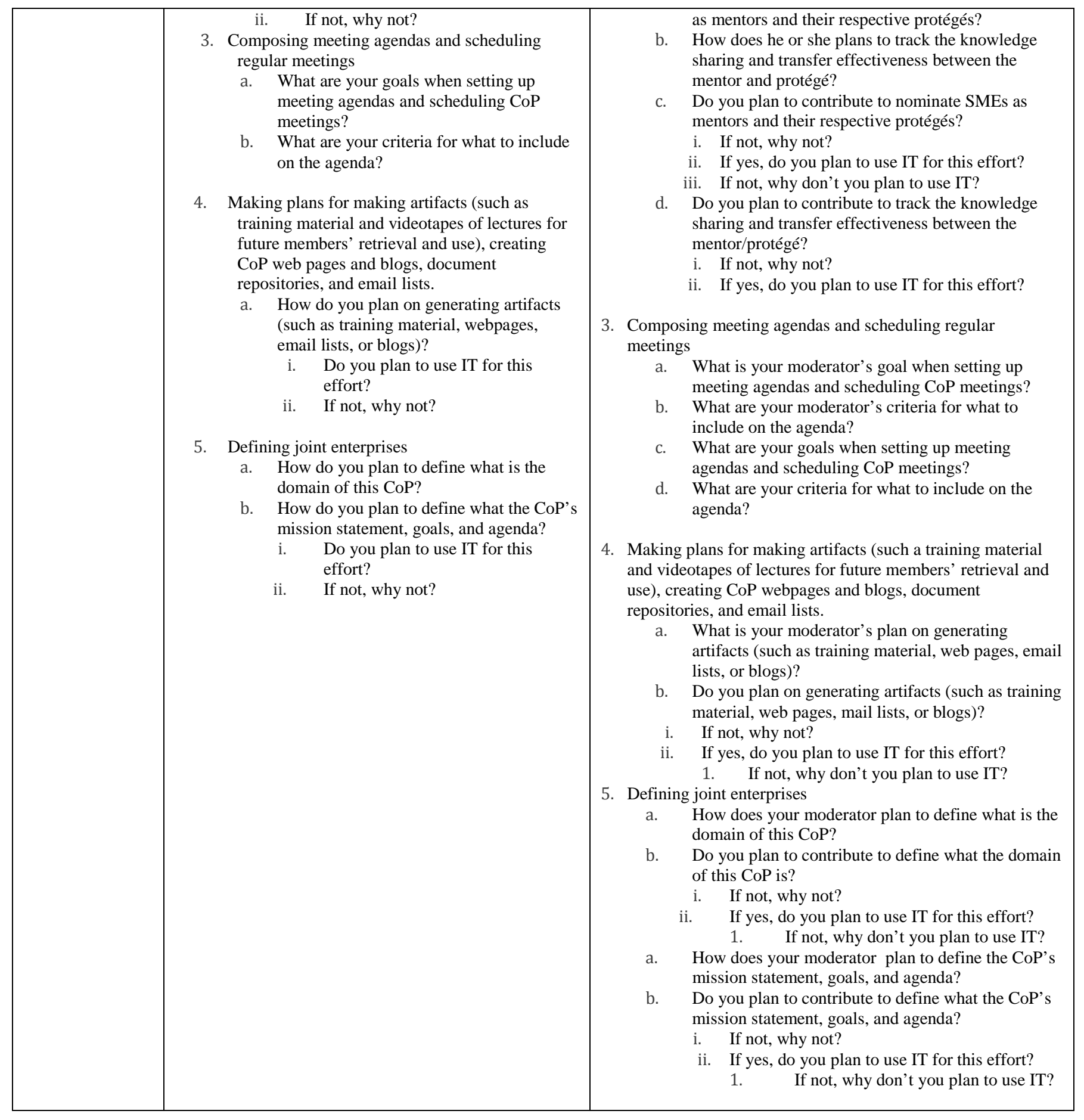




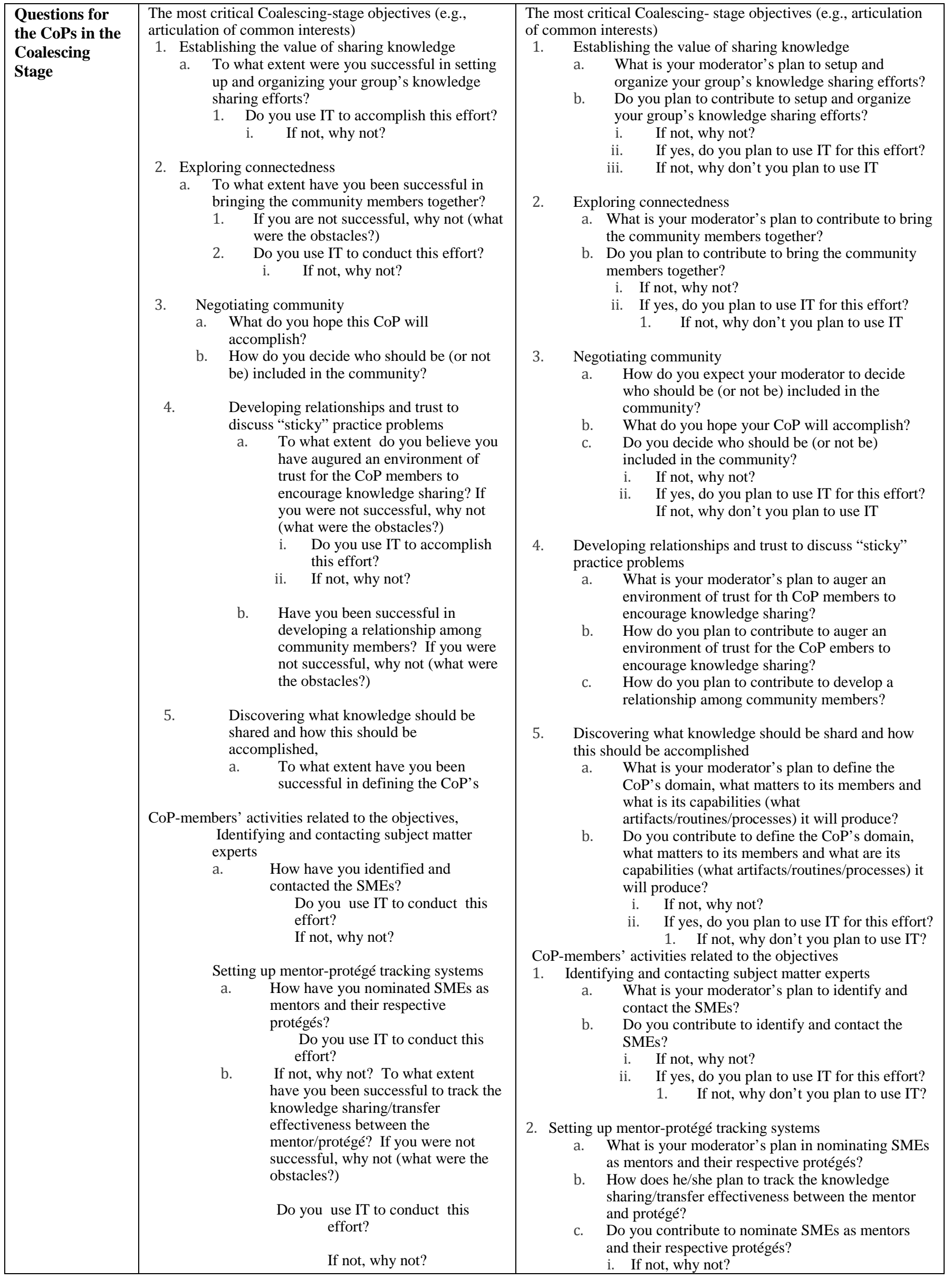


Composing meeting agendas and scheduling regular meetings

a. To what extent have you been successful in meeting your goals when setting up meeting agendas and scheduling CoP meetings? If you were not successful, why not (what were the obstacles?)

b. What are your criteria for including items on the agenda?

Making plans for making artifacts (such as training material and videotapes of lectures for future members' retrieval and use), creating CoP web pages and blogs, document repositories, and email lists.

a. How successful have you been in generating artifacts (such as training material, web pages, email lists, or blogs)?

1. Do you use IT to conduct this effort?

2. If not, why not?

Defining joint enterprises

a. To what extent have you been successful in defining the domain of this CoP?

o you use IT to conduct this effort?

f not, why not?

b. To what extent have you been successful in defining the CoP's mission statement, goals, and agenda?

i. Do you use IT to conduct this effort?

ii. If not, why not? ii. If yes, do you plan to use IT for this effort?

iii. If not, why don't you plan to use IT?

d. Do you contribute to track the knowledge sharing/transfer effectiveness between the mentor/protégé?

i. If not, why not?

ii. If yes, do you plan to use IT for this effort?

3. Composing meeting agendas and scheduling regular meetings

a. What is your moderator's goal when setting up meeting agendas and scheduling CoP meetings?

b. What are your moderator's criteria on what to include on the agenda?

c. What are your goals when setting up meeting agendas and scheduling CoP meetings?

d. What are your criteria on what to include on the agenda?

4. Making plans for making artifacts (such a training material and videotapes of lectures for future members' retrieval and use), creating CoP web pages and blogs, document repositories, and email lists.

a. What is your moderator's plan for generating artifacts (such as training material, web pages, email lists, or blogs)? Using NGWE webpages

b. Do you plan on generating artifacts (such as training material, web pages, mail lists, or blogs)?

i. If not, why not?

ii. If yes, do you plan to use IT for this effort? 1. If not, why don't you plan to use IT?

5. Defining joint enterprises

a. How does your moderator plan to define what is the domain of this CoP?

b. Do you plan to contribute to define what the domain of this $\mathrm{CoP}$ is?

i. If not, why not?

ii. If yes, do you plan to use IT for this effort? 1. If not, why don't you plan to use IT?

c. How does your moderator plan to define what the CoP's mission statement, goals, and agenda?

d. Do you plan to contribute to define what the CoP's mission statement, goals, and agenda?

i. If not, why not?

ii. If yes, do you plan to use IT for this effort? 1. If not, why don't you plan to use IT? 


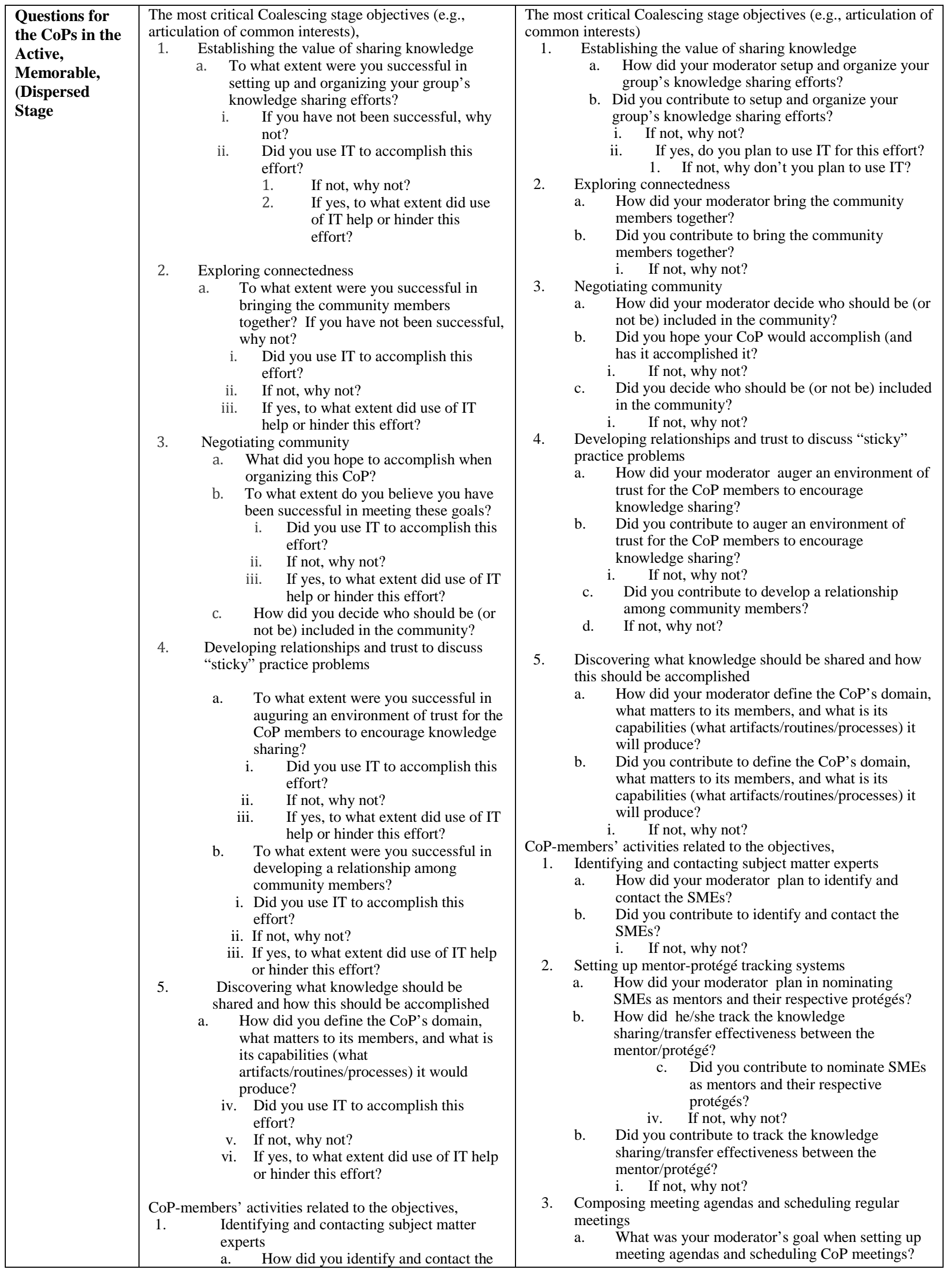




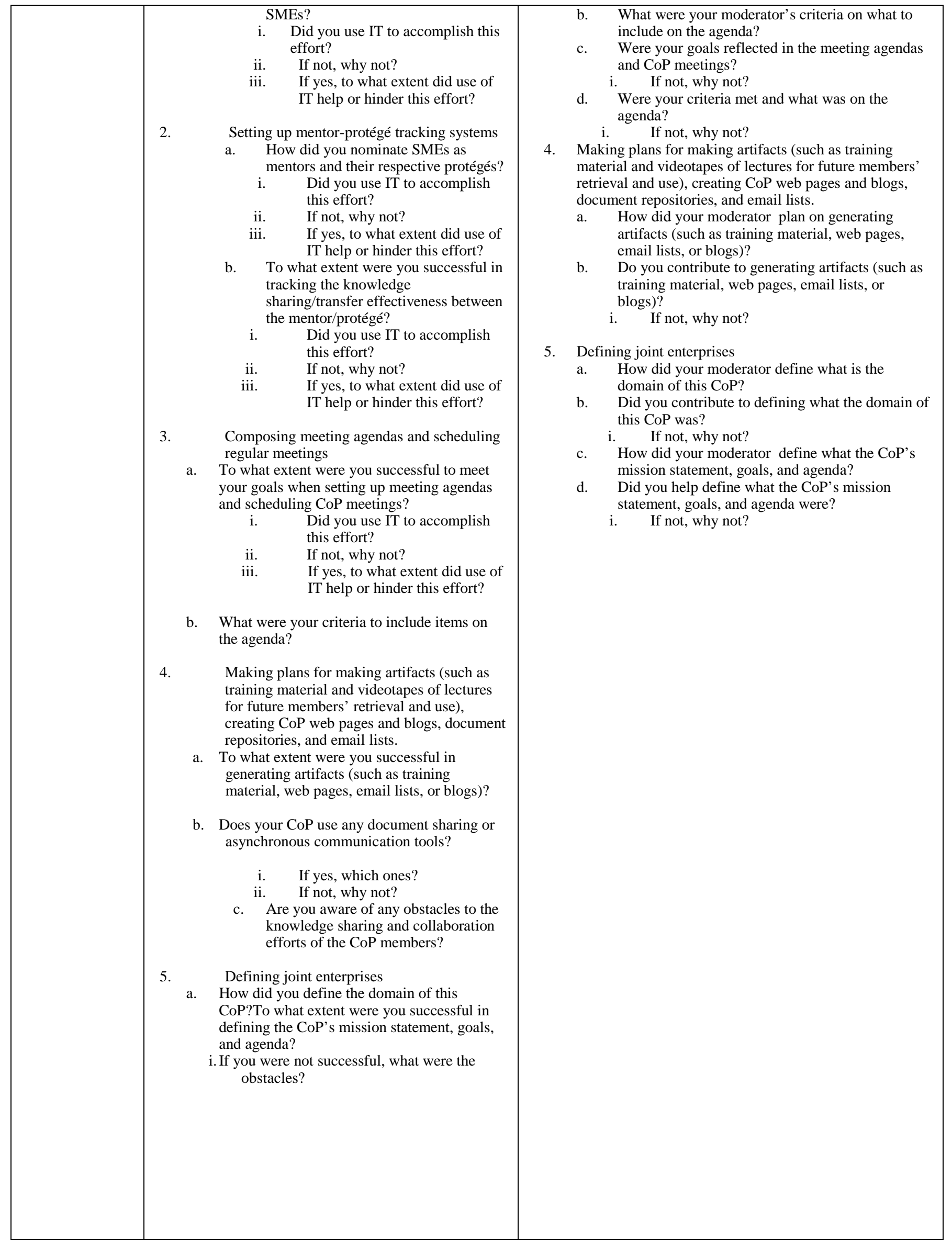




\section{APPENDIX C-Sample Survey Responses}

\begin{tabular}{|c|c|c|c|}
\hline $\begin{array}{l}\text { Coalescing } \\
\text { Moderator } \\
\text { Questions } \\
\end{array}$ & $\begin{array}{l}\text { To what extent were you successful } \\
\text { in setting up and organizing your } \\
\text { group’s knowledge sharing efforts? }\end{array}$ & $\begin{array}{l}\text { i. Do you use IT to accomplish this } \\
\text { effort? }\end{array}$ & $\begin{array}{l}\text { a. To what extent have } \\
\text { you been successful in } \\
\text { bringing the community } \\
\text { members together? }\end{array}$ \\
\hline $\begin{array}{l}\text { Co_CoP_A- } \\
\text { Mod_1 }\end{array}$ & $\begin{array}{l}\text { Successful. The knowledge sharing } \\
\text { methods were set up by my } \\
\text { predecessor. They have been } \\
\text { successful thus far. The CoP } \\
\text { members are spread across the } \\
\text { country. We have used conference } \\
\text { calling, on-line meetings, and shared } \\
\text { workspace to share knowledge. }\end{array}$ & $\begin{array}{l}\text { Yes, we use a number of IT tools. } \\
\text { We have used Net Meeting and } \\
\text { LiveMeeting to share information } \\
\text { during our group meetings. We use } \\
\text { Conference Calling for discussions. } \\
\text { We use E-mail to communicate. } \\
\text { We use TeamCenter to store and } \\
\text { share artifacts. We have a wiki } \\
\text { page to allow anyone to share in } \\
\text { what the CoP is doing. }\end{array}$ & $\begin{array}{l}\text { Successful. Two ways to } \\
\text { take this question - } \\
\text { bringing the members } \\
\text { together to a common } \\
\text { consensus, or bringing } \\
\text { the members together in a } \\
\text { more literal meeting } \\
\text { sense. The group meets } \\
\text { on a regular basis so that } \\
\text { we stay informed. We set } \\
\text { an agreed upon list of } \\
\text { goals for the year and } \\
\text { then work towards those. }\end{array}$ \\
\hline $\begin{array}{l}\text { Co_CoP_A- } \\
\text { Mod_2 }\end{array}$ & $\begin{array}{l}\text { Somewhat Successful. Not sure if } \\
\text { they have been collaborating offline. } \\
\text { But people attend our virtual } \\
\text { meetings }\end{array}$ & $\begin{array}{l}\text { Not so much. Most people try to } \\
\text { use Goldfire to get information and } \\
\text { some times for sensitive programs. }\end{array}$ & $\begin{array}{l}\text { Somewhat successful. } \\
\text { Not sure if they have } \\
\text { been collaborating } \\
\text { offline. But people attend } \\
\text { our virtual meetings }\end{array}$ \\
\hline $\begin{array}{l}\text { Co_CoP_B- } \\
\text { Mod_1 }\end{array}$ & $\begin{array}{l}\text { Successful. The Forum has been held } \\
\text { monthly starting in Feb } 2010 \ldots . . . \text { with } \\
\text { participation (attendance) of about } \\
150 \text { people each session...about } 50 \\
\text { people in person and remainder via } \\
\text { Live Meeting/Telephone }\end{array}$ & Use LiveMeeting & $\begin{array}{l}\text { Successful. .seems to be } \\
\text { lot of interest....at least by } \\
\text { those who attend in } \\
\text { person...I had hoped for } \\
\text { more participative } \\
\text { activity.....and working } \\
\text { on doing that (vs more of } \\
\text { a classroom type } \\
\text { meeting) }\end{array}$ \\
\hline $\begin{array}{l}\text { Co_CoP_C- } \\
\text { Mod_1 }\end{array}$ & Very successful & Primarily ShareCenter & $\begin{array}{l}\text { Very successful. } \\
\text { Although the group is } \\
\text { large geographically } \\
\text { distributed, key members } \\
\text { have met in person at } \\
\text { conferences. }\end{array}$ \\
\hline $\begin{array}{l}\text { Co_CoP_D- } \\
\text { Mod_1 }\end{array}$ & $\begin{array}{l}\text { Successful. I have not yet set up the } \\
\text { a wiki page for the CoP on yet. We } \\
\text { are functioning as a CoP to share } \\
\text { knowledge - lessons learned, best } \\
\text { practices, miscellaneous issues. My } \\
\text { vision is to increase collaboration } \\
\text { with database teams at other sites. }\end{array}$ & $\begin{array}{l}\text { Yes, our meetings are conducted by } \\
\text { Live Meeting. One of our main } \\
\text { topics of discussion is improving } \\
\text { the software tools we use to } \\
\text { conduct our tasks. We use desktop } \\
\text { PCs to conduct our tasks and are } \\
\text { considering more web-based } \\
\text { solutions for the future. }\end{array}$ & $\begin{array}{l}\text { Very successful. The } \\
\text { CoP began with people in } \\
\text { one section and was } \\
\text { expanded to include } \\
\text { others in the department } \\
\text { involved in this effort. } \\
\text { We have also } \\
\text { collaborated with others } \\
\text { with similar CoPs in } \\
\text { other divisions. }\end{array}$ \\
\hline $\begin{array}{l}\text { Co_CoP_E- } \\
\text { Mod_1 }\end{array}$ & $\begin{array}{l}\text { Fairly successful; one can } \\
\text { always do more. }\end{array}$ & N/A & $\begin{array}{l}\text { We have brought the } \\
\text { community members } \\
\text { together on a regular } \\
\text { basis with the exception } \\
\text { for one group, which did } \\
\text { not meet for four months } \\
\text { after its initial first two } \\
\text { meetings. }\end{array}$ \\
\hline
\end{tabular}




\section{APPENDIX D-Interview Questions}

1. What is the impact of IT (communication, hardware, and software tools) use on the role of a community of practice moderator?

2. In terms of IT use (communication, hardware, and software tools), what improvement opportunities do you see for a community of practice?

3. What barriers, in terms of IT use (communication, hardware, and software tools), have you encountered in conducting activities or meeting goals with reference to your role as the community of practice moderator?

Sample Interview Responses follow.

\begin{tabular}{|c|c|c|c|}
\hline & $\begin{array}{l}\text { What is the impact of IT } \\
\text { (communication, hardware, and } \\
\text { software tools) use on the role of a } \\
\text { community of practice moderator? }\end{array}$ & $\begin{array}{l}\text { In terms of IT use (communication, } \\
\text { hardware, and software tools), what } \\
\text { improvement opportunities do you see } \\
\text { for a community of practice? }\end{array}$ & $\begin{array}{l}\text { What barriers, in terms of } \\
\text { IT use (communication, } \\
\text { hardware, and software } \\
\text { tools), have you } \\
\text { encountered in conducting } \\
\text { activities or meeting goals } \\
\text { with reference to your role } \\
\text { as the community of } \\
\text { practice moderator? }\end{array}$ \\
\hline Po_CoP_A-Mod_2 & $\begin{array}{l}\text { We have used IT tools to send } \\
\text { emails, gathering information, } \\
\text { assign action items, collect } \\
\text { feedback to moderators, and keep } \\
\text { meetings on track. We also use } \\
\text { various tools to keep our members } \\
\text { informed of certain events and } \\
\text { activities such as membership } \\
\text { recruitment, } \\
\text { professional development for our } \\
\text { members, and scheduling } \\
\text { community outreach programs }\end{array}$ & $\begin{array}{l}\text { Conducting meetings using } \\
\text { LiveMeetings have some issues as } \\
\text { people drop in and out all the time. } \\
\text { Meetings held at remote locations } \\
\text { need to have video feed to make them } \\
\text { more efficient. Our community of } \\
\text { practice members are at the same } \\
\text { location so this would be irrelevant to } \\
\text { us but when we meet with other } \\
\text { chapters remotely we have the issues. } \\
\text { It would also help for us to use } \\
\text { document/software review software so } \\
\text { people do not use pen and paper to } \\
\text { add their comments and notes which } \\
\text { is very inefficient. }\end{array}$ & $\begin{array}{l}\text { We have not encountered } \\
\text { any barriers but the } \\
\text { software review software } \\
\text { would be a big help. }\end{array}$ \\
\hline Co_CoP_A-Mod_1 & $\begin{array}{l}\text { IT is important to CoP because it } \\
\text { gives them mechanism for } \\
\text { communicaiton and its tools } \\
\text { facilitate the communicaiton. IT is } \\
\text { an important facilitator gives it a } \\
\text { infrastructure. }\end{array}$ & $\begin{array}{l}\text { So many different methods to be } \\
\text { used...to do the same thing... which is } \\
\text { nice...but it gets confusing...one CoP } \\
\text { on teamcenter the other on } \\
\text { wiki...there should be standard tool }\end{array}$ & $\begin{array}{l}\text { Getting permission for } \\
\text { people to get into the right } \\
\text { folders because of all the } \\
\text { methods...training } \\
\text { available for people to } \\
\text { learn how to use all these } \\
\text { knowledge sharing } \\
\text { methods. }\end{array}$ \\
\hline Co_CoP_E-Mod_1 & $\begin{array}{l}\text { These tools are essential to make } \\
\text { our meetings possible because we } \\
\text { are all not at the same } \\
\text { location...commumnicating by } \\
\text { phone, ShareCenter, Conference } \\
\text { calls. IT is very import in sharing } \\
\text { the content. }\end{array}$ & $\begin{array}{l}\text { SharePoint } 2010 \text { will provide a lot of } \\
\text { communicaiton very much...flow of } \\
\text { comm... will be a lot better...In } \\
\text { general our collaboration tools could } \\
\text { use an upgrade... }\end{array}$ & $\begin{array}{l}\text { I did not encounter any } \\
\text { barriers...other than SW } \\
\text { and hardware was } \\
\text { improved then we realize } \\
\text { what we were } \\
\text { missing...it's hard to see } \\
\text { what we are missing at this } \\
\text { point... }\end{array}$ \\
\hline Ac_CoP_A-Mod_1 & $\begin{array}{l}\text { It makes my job a lot easier...email } \\
\text { list for Web } 2.0 \text { CoP....wiki } \\
\text { page...meeting } \\
\text { minutes...Sharepoint team site...no } \\
\text { document repository/sharing } \\
\text { system }\end{array}$ & $\begin{array}{l}\text { I would like us to way to tag contents } \\
\text { through the intranet to be able to find } \\
\text { the items on tag....SharePoint is } \\
\text { powerful and making it available to all } \\
\text { will help out a lot...it is currently } \\
\text { available to limited groups... Better } \\
\text { search tool... }\end{array}$ & $\begin{array}{l}\text { Everyone has a different } \\
\text { level of knowledge on } \\
\text { tools...making more tools } \\
\text { training available...people } \\
\text { don't want to learn the } \\
\text { syntax of how to do } \\
\text { it...our tools need to be } \\
\text { more intuitive and easier to } \\
\text { use...now users don't use a } \\
\text { lot of tools beause they are } \\
\text { hard to use... }\end{array}$ \\
\hline
\end{tabular}

